\title{
Recessions and depressions : a marketing perspective on central issues in the healthcare sector
}

Citation for published version (APA):

Meyer, J. H. (2014). Recessions and depressions : a marketing perspective on central issues in the healthcare sector. [Doctoral Thesis, Maastricht University]. Datawyse / Universitaire Pers Maastricht. https://doi.org/10.26481/dis.20140620jm

Document status and date:

Published: 01/01/2014

DOI:

10.26481/dis.20140620jm

Document Version:

Publisher's PDF, also known as Version of record

\section{Please check the document version of this publication:}

- A submitted manuscript is the version of the article upon submission and before peer-review. There can be important differences between the submitted version and the official published version of record.

People interested in the research are advised to contact the author for the final version of the publication, or visit the DOI to the publisher's website.

- The final author version and the galley proof are versions of the publication after peer review.

- The final published version features the final layout of the paper including the volume, issue and page numbers.

Link to publication

\footnotetext{
General rights rights.

- You may freely distribute the URL identifying the publication in the public portal. please follow below link for the End User Agreement:

www.umlib.nl/taverne-license

Take down policy

If you believe that this document breaches copyright please contact us at:

repository@maastrichtuniversity.nl

providing details and we will investigate your claim.
}

Copyright and moral rights for the publications made accessible in the public portal are retained by the authors and/or other copyright owners and it is a condition of accessing publications that users recognise and abide by the legal requirements associated with these

- Users may download and print one copy of any publication from the public portal for the purpose of private study or research.

- You may not further distribute the material or use it for any profit-making activity or commercial gain

If the publication is distributed under the terms of Article $25 \mathrm{fa}$ of the Dutch Copyright Act, indicated by the "Taverne" license above, 
Recessions Depressions

A Marketing Perspective on Central Issues in the Healthcare Sector

Jan-Hinrich Meyer 
Recessions and Depressions - A Marketing Perspective on Central Issues in the Healthcare Sector (C) Jan-Hinrich Meyer 2014

All rights reserved. No part of this publication may be reprinted or utilized in any form of electronic, mechanical or other means, now known or hereafter invented including photocopying and recording or in any information storage retrieval system, without written permission of the copyright owner.

ISBN 9789461593412 


\title{
RECESSIONS AND DEPRESSIONS - \\ A Marketing Perspective on Central Issues in \\ the HealthCARE Sector
}

\author{
PROEFSCHRIFT \\ TER VERKRIJGING VAN DE GRAAD VAN DOCTOR \\ AAN DE UNIVERSITEIT MAASTRICHT \\ op gezag VAN dE Rector Magnificus, Prof. DR. L.L.G. SOETE \\ VOLGENS HET BESLUIT VAN HET COLLEGE VAN DECANEN, \\ IN HET OPENBAAR TE VERDEDIGEN \\ OP VRIJDAG 20 JUNI 2014 OM 10:00 UUR. \\ DOOR \\ JAN-HINRICH MEYER
}

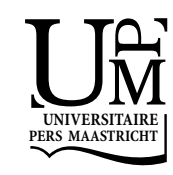


PROMOTOR:

Prof. dr. Ko de Ruyter

COPROMOTOR:

Dr. Kathleen Cleeren

BEOORDELINGSCOMMISSIE:

Prof. dr. Martin Wetzels (Voorzitter)

Prof. dr. Richard Janssen (Tilburg University)

Prof. dr. Jos Lemmink 



\section{ACKNOWLEDGEMENTS}

Recessions and Depressions - a title chosen because of its nice match with the content and context of my studies and simply because it rhymes - fortunately not as a description of my feelings while working on this dissertation. Obviously, the work and effort necessary to compile a dissertation is impossible to deliver without the support, help and guidance of colleagues, friends and family. Therefore, before getting to the actual heart of this dissertation, I want to express my gratitude and indebtedness to everybody who supported me on my way as a PhD candidate.

First and foremost, I want to thank my promoters Prof. Ko de Ruyter and Dr. Kathleen Cleeren. Ko, thanks a lot for your guidance and support by being an idea generator, a gate-keeper and a motivator during the last years. Your expertise and experience in research helped a lot to make this dissertation happen. Kathleen, thanks for your help and efforts on a daily base and for pushing me to new levels of methodological and theoretical knowledge and for helping me making my first moves in the academic world. The diverse combination of skills present among you two is the root of the diversity of topics and methods comprised in this dissertation. I profited a lot from your complementary skills and perspectives which helped me to get a nice roundhouse view upon the field of marketing research.

Marketing and mental healthcare - this combination sounded very unusual, yet extremely intriguing to me from the start. The uncommon and fascinating context of my PhD would not have been possible without the Mondriaan Stichting voor Geestelijke Gezondheit, the sponsor of my position. I had the chance to work together with professionals from the field who deal with mental illnesses and the idiosyncrasies of healthcare systems on a daily basis, which expanded my horizon and enriched my ways of thinking tremendously. I am extremely indebted to Leonne van Santbrink who introduced me to the field of mental healthcare and sparked my interest for it. Thanks a lot for all your efforts, our countless meetings, the nice atmosphere and the interesting projects we tackled together. Thanks as well to Dr. Tony Rasenberg and Marcel Dassen for our inspiring meetings and interesting debates on health policies, healthcare systems and stigma in the field of mental illness.

Next to these practical collaborations, I also had the chance to work together with several great marketing scholars. A special thanks goes to Prof. Dhruv Grewal and 
Dr. Lien Lamey who both provided invaluable input for my research. Lien, thanks a lot for the help with the business cycle project and especially for the expertise on the subject and related methodological issues you shared with us. Dhruv, thanks a lot for your support on the stigma paper, your tremendous experience and expertise in many areas of marketing research were a big asset when thinking about the setup of both, the paper and the studies. Finally I want to thank the members of my committee Prof. Jos Lemmink, Prof. Richard Janssen and Prof. Martin Wetzels for your assessment and your valuable feedback.

On a more personal level, I want to thank all my great colleagues and coworkers. I think our department and especially the PhD students had and have an awesome community, so please keep that up! There are a few colleagues who became good friends over the years, which made this PhD journey a lot of fun. Nina and Jan, thanks for being awesome office mates and for always having an open ear for all sorts of issues. Thanks for being my paranymphs, we'll need another post discussion after this (and hopefully many more in the future)! Matthias, let's do some Ramsey Reset tests together soon and reminisce about the gate building ;). Hannes, Stephan and Dominik: Jongens, zo'n Vuurbal in Rijeka and Krakow!! Nadine and Liz, stay as you are! Thanks to Pascalle and Eefje for supporting us in such a nice manner and for all the "grapjes" in secretariat!

Christoph, or should I say Platt so that you know who I'm talking about, thanks for always having my back even on all the stupid things I've done! I'll always have yours! Henna, thanks for being the reliable and honest friend that you've always been! Juan, danke dass du immer da bist!

Mama und Papa, ihr habt mich immer unterstützt und mir unglaublich viele Dinge ermöglicht ohne die ich sicherlich nicht so weit gekommen wäre. Vielen Dank für alles, ich weiss das zu schätzen und werde es auch nie vergessen!

Christiane, danke, dass du mich durch alle Höhen und Tiefen in den letzten acht Jahren begleitet hast! Du hast immer zu mir gehalten, mich aufgebaut wenn es mir schlecht ging und mit mir gefeiert, wenn es etwas zu feiern gab! Ohne dich hätte ich das alles niemals geschafft und ich bin glücklich mein Leben mit Dir verbringen zu dürfen! 


\section{CONTENTS}

CHAPTER 1: $\quad 14$

INTRODUCTION

CHAPTER 2:

24

HOW BUSINESS CYCLES AFFECT THE HEALTHCARE SECTOR:

A CROSS-COUNTRY INVESTIGATION

CHAPTER 3:

48

THE (INCRE)MENTALIST: ON THE INTERPLAY OF

IMPLICIT THEORY ORIENTATIONS AND MESSAGE DESIGN

IN SOCIAL MARKETING CAMPAIGNS TO REDUCE

MENTAL-ILLNESS STIGMA

CHAPTER 4:

82

CONCLUSION

$\begin{array}{lr}\text { REFERENCES } & 90\end{array}$

$\begin{array}{ll}\text { APPENDIX } & 108\end{array}$ 


\section{LIST OF TABLES AND FIGURES}

CHAPTER 2:

1. TABLE 1: LITERATURE OVERVIEW OF StUdIES 29 LINKING HEALTHCARE EXPENDITURES AND THE GENERAL ECONOMY

2. TABLE 2: Descriptive STATISTICS

3. Figure 1: AVerage Quartile Values of the COMOVEMENT ELASTICITIES

4. TABle 3: Distribution of ElAsticities

5. TABLE 4: LONG-TERM CONSEQUENCES OF CYCLICAL SENSITIVITY

6. TABLE 5: DESCRIPTIVES AND OPERATIONALIZATION OF EXPLANATORY FACTORS

7. TABLE 6: EXPLANATORY FACTORS OF CYCLICAL SENSITIVITY IN HEALTHCARE EXPENDITURES

CHAPTER 3:

1. Figure 1: Conceptual Framework

2. FIGURE 2:

61

STUDY 1A: EFFECTS OF IMPLICIT ORIENTATION ON STIGMA DIMENSIONS 
3. FIGURE 3:

STUDY 1B: EFFECT OF IMPLICIT ORIENTATION ON Stigma After Exposure to Anti-Stigma CAMpaign

4. FIGURE 4:

65

STUdY 2A: IMPLICIT STIGMA -- COMBINED EFFECT

OF MESSAGE WITH SELF-ASSESSED IMPLICIT

ORIENTATION ON STIGMA

5. FIGURE 5

66

StUdY 2A: EXPLICIT STIGMA -- COMBINEd EfFECT

OF MESSAGE WITH SELF-ASSESSED IMPLICIT

ORIENTATION ON STIGMA

6. FIGURE 6

69

Study 2B): COMBIned EfFECt Of Message With

PRIMED IMPLICIT ORIENTATION ON STIGMA

7. FIGURE 7

73

STUdY 3: EFFECTS OF CONTROLLABILITY AND

INCREMENTALIST PRIMES ON ENTITY THEORISTS'

STIGMA ENDORSEMENT WITH A BPS MESSAGE

8. FIGURE 8

STUDY 4: IMPLICIT ORIENTATION-MESSAGE INTERACTION:

LOW ILLNESS SEVERITY

9. FIGURE 9

STUDY 4: IMPLICIT ORIENTATION-MESSAGE INTERACTION:

HIGH ILLNESS SEVERITY 

Chapter 1

INTRODUCTION 
Healthcare is an important subject to each and every one, simply because everybody has at least some experience with certain healthcare elements such as doctors, medication, or therapies. Furthermore, being healthy is usually a top priority for people, often considered more important than a career or personal freedom (Turner et al. 1994). This in turn makes healthcare a topic which is heavily present in conversations and discussions, thereby making it a prominent part of most agendas of bigger political election campaigns (e.g. Obamacare in the U.S.). In short, it is a universal and recurring theme, as it is ultimately and unchangeably related to people's lives (Stremersch 2008). Especially in developed countries, the healthcare sector is often the biggest single contributor to a country's GDP and frequently accounts for more than $10 \%$ of the total economic activity in many countries of the OECD (OECD 2011). Furthermore, healthcare is one of the fastest growing sectors worldwide, which delivers technological, therapeutic, and service-related innovations at a fast pace (Stremersch and van Dyck 2009). This development is predicted to continue for many years to come, as technological breakthroughs and research findings continue to revolutionize medical capabilities, allowing to treat conditions which were considered untreatable only a decade ago (Burns 2005). Additionally, many developing countries exhibit an increased demand for good healthcare, as economic development was often shown to foster an increased ability and willingness to invest in this area (Hartwig 2008). These key facts and the mere size of the industry attracted an increased amount of businessand marketing-related research in the last decade (Camacho 2011). However it is not only the size of the industry which appeals to marketers, but also its uniqueness which demands research with a specialized focus (Stremersch 2008).

\section{HEALTHCARE IS DIFFERENT}

A healthy and wealthy society is one of the key success factors for every government around the globe and therefore, usually, healthcare should be affordable and available for everybody (OECD 2011). Hence, the healthcare sector takes on an important socioeconomic role, which differs from the bottom-line focus of most other industries as it is pivotal in improving people's satisfaction with life (Mladovsky et al. 2012).

Consequently, the healthcare sector is one of the most strongly regulated industries around the globe and has different regulatory regimes on each national level including 
predominantly privately and predominantly publicly funded healthcare systems (Stremersch and Lemmens 2009). Even in mostly privately funded systems like the U.S., public expenditures make up more than $30 \%$ of the country's entire healthcare budget and the public regulation exerts a huge influence on the industry (OECD 2011). Due to these facts, healthcare puts a large strain on public budgets because it is extremely expensive and the expenditures are expected to keep on growing (Hartwig 2008). This problem became especially apparent during the recent economic crisis, as many governments were torn between cost-cutting to prevent further debt or spending to stimulate the economy. So far this decision has always been paired with an extreme uncertainty of the consequences of cost-cuttings in the healthcare domain (Stuckler et al. 2009b). Therefore, cost containment is one of the utmost priorities for many countries, especially in tight economic times, while the overall aim of maintaining or increasing service levels remains in place (De Meijer et al. 2013). For marketers and policy makers, these differences on a macro level imply an increased need for specialized analyses helping to predict market developments. These could yield better guidance to improve marketing and public policy measures which in turn can increase the efficiency and effectiveness of service provision and treatment (Stremersch 2008).

Next to the uniqueness on a macroeconomic level, the inherent characteristics of the healthcare sector also translate into unique circumstances at the micro-, or the consumer level. First of all, healthcare is often an unsought product, meaning that people prefer fewer interactions with the healthcare system over more numerous interactions, as everybody prefers being healthy over being ill, and therapies might be uncomfortable or even painful (Berkowitz 2010). This yields the unique situation that a consumer's needs are not necessarily aligned with his wants (Stremersch 2008). Fields such as mental healthcare offer a vivid illustration of this. Mental illnesses and mentally ill people are often surrounded by a stigma which often prevents people from seeking help or makes them decide for treatment only when it is already too late (Corrigan 2004a). Indeed, mental illnesses, such as depression or addictions, represent a serious threat to a healthy society and prohibit economic growth through lost workforce (OECD 2012). Therefore, there have been recent calls for social marketing research to address the issue of stigma from a social marketing perspective, as further theorizing on the nature of stigma and on the cognitive processes influencing the consumer is needed (Rochlen and Hoyer 2005). 
In addition to the societal relevance of these healthcare-specific issues, there is a compelling need to develop a better theoretical guidance for the previously stated macro- and microeconomic issues at hand (Stremersch 2008). Due to the historically high degree of collaboration between science and practice in the healthcare sector, there is an increased demand for sound know-why structures, which explore underlying rationales for observed effects. This is in opposition to most other industries, which often prefer simpler know-how structures and do not deliver theoretical rationales for proposed effects (Stremersch and van Dyck 2009). Sound context-specific theoretical development is thus of utmost priority for research in this field, which brings along unique challenges and huge opportunities for marketing research in this field (Stremersch 2008). On the one hand, the unique challenges in the healthcare sector on both a macro and a microeconomic level offer huge chances to be addressed by marketing researchers by drawing on their general contributions to a better understanding of markets on aggregate and the consumer as an individual (Kotler 2011). On the other hand, the healthcare sector does not only exhibit unique theoretical needs in terms of the market and the consumer, but also in terms of constructs and concepts of interest. For instance, it is important to not only look at traditional marketing concepts such as profitability or purchase intention (Kotler et al. 2002), but to rather consider socially desirable outcomes such as population health on a macro level, or for instance stigma endorsement, when addressing mental illness challenges. Therefore, it is not enough to simply apply successful marketing concepts, but a new theory development and refinement is needed (Stremersch and van Dyck 2009).

\section{Recent DeVelopments in Healthcare- and Social Marketing}

Overall, marketing is and has always been a crucial part of the healthcare industry. Let alone pharmaceutical companies often spend more money on marketing actions than on the research and development of new therapies and drugs (Manchanda and Honka 2005). However, as stated before, especially government bodies and practitioners exhibit a persistent skepticism towards marketing and marketing-related activities in the healthcare domain (Kamperman et al. 2014). Marketing management of producers, such as pharmaceutical companies, usually focuses on profit implications while other parties of the value chain, such as hospitals, set patient welfare as their utmost priority 
(Stremersch and van Dyck 2009). This demands from market researchers to not only consider profit implications, but to put more emphasis on positive societal marketing effects (Stremersch 2008).

Simultaneously to these specific attitudes in the healthcare sector, there has also been a shift in the domain of marketing research. Researchers as well as practitioners recognized an increasing need for research in social marketing, focusing on the effective application of commercial marketing technology to socially relevant topics, which attempt to primarily benefit individuals or society as a whole and not the marketing institution itself (Kotler 2011). This development fostered research in the healthcare domain, addressing consumer-related issues such as communication design for prevention-, compliance- and treatment-related campaigns for numerous physical diseases such as cancer (Keller et al. 2002), obesity (Belei et al. 2012) or smoking prevention (Pechmann and Shih 1999). The topic of mental illnesses, however is still relatively untapped and needs further research (Rochlen and Hoyer 2005), especially since the concept of stigma and stereotypes has rarely been studied in conjunction with marketing and communication mechanisms (Keller and Lehmann 2008). Therefore, a sound investigation of the nature of stigma in combination with different message framings is needed, in order to develop theoretical insights for communication design and to reduce the problem. Recent advances in marketing and cognitive psychology indicated that an individual's perspective of seeing other people's characters as either malleable or fixed has far-reaching implications for the evaluation of other people, brands, and marketing stimuli (Chiu et al. 1997; Jain et al. 2009; Yorkston et al. 2010). Therefore, it seems likely that the endorsement of either implicit worldview might play a pivotal role in both stigma endorsement and the evaluation of anti-stigma campaigns. Next to the question of stigma endorsement, there is the question which communication strategies are useful to combat it, combined with a lack of theoretical guidance (Levy Paluck and Green 2009). Practitioners and researchers in the field have been arguing over the last decades whether to display mental illnesses to the public as medical disease conditions or rather as a combination of biological psychological and social factors (Ghaemi 2009). This professional debate needs to be better connected to the individual's perspective, in order to develop theoretical knowledge on this issue and to be ultimately able to design effective communication tools. 
Furthermore, there is also an increased research focus on macro-oriented market mechanisms guiding both commercial and public policy interests. Interesting work includes areas such as drug regulation on an international level (Stremersch and Lemmens 2009), detailing (Manchanda and Honka 2005), and the overall market development of the healthcare sector in relation to the overall economy in the shortand the long run (Hartwig 2008). Economic downturns, however, represent a mid-term perspective which demands special attention by market researchers (Lamey et al. 2007) and has not received enough consideration at in the healthcare sector (Narayan and Narayan 2008). It has long been known that industrial sectors and often even entire countries vary in their degree of cyclical volatility (see e.g. Deleersnyder et al. 2009; Lane 2003b), and stronger cyclical fluctuations can impose serious long-term effects for industries and countries as a whole. However, most industrial sectors take an overall direction of being either procyclical or countercyclical (Deleersnyder et al. 2004), meaning that they either move in line with the overall economic cycle or against it. In the healthcare sector, this is not as obvious a priori due to the various regulations across different countries and the social importance of the healthcare sector. In addition, it has been shown that marketing actions can influence or mitigate adverse consequences of procyclical fluctuations for single companies as well as entire industries as such (Lamey et al. 2007; Lamey et al. 2012). Therefore, it is interesting to see whether such conditions apply for the healthcare sector as well, and especially how economic cycles affect healthcare-related indicators such as the overall population health in the long-run.

These phenomena, which could be summarized as "Recessions and Depressions", have not yet been investigated from a marketing perspective and exhibit relevant theoretical questions, as stated above. For instance, further insight is required on the nature of stigma and the right use of economic theory to respond during economic downturns. Moreover, both concerns are among the most pressing issues in the healthcare sector (Strøm-Erichsen 2011; WHO 2001), as will be explained in the following paragraphs.

\section{DEPRESSIONS AND RECESSIONS - TWO TIMELY ISSUES}

Among numerous challenges which policy makers and health marketers are facing on the macro- and micro level of the healthcare sector, this dissertation aims to contribute to two major topics. On the one hand, in light of the global financial crisis from 2008, 
an increased demand for research investigating business-cycle effects on the healthcare sector emerged, as policy makers and marketers need better guidance to trade-off costcuttings and their consequences. On the other hand, the area of mental illnesses still faces problems of people's reluctance to undergo timely treatment and discrimination against people who suffer from mental illnesses. In essence, we contribute to the discussions on (i) the control of raising cost in turbulent economic times and (ii) the stigmatization of mental illnesses, or "recessions and depressions", to put it in a more colloquial way.

As stated previously, healthcare expenditures have been on the rise for decades. Therefore, cost containment on a national level becomes increasingly important in times of government austerity mechanisms and increasing consumer debt (Stuckler et al. 2009b). Keeping healthcare affordable and accessible for everyone and investing and marketing the right mechanisms is of utmost importance, as a healthy population enjoys a higher quality of life, can perform more competitively and thus fosters economic growth in the long run (Suhrcke et al. 2006). Therefore it is interesting to see how external economic conditions impact the healthcare industry and to gain insights on best practices of public policy and marketing activities. This can help to improve the situations for patients and providers by aligning their interests and recommending the right actions in different situations. Researchers have already developed sound investigations of the relationship between the overall economy and the healthcare sector, which comprise both long- and short-term oriented studies (for a detailed overview, please consult chapter 2 of this dissertation). However, during the recent economic downturn, it emerged that insights on the business cycle or mid-term perspective are missing (Narayan and Narayan 2008). Further insight is needed in order to see how the healthcare sector is affected and which public policy and marketing measures are useful to mitigate negative long-term effects of economic downturns.

Secondly, an important issue is the area of mental illnesses which represent a major burden, as only $1 / 3$ of illnesses are treated, while approximately $1 / 4$ of the population will encounter them (OECD 2012). Mental illnesses such as depression or impulse control disorders like internet addiction are said to become the major impediment to a healthy population in the 21st century (WHO 2001). Especially in developed countries, which offer advanced structures of care and a universal coverage there is no structural threshold in access to care but rather an attitudinal challenge, or a stigma, which prevents people from seeking treatment (Sareen et al. 2007). The area of consumer- or patient- 
focused research in the healthcare marketing areas has delivered interesting insights to increase the effectiveness of communication for several physical disease conditions such as aids or cancer prevention (Keller and Lehmann 2008). Mental illnesses and the surrounding stigma, however, have not yet been a focal issue of investigation, albeit a crucial need for better communication tools and recent calls from industry insiders for an increased amount of social marketing research. We address this gap by merging the research stream on implicit theories of an individual's perspective to see character traits as fixed or malleable with the discussion on message design in the field of mental illnesses.

\section{OVERVIEW AND STRUCTURE}

This dissertation includes two empirical studies in the healthcare market focusing on delivering implications for marketers and policy makers. Even though the studies diverge in their perspectives (macroeconomic vs. individual level) and their resulting context-specific implications, they both aim at identifying positive effects of marketing for the society as a whole and the consumer as an individual. This is in line with recent calls for marketing research to tackle socially relevant issues and to contribute to a better understanding of socio-economic phenomena. In the following sections we introduce both studies and summarize their empirical findings.

\section{STUdY 1: HOW BUSINESS CYCLES AFFECT THE HEALTHCARE SECTOR: A CROSS-COUNTRY INVESTIGATION}

As it is imperative for managers and policy makers to understand the markets they work in, a detailed knowledge of market responses and dynamics is needed to make informed decisions (Sheng et al. 2011). Indeed, researchers have been studying the link between healthcare expenditures and GDP in order to explain cross-country differences and to evaluate the efficiency of resource allocation (see Hartwig (2008) for a recent overview). However, previous research has focused on the long- and/or short-term relationship between both series, while the mid-term (business cycle) perspective has been currently overlooked. The relationship between two time series can be substantially different when taking different time perspectives (see e.g. Lemmens et al. 2007). Therefore investigating the cyclical fluctuations in healthcare expenditure may yield interesting additional insights. 
In this study, we identify the cyclical sensitivity of the public and private parts of the healthcare market for a large sample of countries across the world. We find evidence for variability in responses to the business cycle, both across spending sources (i.e., public vs. private) and across countries. Indeed, while consumers and/or governments consistently cut back on healthcare expenditures during economic contractions in some countries, private and/or public healthcare buyers have the tendency to spend more when the economy declines in other countries. Furthermore, we investigate whether cyclical (temporary) fluctuations in healthcare expenditures have a long-lasting influence on the healthcare sector by looking at their impact on overall population health and long-term healthcare expenditure growth. Our results show that a decrease in private expenditures during economic downturns is adversely related to the healthiness of the overall population in the long run and thus should be circumvented by all means. Additionally, we demonstrate that states which cut on their public expenditures during economic contractions have to overcompensate in the long-run and thus face a higher increase of their expenditures, which is also undesirable from a socioeconomic point of view. Moreover, given that managers have been shown to influence the business-cycle sensitivity in their sector (Lamey et al. 2012), we analyze whether policy and marketing decision making influences the country-specific sensitivity of healthcare expenditures. Our exploratory analyses show that both, the maintenance of selling activities by pharmaceutical firms as well as an increased amount of public prevention activity are able to mitigate the adverse effects of business cycles.

\section{STUDY 2: THE (INCRE)MENTALIST: ON THE INTERPLAY OF IMPLICIT THEORY ORIENTATIONS AND MESSAGE DESIGN IN SOCIAL MARKETING CAMPAIGNS TO REDUCE MENTAL-ILLNESS STIGMA}

Mental illnesses are a burden for individuals who are affected, as well as to society as a whole, due to their widespread occurrence and the low degree of treatment (Corrigan et al. 2006). Yet, in many cases the reasons for the reluctance to treatment do not originate in a lack of therapy offerings or structural deficiencies but rather stem from stigmatized attitudes among the general public (Sareen et al. 2007). Often, people try to avoid the topic of mental illnesses and keep a distanced negative attitude towards mental illnesses and mentally ill people (Corrigan 2004a). Therefore, overcoming 
mental-illness stigma is a challenge for social marketers around the globe in which many attempts have been made to achieve attitudinal change via mass media campaigns (Rochlen and Hoyer 2005). However, often those campaigns failed to achieve the desired results (Clement et al. 2010). In this research we examine how such campaigns can be improved by matching the recipient's worldview of seeing human personality as fixed or malleable with the message design of a campaign. Our results show that, in general, people who believe in the fixedness of traits, or entity theorists, exhibit higher levels of stigma than incrementalists, who see personality as malleable (Study 1 ). This finding extends knowledge from stereotype research to the field of mental illness stigma, as entity theorists tend to overgeneralize the stimuli they encounter and are likely to adopt a black or white perspective, which makes them quicker in judgment. This inherent difference can be reduced by framing mental illnesses as medical conditions, opposed to positioning them as biopsychosocial conditions (Study 2). A medical framing is preferred by entity theorists, as it is more in line with their clear-cut line of reasoning, and exhibits less room for interpretation than the biopsychosocial model. In contrast, incrementalists are indifferent between the two different message designs as they are more tolerant and accept several points of view. As both message framings find practical applications, we show that an increased level of controllability in the message can reduce the difference when displaying illnesses as biopsychosocial phenomena (Study 3). Finally, we show that the level of illness severity acts as a boundary condition of our findings (Study 4) and develop the necessary practical implications resulting from our research.

\section{CONCLUSION}

In conclusion, in this dissertation we try to contribute to the existing stream of healthcare marketing research by enhancing the knowledge on two central topics which are important to health marketers, policy makers and the society as a whole. We attempt to fill knowledge gaps on both sides of the research continuum by addressing (i) the macroeconomic phenomenon of economic up- and downturns and their effects on the healthcare industry and (ii) finding effective communication designs to reduce the stigmatization of mental illnesses and mentally ill people on an individual or micro level. 
ChAPTER 2

HOW BUSINESS CYCLES AFFECT

THE HEALTHCARE SECTOR:

A CROSS-COUNTRY INVESTIGATION 


\section{ABSTRACT}

The healthcare sector has gained a lot of research interest by marketing scholars because of its high economic and social importance. While the long-term relationship between GDP and healthcare expenditures has been extensively researched to explain differences in healthcare spending between countries, the mid-term (i.e., businesscycle) perspective has currently been overlooked. In this paper, we explore such business-cycle sensitivity of both the public and private parts of the healthcare sector, and assess its long-term consequences across 27 countries worldwide. We find evidence for variability in responses to the business cycle, both across spending sources (i.e., public vs. private) and across countries. Indeed, while consumers and/or governments consistently cut back on healthcare expenditures during economic contractions in some countries, private and/or public healthcare buyers have the tendency to spend more when the economy declines in other countries. Moreover, we find important long-term consequences. We show that cost cuttings during economic downturns in the private part of the healthcare sector reduce the growth in the health status of the population in the long run, while public cut backs increase the long-term growth in total healthcare expenditures. 


\section{INTRODUCTION}

Because of its huge social and economic importance, the healthcare sector has received increasing attention from both economic and business researchers (Stremersch and van Dyck 2009). Also in marketing, the sector has become an important research field, as reflected in special sessions on Marketing and Health in mainstream marketing conferences (Stremersch 2008), and the special issue on the same topic in the International Journal of Research in Marketing (2008). One of the biggest concerns in the field are the exploding healthcare expenditures which tie up funds that could be used for other purposes, or increase the buyers' debt (Orszag and Ellis 2007; Pearson 2011). While healthcare expenditures have a positive impact on the general health status of the population, countries are still struggling to keep the growth of healthcare expenditures under control, currently even outpacing the growth of the general economy in most Western countries (Huber and Orosz 2003).

The (long-run) relationship between the healthcare expenditures and the general economy has been studied extensively to explain differences between countries in healthcare spending levels and growth (see e.g. Barros 1998; Clemente et al. 2004; Gerdtham and Loethgren 2000; Hitiris and Posnett 1992; Newhouse 1977). Still, as indicated by Narayan and Narayan (2008), prior literature has overlooked the businesscycle perspective, which may lead to substantially different conclusions on the link between the economy and healthcare (Lemmens et al. 2007), and hence may have important policy implications.

Although, a priori, the healthcare industry could be assumed unrelated to the economic conditions, given that people's medical needs would be expected to not fluctuate with the business cycle (Morris 2008; Price 2009), anecdotal evidence on healthcare expenditures during the latest recession seem to indicate otherwise. According to the 2011 edition of Deloitte's annual Survey of Health Care Consumers, about half of the respondents in all countries surveyed (except for Luxembourg) indicate that the economic downturn has impacted their willingness to spend on healthcare. In the US, for example, $41 \%$ of the respondents indicate that the bad economic climate has made them more cautious about spending on health. In an effort to save money, $36 \%$ of the US respondents ask doctors to prescribe a generic drug instead of the more expensive brand name drug, while $19 \%$ delayed or decided not

\footnotetext{
${ }^{1}$ http://www.zita.be/nieuws/binnenland/1815779_aantal-bezoeken-aan-huisarts-piekt-door-crisis.html.
} 
to follow a course or treatment. In contrast, about half of the respondents worldwide (except for the UK, Canada and China) indicate an increased household spending on healthcare during the latest recession (Deloitte 2011). Indeed, economic downturns may have an impact on people's health because of an increased feeling of anxiety about losing their job (Brenner and Mooney 1983), or about the future in general (Neumayer 2004). In Belgium, for example, the number of doctor visits has increased with 900,000 to about 32 million in 2011 because of the economic crisis ${ }^{1}$.

Also, on the public side, the business press indicates different responses to the latest economic crisis in terms of spending on healthcare. The US government, for example, introduced a $\$ 150$ billion stimulation package for the healthcare industry as part of their Recovery and Reinvestment Act (Steinbrook 2009), and also Norway chooses to invest in reforming and improving healthcare systems in order to avoid social inequalities in health caused by the tough economic times (Strøm-Erichsen 2011). In contrast, countries as Estonia, Ireland and Iceland have recently introduced big cuts in their public healthcare expenditures (Pearson 2011). Taken together, this anecdotal evidence seems to point to the fact that both private and public healthcare expenditures may well be related to cyclical up- and down-movements in the general economy (i.e., the business cycle), and that differences between countries are very likely to occur.

Apart from the sheer insight on whether or not healthcare spending is sensitive to the business cycle, most imperative for policy makers is how these cyclical fluctuations impact the sector in the long run. The decision to undergo urgent medical procedures is probably not influenced by spending decisions during economic downturns. However, as indicated in the business press, healthcare expenditures are mostly cut in less urgent areas entailing prevention and procedures that can be postponed such as quit-smoking procedures, and diabetes and cancer prevention (Goozner 2012; Rubin 2012). While these decisions may indeed help cutting healthcare expenditures during bad times, not preventing or treating problems in time may have an impact on the long-term health status (Gurria 2011). Moreover, in order to restore the health status to the level before the crisis, overcompensation in terms of healthcare spending may be needed, which implies a long-term impact on the total healthcare expenditures.

In this paper, we study the business-cycle sensitivity of private and public expenditures on healthcare in a sample of 27 countries worldwide, and asses the long-term implications 
for the growth in the health status of the population and the total healthcare expenditures. We first explore to what extent private and public healthcare expenditures co-move with cyclical fluctuations in the economy in each investigated country, thereby contributing to the controversial debate on the cyclicality of the healthcare market (Price 2009). Next, we examine whether the cyclical sensitivity of both types of healthcare spending translates in long-term consequences in terms of the health status and total healthcare expenditures.

\section{HEALTHCARE AND THE ECONOMY}

A wide body of research has studied the relationship between healthcare expenditures and the general economy (GDP) in an attempt to explain cross-country differences in spending on healthcare. Table 1 provides an overview of this literature stream.

In his pioneering study, Newhouse (1977) identified a strong positive relationship between healthcare expenditures and GDP using a cross-sectional analysis of 13 OECD countries. Newhouse's (1977) results indicate that a country's GDP is the most important driver of healthcare expenditures. Different studies (see e.g. Brown 1987; Leu 1986) replicated this cross-sectional approach with more countries. Starting from the nineties, when time series data on healthcare expenditures were made available, more sophisticated analyses appeared, investigating whether this positive relationship between healthcare expenditures and GDP holds over time. Several studies explored whether there exists a long-run relationship on a country-by-country basis (see e.g. Blomqvist and Carter 1997; Hansen and King 1996; Herwartz and Theilen 2003), or across countries using panel-data techniques (see e.g. Dreger and Reimers 2005; Gerdtham and Loethgren 2000; McCoskey and Selden 1998). Even though there is some debate in the literature on this relationship (see e.g. Hansen and King 1996), the majority of these studies indicate that healthcare expenditures and GDP are co-integrated (Blomqvist and Carter 1997; Gerdtham and Loethgren 2000; Herwartz and Theilen 2003), which means that they co-move in the long run.

Recently, it was proposed that healthcare expenditures should be analyzed separately for the private buyer and the government, as it is not clear whether the two 
TABLE 1: LITERATURE OVERVIEW OF STUDIES LINKING HEALTHCARE EXPENDITURES AND THE GENERAL ECONOMY

\begin{tabular}{|c|c|c|c|c|}
\hline Study & $\begin{array}{l}\text { Time } \\
\text { perspective }\end{array}$ & $\begin{array}{l}\text { Nr. of } \\
\text { countries }\end{array}$ & $\begin{array}{l}\text { Type of healthcare } \\
\text { expenditures }\end{array}$ & Main findings \\
\hline Newhouse 1977 & $\begin{array}{l}\text { Cross- } \\
\text { sectional }\end{array}$ & 13 & Total expenditures & $\begin{array}{l}\text { GDP most important driver } \\
\text { of healthcare expenditures }\end{array}$ \\
\hline Leu 1986 & $\begin{array}{l}\text { Cross- } \\
\text { sectional }\end{array}$ & 19 & $\begin{array}{l}\text { Public and Private } \\
\text { expenditures }\end{array}$ & $\begin{array}{l}\text { GDP most important driver } \\
\text { for public and private } \\
\text { healthcare expenditures }\end{array}$ \\
\hline Brown 1987 & $\begin{array}{l}\text { Cross- } \\
\text { sectional }\end{array}$ & 18 & Total expenditures & $\begin{array}{l}\text { GDP most important driver } \\
\text { of healthcare expenditures }\end{array}$ \\
\hline Hitiris and Posnett 1992 & Long term & 20 & Total expenditures & $\begin{array}{l}\text { GDP most important } \\
\text { driver, but cross-country } \\
\text { variation }\end{array}$ \\
\hline Hansen and King 1996 & Long term & 20 & Total expenditures & $\begin{array}{l}\text { Healthcare expenditures \& } \\
\text { GDP nonstationary but not } \\
\text { co-integrated }\end{array}$ \\
\hline $\begin{array}{l}\text { Blomqvist and Carter } \\
1997\end{array}$ & Long term & 20 & Total expenditures & $\begin{array}{l}\text { Healthcare expenditures \& } \\
\text { GDP nonstationary and } \\
\text { co-integrated }\end{array}$ \\
\hline $\begin{array}{l}\text { McCoskey and Selden } \\
1998\end{array}$ & Long term & 20 & Total expenditures & $\begin{array}{l}\text { Healthcare expenditures \& } \\
\text { GDP nonstationary and } \\
\text { co-integrated }\end{array}$ \\
\hline $\begin{array}{l}\text { Gerdtham and Loethgren } \\
2000\end{array}$ & Long term & 21 & Total expenditures & $\begin{array}{l}\text { Healthcare expenditures \& } \\
\text { GDP nonstationary and } \\
\text { cointegrated }\end{array}$ \\
\hline $\begin{array}{l}\text { Herwartz and Theilen } \\
2003\end{array}$ & Long term & 19 & Total expenditures & $\begin{array}{l}\text { Healthcare expenditures \& } \\
\text { GDP nonstationary and } \\
\text { co-integrated, but cross- } \\
\text { country variation in recent } \\
\text { years }\end{array}$ \\
\hline Clemente et al. 2004 & Long term & 22 & $\begin{array}{l}\text { Public and Private } \\
\text { expenditures }\end{array}$ & $\begin{array}{l}\text { Private and public } \\
\text { healthcare expenditures } \\
\text { related to GDP, but } \\
\text { evolved differently over } \\
\text { time }\end{array}$ \\
\hline Dregers and Reimers 2005 & Long term & 21 & Total expenditures & $\begin{array}{l}\text { Healthcare expenditures \& } \\
\text { GDP nonstationary and } \\
\text { co-integrated }\end{array}$ \\
\hline Our Study & Mid term & 27 & $\begin{array}{l}\text { Public and Private } \\
\text { expenditures }\end{array}$ & $\begin{array}{l}\text { Differences between countries } \\
\text { in GDP and public and private } \\
\text { healthcare expenditures over } \\
\text { the business cycle }\end{array}$ \\
\hline
\end{tabular}


different expenditure sources develop in the same way (Getzen 2000). Disentangling the private from the public expenditures allows getting a more fine-grained picture of the actual developments in total healthcare spending. In line with this, Clemente et al. (2004) find that the long-term relationship between the overall economy on the one hand, and private and public healthcare expenditures, on the other hand, evolve differently over time. Therefore, it is of high importance to distinguish between the two different expenditure sources.

Overall, general economic activity remains the most consistent and most used predictor for over-time developments in healthcare expenditures (Di Matteo and Di Matteo 1998). While the focus of these studies has been on the long-term relationship, to the best of our knowledge, no study has systematically analyzed the relationship between healthcare expenditures and the economy from a business-cycle perspective. Prior studies have pointed out that the nature of interactions between the same variables can differ across different periodicities (see e.g. Bronnenberg et al. 2006; Lemmens et al. 2007). For example, Baxter (1994) shows that the relationship between real exchange rates and real interest rate differentials is non-existing in the short run (i.e., at high frequencies), but is actually quite strong at both long-run and businesscycle periodicities. Lemmens, Croux, \& Dekimpe (2007), in turn, show that short-run movements in consumer confidence are country specific, while more homogeneous patterns emerge as the planning horizon is extended. Hence, the need for additional investigations on the mid-term (business-cycle) perspective emerges, as it is not clear how mid-term fluctuations in GDP translate into healthcare expenditures. This is also put forward by Narayan and Narayan (2008), who explicitly call for an investigation of the relationship between the aggregate economic cycle and cyclical fluctuations in healthcare expenditures.

\section{CONCEPTUAL BACKGROUND}

Due to their direct and strong influence on consumers and organizations, empirical research on cyclical fluctuations and their long-term consequences has gained an increased importance in the recent marketing literature (Gijsenberg et al. 2009). Prior 
marketing literature has indicated that people adjust their (buying) behavior in line with the business cycle (Millet et al. 2012). For example, the demand for consumer durables (like Refrigerators and Color TVs) has been shown to go up during expansions, and to go down during contractions (i.e., to behave procyclical) (Deleersnyder et al. 2004). In contrast, private-label products in the FMCG sector gain during contractions, and loose when the economy expands again (i.e., behave countercyclical) (Lamey et al. 2012). Organizations also adjust their behavior when the economy fluctuates. For example, Deleersnyder and colleagues (2009) report strong procyclical patterns in the advertising industry, whereas Lamey et al. (2012) show that in the FMCG sector both national-brand manufacturers and retailers adjust their marketing conduct in line with the business cycle. Also for the healthcare market, arguments can be formulated for the existence of business-cycle sensitivity for both the public and private components.

\section{PUBLIC EXPENDITURES}

Economic contractions might lead to cost cuts, hence procyclical fluctuations, in public healthcare expenditures for two reasons. First, countries might face severe budget constraints due to tumbling revenues, and might simply be forced to cut down expenditures in all public sectors (Stuckler et al. 2009a). Second, downturns can be used to make cuts in socially important sectors as they are easier to justify when the overall economy turns sour (Mascarenhas and Aaker 1989). Indeed, Lane (2003a) indicates that during downturns the different institutions are less demanding in the budget negotiations as everybody knows that there is a smaller amount to be redistributed.

On the other hand, there is also quite some evidence for the opposite reaction, i.e., increasing public expenditures during contractions, or a countercyclical sensitivity. Often, countries adopt a classical Keynesian approach and try to stimulate the economy during tough economic times (2003a). Government stimulation packages often contain general investments in infrastructure or other institutions of common interest, including the healthcare sector (Spilimbergo et al. 2008). As the healthcare industry is a sector of great social and economic importance in all developed countries (Stremersch 2008), it is a useful target for investments in economic stimulation. In the recent economic crisis, for example, the US devoted a stimulus package of $\$ 150$ Billion to the healthcare sector (Steinbrook 2009). 


\section{PRIVATE EXPENDITURES}

Private expenditures might also be related to the business cycle, but for different reasons. On the one hand, private consumers are known to economize on spending in general during economic downturns (i.e., behave procyclically) (Katona 1974). For example, when the economy turns sour, people economize on price (Estelami et al. 2001), switch to lower-priced private labels (2012), and postpone expensive purchases (Deleersnyder et al. 2004; Zurawicki and Braidot 2005). Also in the healthcare industry, people buy more generic pharmaceuticals, and postpone treatments with higher out-of-pocket payments in order to save money during rougher economic times (Deloitte 2011; Neumayer 2004).

On the other hand, private healthcare expenditures could also behave countercyclically. Economic downturns were shown to affect people's mental health due to increased anxiety about the future (Neumayer 2004). This might lead to increased spending in the mental health sector. Moreover, it was found that people who are on the edge of losing a job, experience increased health risks (Brenner and Mooney 1983). As this group usually gets bigger when the economy declines, treatment costs may increase. Furthermore, Millet et al. (2012) show that business-cycle fluctuations trigger distinct motivational orientations for consumers, resulting in - among others - an increased consumption of products which avoid negative outcomes, such as preventive healthcare and health insurance, during economic downturns.

All arguments mentioned above put forward a wide range of possible outcomes with regard to the business-cycle sensitivity of public and private healthcare expenditures. We expect a large amount of cross-country heterogeneity in private and public sensitivities, which is in line with the differences across countries in the cyclicality of total government expenditures as established by Lane (2003a). Furthermore, when comparing recessionary indicators and total healthcare expenditure growth rates across five different countries, Narayan and Narayan (2008) indicate that cross-country differences are highly likely.

\section{LONG-TERM CONSEQUENCES OF CYCLICAL SENSITIVITY}

Temporal changes in a market can alter its overall long-term development (Simon 1997). Indeed, it has been shown that maintaining pre-recession spending levels through 
tough times leads to an easier recovery due to a smoother transition, while cuts during contractions can cause permanent losses (Doyle 2000; Lamey et al. 2007; Steenkamp and Fang 2011). For example, Deleersnyder et al. (2009) found that strong procyclical fluctuations in the advertising industry result in negative long-term consequences for the entire industry by fueling private-label growth and slowing down firm performance. In a similar vein, Lamey et al. (Lamey et al. 2012) showed that national brands experience permanent losses in market share due to cyclical fluctuations in the demand for their private-label alternatives. In general, (temporary) cyclical fluctuations in a sector can have severe long-term consequences.

In the healthcare sector, temporal cuts in healthcare spending may cause permanent losses in the health status of the population (Musgrove 1987; Stuckler et al. 2009a). Indeed, if certain diseases or problems, such as HIV, Schizophrenia or Visual Impairment are not treated in time, they can cause irreversible harm to patients, which might lead to long-term losses in the overall health status of the population (Loebel et al. 1992; Muether et al. 2012; Petersen et al. 2008). Therefore, it seems likely that reductions in public and private healthcare expenditures during an economic downturn have a negative long-term impact on the health status.

Furthermore, cost cuttings during an economic downturn require subsequent overcompensation to reach the same level prior to the reductions (Blanchard and Summers 1986; Steenkamp and Fang 2011). Procyclical reductions of public and private healthcare expenditures might result in the postponement of less urgent treatments (Deloitte 2011). This increases the chance of extremely costly and urgent procedures later, which might inflate the total healthcare expenditures in the long run (OECD 2011).

\section{METHODOLOGY}

We use two stages of analysis to address our research questions. In the first stage, we derive the cyclical comovement elasticity, quantifying the cyclical sensitivity of public and private healthcare expenditures for each of the 27 countries under investigation. Therefore, we first filter out those fluctuations in healthcare expenditures that 
correspond to business-cycle periodicities, and then relate these cyclical fluctuations in healthcare expenditures to those of the economy as a whole, which leads to the comovement elasticities. In the second stage, we measure the long-term consequences of the cyclical fluctuations in healthcare expenditures on the long-term growth in the health status and total healthcare expenditures. In order to do so, we quantify a longterm growth measure of health status and total healthcare expenditures, and use the cyclical comovement elasticities of private and public healthcare expenditures from stage 1 as explanatory variables.

\section{QUANTIFYING THE CYCLICAL SENSITIVITY OF HEALTHCARE EXPENDITURES}

To quantify the cyclical sensitivity, we first extract those fluctuations from the public and private healthcare expenditures series that occur at business-cycle periodicities. Next, we relate these fluctuations to the aggregate business cycle.

Extracting the cyclical component. In line with recent studies (e.g. Cook 1999; Deleersnyder et al. 2009), we use the well-known Hodrick and Prescott (HP) filter (1997) to extract the cyclical component from the series of public and private healthcare expenditures. The HP filter decomposes a time series $\left(y_{t}\right)$ into a steadily evolving longterm trend component $\left(y_{t}^{\text {trend }}\right)$ and a cyclical component $\left(y_{t}^{c}\right)$ which fluctuates around the long-term trend (see Lamey et al. (2007) for a detailed review of the properties of the HP filter). The HP filter extracts the trend component $\left(y_{t}^{\text {trend }}\right)$ of a time series by minimizing the following specification:

$$
\sum_{t=1}^{T}\left(y_{t}-y_{t}^{\text {trend }}\right)^{2}+\lambda \sum_{t=2}^{T-1}\left(\left(y_{(t+1)}^{\text {trend }}-y_{t}^{\text {trend }}\right)-\left(y_{t}^{\text {trend }}-y_{(t-1)}^{\text {trend }}\right)\right)^{2}
$$

where T represents the number of years included in the time series. The first quadratic term is a goodness of fit measure, while the second quadratic expression determines the smoothness of the trend component. The solution to specification (1) is a tradeoff between fit and smoothness based on the smoothing parameter $\lambda(1997)$. The larger the value of $\lambda$, the smoother the trend component will become. In line with prior studies with annual data (e.g. Baxter and King 1999; Lamey et al. 2007), $\lambda$ is set to 10 . To obtain the cyclical component $\left(y_{t}^{c}\right)$ we remove the long-term component $\left(y_{t}^{\text {trend }}\right)$ from the original series $\left(y_{t}\right)$ : 


$$
y_{t}^{c}=y_{t}^{-} y_{t}^{t r e n d}
$$

To enhance the comparability across series, we analyze $y_{t}$ in logarithms which makes the units of $y_{t}^{c}$ to represent percentage deviations of the long-term trend when multiplied by 100 (Stock and Watson 1999).

As we are interested in the per-country sensitivity of public and private healthcare expenditures, we apply the procedure outlined before to the log-transformed time series of healthcare expenditures ( $h c e_{i s t}$ ) of country $i$, expenditure source $s$ (i.e. public $(p u b)$ or private (pri)) and time period $t$ to obtain the cyclical component (hce $\left.e_{i s t}^{c}\right)$.

Relating the cyclical component to the aggregate business cycle. To measure the relationship between healthcare expenditures and the aggregate business cycle, we compute the cyclical comovement elasticity. This comovement elasticity measures how cyclical fluctuations of the aggregate economy translate into cyclical fluctuations in private and public healthcare expenditures (see Deleersnyder et al. 2004 for a similar practice; Deleersnyder et al. 2009; Lamey et al. 2007; Lamey et al. 2012). This comovement elasticity is obtained by regressing the cyclical component of private and public healthcare expenditures ( $\left.h c e_{i s t}^{c}\right)$ on the cyclical component of GDP $\left(g d p_{i t}^{c}\right)$ on a per-country base, as displayed in equation (3). The cyclical component of GDP $\left(g d p_{i t}^{c}\right)$, obtained via the HP-filter (following equations (1) and (2)), entails the business-cycle fluctuations across many industries on a national level. Therefore, this comprehensive measure represents an appropriate indicator for the national business cycle (Stock and Watson 1999).

$$
h c e_{i s t}^{c}=\beta_{i s} g d p_{i t}^{c}+\varepsilon_{i s t}
$$

Both series are log-transformed before the filtering, and therefore represent percentage deviations from a long-term trend. Therefore, $\beta_{\text {is }}$ can be interpreted as a comovement elasticity. The sign of the elasticity indicates whether a country's public or private healthcare expenditures are procyclical $\left(\beta_{i s}>0\right)$ (i.e., increase during expansions and decrease during contractions) or countercyclical $\left(\beta_{i s}<0\right)$ (i.e., decrease during expansions and increase during contractions). To control for potential autocorrelation, we allow for auto-regressive (AR) error terms in equation (3) (Engle 1974), which also account for potential dynamics in the relationship (Deleersnyder et al. 2009). 
The number of included AR terms is based on the Hannan-Quinn information criterion (Hannan and Quinn 1979).

\section{IDENTIFYING LONG-TERM CONSEQUENCES OF CYCLICAL SENSITIVITY}

In the second stage, we look for long-term consequences of cyclical sensitivity in healthcare expenditures. Therefore, we link the comovement elasticities of public and private healthcare expenditures to the long-term average growth in the health status (equation (4)) and total healthcare expenditures (equation (5)):

$$
\begin{gathered}
\overline{\Delta \text { health status }{ }_{i}^{\text {trend }}}=v_{0}+\gamma_{1} \hat{\beta}_{\text {ipub }}+\gamma_{2} \hat{\beta}_{i p r i}+\gamma_{3} \overline{\Delta h c e_{i}^{\text {trend }}}+\vartheta_{i} \\
\overline{\Delta h c e_{i}^{\text {trend }}}=\delta_{0}+\delta_{1} \hat{\beta}_{\text {ipub }}+\delta_{2} \hat{\beta}_{\text {ipri }}+\delta_{3} \overline{\Delta g d p_{i}^{\text {trend }}}+\varkappa_{i}
\end{gathered}
$$

Health status ${ }_{i}^{\text {trend }}$ and $h c e_{i}^{\text {trend }}$ are the long-term components of, respectively, the health status and total healthcare expenditures series derived through the HP filter (see equation (1)). We focus on the average yearly growth rates of these series (i.e., $\overline{\Delta \text { health status trend }}$ and $\overline{\Delta h c e_{i}^{\text {trend }}}$ ) to capture the long-term growth. Following Deleersnyder et al. (2009), we estimate the average long-term growth by running an intercept-only regression on the first differences of the log-transformed trend components of the series (i.e., $\Delta$ health status ${ }_{i}^{\text {trend }}$ and $\Delta h c e_{i}^{\text {trend }}$ ).

As past research has shown that the health status is related to the healthcare expenditures in the long run (see e.g. Hitiris and Posnett 1992; Wolfe 1986), we use the long-term average growth of total healthcare expenditures $\left(\overline{\Delta h c e_{i}^{\text {trend }}}\right)$ as a control variable in equation (4). In equation (5), we control for the long-term average growth of GDP $\left(\overline{\Delta g d p_{i}^{\text {trend }}}\right)$, given that it is shown to be the most influential factor in driving long-term healthcare expenditure growth (Barros 1998; Huber 1999). The dependent variables in equations (4) and (5) are estimated values with differing degrees of estimation accuracy. Hence, ordinary least squares (OLS) might yield biased standard error estimates (Narasimhan et al. 1996). Therefore, we use WLS, where the inverse of the standard errors of the long-term average growth rates serve as weights (see e.g. Nijs et al. 2001 for a similar practice). Furthermore, also the comovement elasticities on the right-hand side of the equations are estimated parameters with error, which might 
lead to biased standard errors in equations (4) and (5). As suggested by Nijs, Srinivasan and Pauwels (2007), we use a bootstrapping bias-correction algorithm applying 250 Monte-Carlo simulations on 1000 random resamples with replacement to compute unbiased standard errors.

\section{DATA}

Our dataset covers 27 countries from around the world ranging from 1990 until 2009, including at least 18 observations per country. This time period is sufficiently long to capture multiple business cycles, and is comparable in length to prior work on cyclical sensitivity (see e.g. Lamey et al. 2012; Mills 2001). Moreover, the number of countries largely exceeds the number used in prior literature on the relationship between healthcare expenditures and GDP (see Table 1). An overview of our key measures is provided in Table 2.

\section{TABLE 2: DESCRIPTIVE STATISTICS}

\begin{tabular}{|c|c|c|c|c|}
\hline Series & Mean & SD & Min & Max \\
\hline $\begin{array}{l}\text { Average per-country private healthcare } \\
\text { expenditures (in \$ per capita) }\end{array}$ & 568.662 & 509.321 & 17.000 & 3311.000 \\
\hline $\begin{array}{l}\text { Average per-country public healthcare } \\
\text { expenditures (in \$ per capita) }\end{array}$ & 1398.070 & 686.676 & 122.000 & 3115.000 \\
\hline $\begin{array}{l}\text { Average per-country growth in health status* } \\
\text { (in \%) }\end{array}$ & 0.013 & 0.006 & -0.017 & 0.033 \\
\hline $\begin{array}{l}\text { Average per-country growth in total health } \\
\text { expenditures (in \%) }\end{array}$ & 3.738 & 2.062 & -0.869 & 12.109 \\
\hline
\end{tabular}

*Note that health status figures were not available for Turkey

We obtained annual public and private healthcare expenditures, measured in US dollars, from the OECD Health Data 2010, which provides the most complete and differentiated 
data on healthcare expenditures. All data are in constant terms of year 2000 and measured on a per-capita basis in yearly terms. Private healthcare expenditures are the combined expenditures of all privately funded sources such as private insurance payments and out-of pocket payments for treatments or medication by consumers. Public healthcare expenditures, on the other hand, include both general and regional government expenditures which are financed with tax revenues as well as expenditures through social security funds. While private expenditures make up, on average, $28 \%$ of total healthcare expenditures in a country, substantial cross-country variation is observed in our sample ranging from only $11 \%$ in the Czech Republic to $56 \%$ in the US. Per-country data on the standardized number of deaths per 100,000 inhabitants per year are provided by the OECD. This variable is comparable across countries, as it controls for differences in age structures (OECD 2010). Therefore, dynamics in this figure depict pure gains or losses in the health of a country's population. We obtain a measure for the yearly health status by subtracting this mortality number from 100,000.

Finally, data on GDP per capita in constant 2000 US dollar prices is obtained from the OECD Economic Indicator database as a measurement for a country's general economic activity. The cyclical fluctuations in real GDP per capita have been shown to be an appropriate indicator for the overall economic cycle in a country (Stock and Watson 1999).

\section{RESULTS}

\section{CYCLICAL SENSITIVITY OF HEALTHCARE EXPENDITURES}

Our first-stage analysis estimates the extent of cyclical sensitivity of private and public expenditures through equations (1) to (3). Figure 1 shows the distribution of the estimated elasticities of public and private healthcare expenditures by displaying the mean elasticity per quartile across all countries of investigation. 


\section{Figure 1: AVERAge QUARTILE VALUES OF THE COMOVEMENT ELASTICITIES}

A: Private comovement elasticities

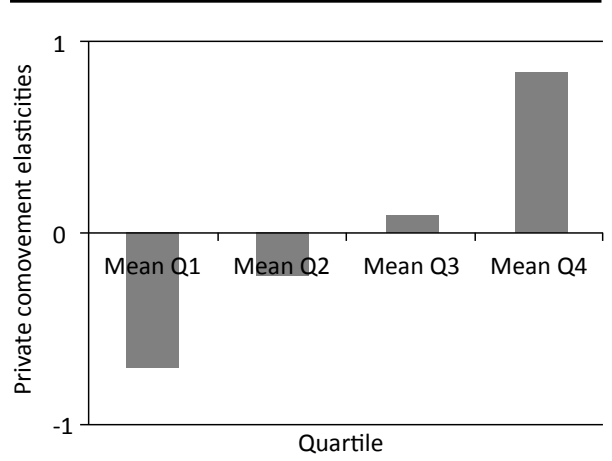

B:Public comovement elasticities

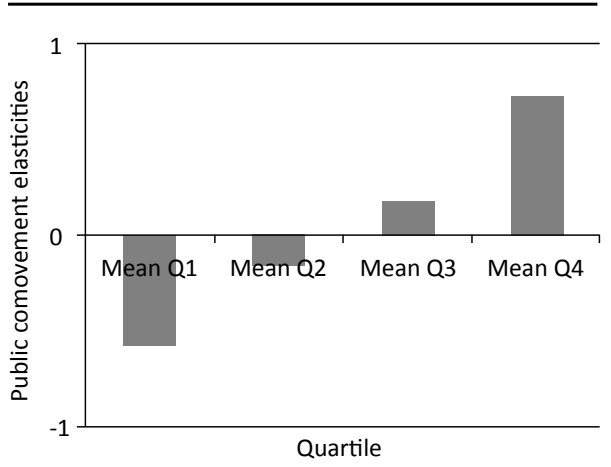

As mentioned above, the sign of the elasticity can be used to assess whether the studied healthcare expenditures behave (i) pro- (+), i.e., move in the same direction as the economy, or (ii) countercyclical (-), i.e., move in the opposite direction as the economy. As expected, Figure 1 demonstrates a high diversity in the obtained comovement elasticities both across countries and across spending source (i.e., private versus public). While the Danish and Swiss governments consistently invest in the healthcare sector during economic contractions, Korea and the Czech Republic cut public expenditures in the industry. The business-cycle sensitivity of private healthcare expenditures is also very different across countries. As such, private consumers economize on their healthcare during economic downturns in Austria and Portugal, while Australian and German private consumers, in contrast, feel the need to spend more on healthcare when the economy goes sour. A meta-analysis, obtained by the method of adding weighted Z's (Rosenthal 1991), confirms that no unidirectional effect of business-cycle sensitivity can be found either within ( $Z=-0.113 ; p>.10$ and $Z=0.508 ; p>.10$ for the private and public comovement elasticities, respectively) or across spending types $(Z=0.280 ; p>.10$ for the pooled private and public comovement elasticities). 
Moreover, we look at whether the elasticities of public and private expenditures within country tend to move in the same direction. In Table 3, we summarize the number of countries displaying each combination of private and public business-cycle sensitivity. The combination of countercyclical private and public healthcare expenditures is the most frequent and includes about one third of all countries in the sample. For Norway, for example, we find that both the private consumers and the government invest consistently in healthcare during economic contractions. Also the combination for which both the private and public expenditures behave procyclically is rather frequent (30\% of the observations). In these countries, such as the Czech Republic and Korea, both people and public policy makers appear to cut healthcare when the economy goes down. Although somewhat less frequent, private and public expenditures may also behave in the opposite direction. Indeed, in $22 \%$ of the cases (amongst which Germany), bad economic times make private consumers consistently spend more on healthcare, while the government uses the opportunity to save money in the sector. Finally, in the remaining countries ( $15 \%$ of the cases including Switzerland), healthcare spending is decreased by private consumers when the economy turns sour, while the government consistently tries to stimulate the healthcare industry by extra spending.

\section{TABLE 3: DISTRIBUTION OF ELASTICITIES}

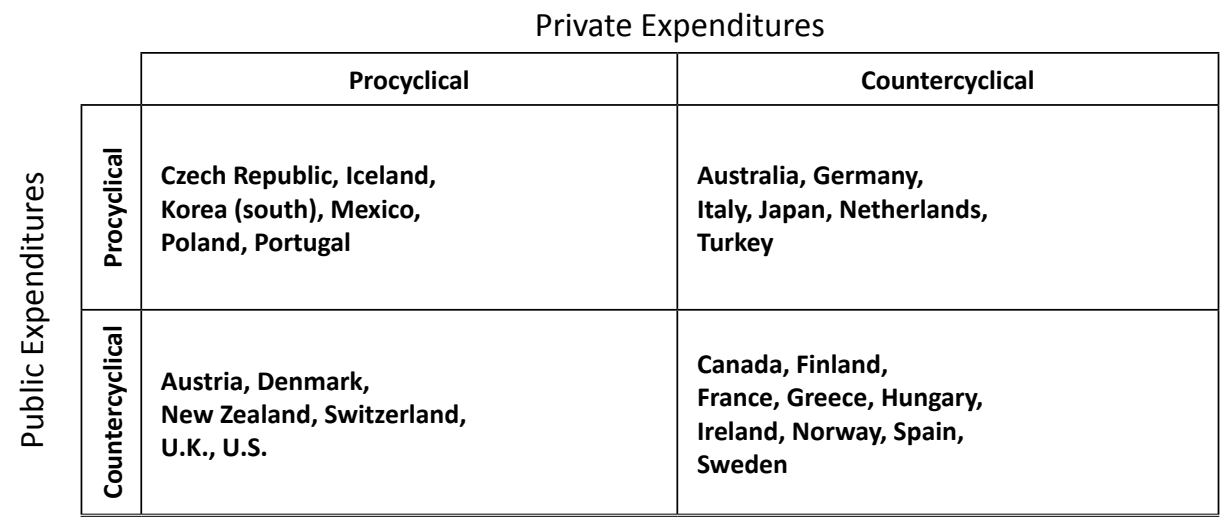




\section{LONG-TERM CONSEQUENCES OF CYCLICAL SENSITIVITY}

In the second step of our analysis, we relate the cyclical fluctuations of private and public healthcare expenditures to the average long-term growth in the health status (equation 4) and total healthcare expenditures (equation 5). The results of these regression models are summarized in Table 4.

\section{TABLE 4: LONG-TERM CONSEQUENCES OF CYCLICAL SENSITIVITY}

\begin{tabular}{|c|c|c|c|c|c|c|c|}
\hline \multicolumn{4}{|c|}{ Dependent variable: $\overline{\Delta \text { health status }}{ }_{i}^{\text {trend }}$} & \multicolumn{4}{|c|}{ Dependent variable: $\overline{\Delta h c e_{i}^{\text {trend }}}$} \\
\hline Independent Variable & Coefficient & & t-Value & Independent Variable & Coefficient & & t-Value \\
\hline intercept & 0.009 & $* * *$ & 4,166 & intercept & -0.002 & & -0.147 \\
\hline$\hat{\beta}_{i p r i}$ & -0.002 & $* *$ & -2.194 & $\hat{\beta}_{i p r i}$ & -0.004 & & -0.746 \\
\hline$\hat{\beta}_{\text {ipub }}$ & 0.001 & & 1.256 & $\hat{\beta}_{\text {ipub }}$ & 0.020 & $* * *$ & 2.960 \\
\hline$\Delta h c e_{i}^{\text {trend }}$ & 0.110 & $* * *$ & 2.624 & $\Delta g d p_{i}^{\text {trend }}$ & 0.956 & $* * *$ & 2.944 \\
\hline Adjusted $\mathrm{R}^{2}$ & & $5.0 \%$ & & Adjusted $\mathrm{R}^{2}$ & & $8.8 \%$ & \\
\hline Number of observations & & 26 & & Number of observations & & 27 & \\
\hline
\end{tabular}

*two-sided $\mathrm{p}<.10 * *$ two-sided $\mathrm{p}<.05, * * *$ two-sided $\mathrm{p}<.01$

As predicted, the private comovement elasticity has a significant negative effect on the average long-term growth in the health status $\left(\gamma_{\hat{\beta}_{i p r i}}=-.002 ; p<.05\right)$. This implies that countries with greater procyclical sensitivity in private healthcare expenditures have a lower long-term growth rate in population health. When people cut down on healthcare during contractions, they usually cut down on prevention and less urgent treatments, which will have an impact on their long-term health. Interestingly, we find no such effect for the public comovement elasticity $\left(v_{\hat{\beta}_{\text {ipub }}}=.001, p>.10\right)$. In line with Hitiris and Posnett (1992), we find that the average long-term growth in total healthcare expenditures has a positive effect on the average long-term growth in health status $\left(\gamma \overline{\Delta h c e_{i}^{\text {trend }}}=.110, p<.01\right)$. 
While the long-term growth in the health status of a country is affected by the cyclical sensitivity of its private healthcare expenditures, the long-term growth in total healthcare expenditures is driven by the cyclical sensitivity of the public investments in healthcare. Indeed, the public comovement elasticity has a significant positive impact on the average long-term growth of total healthcare expenditures $\left(\delta_{\hat{\beta}_{\text {ipub }}}=.020\right.$, $p<.01)$. When governments decide to economize on healthcare provisions during tough economic times, urgent treatments are postponed, which increases the chance of extremely costly and urgent procedures later (OECD, 2011). The private comovement elasticity, in contrast, does not have an impact on the long-term growth in total healthcare expenditures $\left(\delta_{\hat{\beta}_{i p r i}}=-.004, p>.10\right)$. This is probably due to the fact that public expenditures usually make up the largest share of the total healthcare expenditures. Finally, in line with Gerdtham and Loethgren (2000) and Herwartz and Theilen (2003), we find that the growth in GDP has a significant positive impact on the average longterm growth in total healthcare expenditures $\left(\delta \frac{\overline{\Delta g d p_{i}^{\text {trend }}}}{\Delta}=0.956 ; p<.01\right)$.

\section{CONCLUSION}

The healthcare sector is an industry of enormous social and economic importance. One of the biggest concerns in the field are the exploding healthcare costs, given that they tie up funds that might be used for other purposes or increase the debt of the buyers (see e.g. Getzen 2000; Narayan and Narayan 2008). Although the link between the healthcare expenditures and the general economic activity has been studied extensively as a way to explain cross-country differences in the long-run patterns in healthcare spending, the business-cycle perspective has currently been overlooked.

In this study, we examine the business-cycle sensitivity of public and private healthcare expenditures for 27 countries. As predicted, we find an enormous diversity in how public and private healthcare spending are related to the business cycle. As such, private buyers in $44 \%$ of the considered countries have a tendency to economize on their healthcare expenditures during economic contractions. Strategies to cut down on healthcare during downturns might include switching to less-expensive generic pharmaceuticals and postponing less urgent medical treatments (Deloitte 2011; Neumayer 
2004). In contrast, private healthcare expenditures move in the opposite direction of the economic business cycle in $56 \%$ of the countries. In these countries, economic contractions may lead to an increase in different diseases (Stuckler et al. 2009b), which forces the consumers to spend more on healthcare when facing difficult economic times.

For the public component of healthcare expenditures, we find a similar diversity in the cyclical sensitivity across countries. As such, somewhat more than half of the governments consistently spend more during rougher economic times. These countries seem to follow the classical Keynesian approach, and stimulate the economy by increasing public spending on healthcare when the economy stumbles (Lane 2003b). In contrast, the other half of the countries considered, appear to follow the opposite strategy of cutting healthcare expenses during contractions. Indeed, when the economy goes sour, governments may feel forced to cut down their expenditures (Barro 1979). The economic contraction may even offer a good justification to reorganize the socially delicate healthcare sector (Lane 2003b). Although the spread in cyclical sensitivity is more or less the same for both parts of healthcare expenditures, private and public comovement elasticities turn out very different in a lot of countries.

Apart from the sheer insight on the cyclical sensitivity of private and public healthcare expenditures, it is imperative for policy makers to establish the consequence of these different strategies in the long term. We find that economizing on private expenditures during economic crises decreases the growth in the health status. Indeed, by cutting on preventive treatment and postponing less-urgent medical procedures, diseases may not be treated in time. This can cause irreversible harm to the patients. It is thus crucial for policy makers to avoid this postponement behavior by educating people on the underlying risk, or by reducing temporarily the out-of-pocket payments linked to them. Moreover, procyclical behavior from the public side of the sector leads to a further explosion in total healthcare expenditures in the long term. When governments decide to cut down on healthcare during economic contractions, they might need to overcompensate later to restore the sector to the same level prior to the reductions (Steenkamp and Fang 2011). Governments should thus especially be wary of cutting down expenditures in the healthcare market during contractions. Although, admittedly, public budgets usually are lower during downturns because of a decrease in tax returns (Lane 2003b), policy makers could start to build up extra reserves during economic upturns to avoid having to cut extensively in the healthcare sector when the economy declines again. 
Given that procyclical behavior in the healthcare sector has such important longterm consequences, we explored variables that could explain the across-country variability in cyclical sensitivity of healthcare expenditures by regressing the pooled comovement elasticities on a number of interesting characteristics that could provide more insight into how to avoid procyclical behavior. Table 5 provides an overview of the included variables and their operationalization, and the results are shown in Table 6.

We find that the three major players in the healthcare sector, i.e., the private organizations, the government, and the consumers (Stremersch 2008), all contribute to the cyclical sensitivity of healthcare expenditures. In line with Lamey et al. (2007) and Deleersnyder et al. (2009), we are able to show that countries in which healthcare companies (such as Pfizer, Roche or Medtronic) consequently reduce their sales expenditures during economic crises behave more procyclically in terms of healthcare expenditures $(\beta=.228, p<.05)$, while the general level of research and development does not have an impact $(\beta=-.009, p>.10)$. Maintaining selling activities during economic contractions may be crucial to keep consumers from postponing treatments (Deloitte 2011; Lamey et al. 2007).

Also public policy seems to matter. We find that countries who invest more in general health prevention activities, have a less procyclical healthcare sector $(\beta=-.005$, $p<.10)$. These prevention campaigns and trials should make people more conscious about healthy behaviors, increase the usage of preventive treatments and actions, and hence make them cut less on health during rougher economic times (Jacobsen and Jacobsen 2011). Countries with a predominantly privately-funded healthcare system have a more procyclical healthcare industry $(\beta=.984, p<.05)$. These systems have a lower amount of risk pooling and rely more on out-of-pocket costs (also in times of a bad economic climate) (Glied 2008). In addition, the increased self-responsibility will lower the pressure of interest groups on the government to increase healthcare budgets during crisis times (Lane 2003b). Countries rating high on self-expressionist values show a strong attitude towards autonomy and freedom of choice (Inglehart and Baker 2000), which usually leads to a higher self-responsibility for each individual and a lower collectivistic support (Flanagan and Lee 2003). As was argued above, this translates in a more procyclical healthcare industry $(\beta=.206, p<.05)$. The traditional/rationalism cultural dimension is unrelated to the cyclical fluctuations in healthcare expenditures $(\beta=-.154, p>.10)$. 
TABLE 5: DESCRIPTIVES AND OPERATIONALIZATION OF EXPLANATORY FACTORS

\begin{tabular}{|c|c|c|c|c|}
\hline Variable Name & Operationalization & Mean & $\begin{array}{c}\text { Standard } \\
\text { Deviation }\end{array}$ & Data source \\
\hline $\begin{array}{l}\text { Procyclical selling } \\
\text { expenditures }\end{array}$ & $\begin{array}{l}\text { Dummy variable indicating } \\
\text { whether the selling } \\
\text { expenditures of healthcare } \\
\text { firms behave procyclical (based } \\
\text { on the comovement elasticity) }\end{array}$ & 0.231 & 0.983 & Compustat \\
\hline Research and Development & $\begin{array}{l}\text { Mean of healthcare-related } \\
\text { patents, per capita }\end{array}$ & 0.096 & 0.089 & OECD \\
\hline Prevention Activities ${ }^{(a)}$ & $\begin{array}{l}\text { Mean of public prevention } \\
\text { expenditures, per capita }\end{array}$ & 0.610 & 0.425 & OECD \\
\hline Health system & $\begin{array}{l}\text { Dummy variable indicating } \\
\text { whether the healthcare sector } \\
\text { is predominantly privately } \\
\text { financed ( }>50 \% \text { of total } \\
\text { expenditures) }\end{array}$ & 0.111 & 0.317 & OECD \\
\hline Rationalism & $\begin{array}{l}\text { Mean score of traditional - } \\
\text { rational orientation (on a scale } \\
\text { from }-2 \text { to } 2 \text { ) }\end{array}$ & 0.315 & 0.764 & $\begin{array}{l}\text { World } \\
\text { Values } \\
\text { Survey }\end{array}$ \\
\hline Self-Expressionism & $\begin{array}{l}\text { Mean score of survival - self- } \\
\text { expression orientation (on a } \\
\text { scale from -2 to } 2 \text { ) }\end{array}$ & 0.723 & 0.753 & $\begin{array}{l}\text { World } \\
\text { Values } \\
\text { Survey }\end{array}$ \\
\hline
\end{tabular}

(a) Given that the public prevention expenditures are part of the public healthcare expenditures, we only test their effect on the private comovement elasticity.

Although we provide interesting new insights on the cyclical sensitivity of the healthcare sector and its long-term consequences, our study has some limitations which can provide avenues for future research. First, while our analysis already considers private and public expenditures separately, it might be interesting to even further disentangle these series into smaller subcategories. This would allow us to investigate reductions during contractions in which specific private (e.g., out-of-pocket payments and over-the-counter drug expenses) and public expenditures (e.g., public insurance payments and investments in health infrastructure) are responsible for its detrimental long-term consequences on the health status and total healthcare spending. These insights enable policy makers to set priorities into which healthcare posts they 
should protect most when cost cutting becomes necessary. Furthermore, although our explorative analysis reveals already several drivers of healthcare cyclical sensitivity, a more systematic research on the topic is needed.

\section{TABLE 6: EXPLANATORY FACTORS OF CYCLICAL SENSITIVITY IN HEALTHCARE EXPENDITURES}

\begin{tabular}{l|c|c} 
Independent Variable & Coefficient & t-Value \\
\hline Private & -0.046 & -0.322 \\
\hline Public & 0.246 & 1.197 \\
\hline Procyclical Selling Expenditures & $0.228^{* *}$ & 2.423 \\
\hline Research and Development & -0.009 & -0.819 \\
\hline Prevention & $-0.005^{*}$ & -2.026 \\
\hline Health system & $0.984^{* *}$ & 2.394 \\
\hline Rationalism & -0.154 & -1.357 \\
\hline Self-Expressionism & $0.206^{* *}$ & 2.446 \\
\hline \hline Adjusted R & $15.5 \%$ & \\
Number of Observations & 42 & \\
\hline
\end{tabular}

Parameters are from a WLS regression on the pooled private and public comovement elasticities.

*two-sided $p<.10, * *$ two-sided $p<.05$. 


\section{ChAPTER 3}

THE (INCRE)MENTALIST: ON THE INTERPLAY OF IMPLICIT THEORY ORIENTATIONS AND MESSAGE DESIGN IN SOCIAL MARKETING CAMPAIGNS TO REDUCE MENTAL-ILLNESS STIGMA 


\section{ABSTRACT}

Overcoming mental-illness stigma is a challenge for social marketers around the globe. In this research, we examine how such campaigns can be improved by matching the recipient's worldview of seeing human personality as fixed or malleable with the message design of a campaign. Our results show that, in general, people who believe in the fixedness of traits exhibit higher levels of stigma (Study 1). This difference can be reduced by framing mental illnesses as medical conditions as opposed to positioning them as biopsychosocial conditions (Study 2). People who see personality as malleable in contrast, are indifferent between the two different message designs. As both message designs find practical applications, we show that an increased level of controllability in the message can reduce the difference when displaying illnesses as biopsychosocial phenomena (Study 3). Finally, we show that the level of illness severity acts as a boundary condition of our findings (Study 4). 


\section{INTRODUCTION}

Mental disorders (e.g., internet addiction, depression, mania) are a substantial concern for health policy makers in most countries, as an estimated one out of every four persons is affected (WHO 2001). At the same time, only about $30 \%$ of mental disorders are actually treated (Demyttenaere et al. 2004; OECD 2012). The huge demand for more and better treatment has fuelled the establishment of private and public mental healthcare clinics, creating a new, extremely competitive services market that appears poised to grow even further (Dowideit and Neller 2011; van Dorresteijn 2012). However, a mere increase in the supply of mental healthcare services has not proven sufficient in reaching a wider array of people in need of treatment (Sareen et al. 2007), because those who suffer from disorders often are reluctant or even afraid to seek out help (see e.g. Rüsch et al. 2009), regardless of low or nonexistent monetary costs (Sareen et al. 2007).

Important reasons behind such reluctance are negative labels or stigma assigned to mental illnesses (Corrigan 2004a), which cause people not to pursue treatment or to opt in too late (Chew-Graham et al. 2003). In response, researchers have called for more social marketing research to better understand the stigma issue and to develop better guidelines for developing convincing messages in social marketing campaigns (see e.g.Rochlen and Hoyer 2005; Rüsch et al. 2009). Social marketing research has guided communication strategies to address health issues, such as AIDS, cancer, and smoking prevention (Kotler 2011; Zhao and Pechmann 2007), but the mental health field remains uncharted (Keller and Lehmann 2008). Yet, there is a pressing need to develop insights into message framing to help reduce stigma and encourage help-seeking in this field, as becomes clear from a recent health marketing campaign (Clement et al. 2010). In a $f 20$ million U.K. campaign by timetochange.org counter-stigmatic message framing had the unexpected adverse effect of increasing mental-illness stigma among parts of the general public (Clement et al. 2010; Levy Paluck and Green 2009).

To address the issue of effective message framing for stigma reduction, we turn to advances in social marketing and cognitive psychology by zooming in on how people may differ in their interpretation of mental healthcare marketing messages. More particularly, we turn to recent theorizing on so-called implicit theories or worldviews that people hold about themselves and their environment (Yorkston et al. 2010). It has been demonstrated that people may theorize their environment as either static or 
dynamic (Chiu et al. 1997). Those who hold the former worldview have been referred to as entity theorists, as they perceive human traits to be fixed and tag information generally as positive or negative (Jain et al. 2009). In contrast, so-called incrementalists believe that human character traits are malleable and changeable, and therefore place more emphasis on surroundings and external factors (Yorkston et al. 2010). In several studies, an individual's implicit worldview has been shown to influence stereotyping; entity theorists display more stereotyping views on gender and race related issues, that they are unlikely to give up, even when confronted with counter indicative information (Plaks et al. 2001). It has remained unclear, however, whether this holds for mentalhealth campaigns as well. Mental-illness stigma are strongly associated with nonpermanence (i.e., everybody runs the risk of developing a mental disorder or has the chance of being cured) and aversive connotations, unlike, for instance, stereotypes related to permanent groups such as gender for which positive generalizations can be developed as well (Corrigan 2004a).

A further complicating factor is based on the ongoing debate among mental-health experts on how to design messages when presenting mental illnesses to the public. In general, anti-stigma campaigns can be presented with two different underlying message tactics: a medical approach displaying mental illnesses as equivalent to physical diseases (Guze 1992) or a biopsychosocial (BPS) approach which focuses on individual social and psychological factors in relation to these disorders (Kiesler 1999). Whereas both messaging tactics are widely used in social marketing campaigns, their interplay with people's implicit orientation remains unclear, and requires further investigation in order to improve the effectiveness of mental-healthcare campaigns (Levy Paluck and Green 2009).

We address these issues by making the following contributions. First, we extend the current knowledge on mental-illness stigma endorsement by linking it to an individual's implicit orientation. In doing so, we demonstrate the applicability of implicit theories to a new domain. Furthermore, we add to the ongoing debate on message design by connecting medical or BPS arguments in message tactics to the aforementioned worldviews. Overall, we are able to conclusively demonstrate that the effectiveness of anti-stigma campaigns is contingent upon the match between an individual's implicit orientation and the type of arguments used. This integration allows us to develop the much needed systematic guidelines for reducing stigma through marketing campaigns (Corrigan 2004a). 
The rest of this paper is structured as follows. We begin by establishing a theoretical background for the stigma phenomenon and the influence of implicit theory orientation. Then we delineate the potential match between implicit orientations and mentalillness messages, and describe how a better fit between them might reduce stigma more effectively. We test our hypotheses empirically in four studies, and derive both theoretical and managerial implications.

\section{CONCEPTUAL FOUNDATIONS}

\section{MENTAL-ILLNESS STIGMA}

Corrigan and colleagues (2006) conceptualize mental-illness stigma as a discriminatory view of mentally ill people, starting with stereotypes about them (e.g., "Mentally ill are incompetent and have weak character"). These stereotypes transform into prejudice or agreement with a stereotype, which may translate into emotional reactions such as anger or fear. Finally, prejudice becomes stigma, which represents the enactment of prejudice, often manifest in behaviors such as withholding help, avoiding mentally ill people or even criminalizing them (Kamperman et al. 2014). Thus stigma is a purely negative result of the stereotyping process, which by definition is harmful to the target (Corrigan 2004a), whereas stereotypes are the "set of attributes that subjects agreed on as typical of a group" including both negative and positive valence (Judd and Park 1993). Therefore, the concept of mental-illness stigma partially overlaps with negatively coined racial prejudice or gender-based stereotypes, in terms of its discriminatory nature and negative effects on targets (Byrne 2000). It differs, however on the dimensions of permanence, as everyone runs the risk of becoming mentally ill, or has the chance of being cured, and its valence which is per se negative while gender or racial stereotypes can be positive as well. For these reasons, the mental-illness context involves a yet another difference which may prevent people from seeking help when in need, because the stigma serves to separate the mentally ill from the "healthy" self (Link and Phelan 2006). The question of whether research conducted in relation to other stereotypes and prejudice extends to 
the field of mental illnesses has not been investigated specifically, and is thus of crucial importance (Stier and Hinshaw 2007).

\section{IMPLICIT THEORY ORIENTATIONS AS AN ANTECEDENT OF STEREOTYPE ENDORSEMENT}

Marketing and consumer researchers are increasingly aware of the impact of implicit theories on how people derive judgments of stimuli they encounter (Jain et al. 2009). Levy, Stroessner, and Dweck (1998) introduce implicit theory orientations to predict stereotype formation and endorsement. They find that entity theorists make extreme trait-based judgments of an individual target on the basis of limited information, and posit that this mechanism extends from individuals to groups. Entity theorists and incrementalists were shown to be equally knowledgeable about stereotypes, however, the former display greater endorsements of both positive and negative groupstereotypes. These findings hold across a variety of settings and contexts, such as racial stereotypes (Levy et al. 1998) or, and views of religious or ideological groups (Plaks et al. 2001). In addition, Plaks et al. (2001) find that it is extremely difficult to convince entity theorists to let go of their stereotype endorsements, because they assume the stability of traits and human personality as a whole (Hong et al. 2001). Therefore it is worthwhile to see whether those findings related to a permanent trait, and referring to both positive and negative statements extend to the mental-illness field, for which the state of belonging to the stereotyped group is less permanent, and stigma only refer to negative statements.

\section{Message Perspectives of Mental Illness}

In the fierce debate that continues in the mental-healthcare sector regarding how to display mental illnesses to the public (Haslam and Ernst 2002), the two prevailing schools of thought that are used in social marketing campaigns, are the biopsychosocial (BPS) (Kiesler 1999) and the medical perspective (Guze 1992). The BPS message supports highly individualized disease conditions, with fuzzy boundaries and interlinks across disorders. It also implies that mental illnesses result from individual circumstances and may vary across cultures or time (Haslam et al. 2002). This holistic view centers 
clearly on the individual patient and illness (Ghaemi 2009). Therefore, it may have a stigma-reducing capacity, by shifting the focus from a group of ill people to individual cases, preventing generalizations and eliminating the root of prejudice (Read et al. 2006). Yet the BPS perspective, with its eclectic message, also prevents standardization or established measures of success (Ghaemi 2009). According to critics, the BPS perspective is too vague, cannot help laypeople understand mental disorders, and instead causes further distance from the illnesses and mentally ill people, which could fuel stigma (Ghaemi 2009).

The medical perspective of mental illnesses instead, considers mental disorders as time invariant and comparable worldwide. The medical perspective thus offers substantial gains in treatment efficiency and assessment through standardization and measurability (Ghaemi 2009). Accordingly, it often has been proposed as a means for social marketing communications to combat mental-illness stigma, which develops from a lack of knowledge or understanding of certain observations (Corrigan 2004b). Furthermore, by matching mental with physical illnesses, a medical message could reduce attributions of blame or anger toward mentally ill persons (Lincoln et al. 2008). However, the perspective's simplicity and sometimes far-fetched comparison to physical illnesses have subjected it to criticism. Grouping and categorizing mentally ill people may demand too much generalization, which could yield group stereotypes and result in discrimination (Rüsch et al. 2010).

Both schools of thought on how to present mental illnesses thus have unique strengths and weaknesses, and both appear in a wide range of applications and antistigma campaigns (Levy Paluck and Green 2009). Accordingly, we need to determine how convincing these schools of thought are for different types of people with regard to their stigma endorsement, or interact with the two implicit worldviews.

\section{HYPOTHESIS DEVELOPMENT}

As emerged from our literature review, mental-illness stigma and general stereotypes are related but different concepts (Stier and Hinshaw 2007). Therefore it is of crucial importance to investigate, whether research from the stereotype domain extends 
to the field of mental-illness stigma as well. Levy and colleagues (1998) demonstrate that entity theorists are more prone to stereotyping than incrementalists due to their chronic disposition to make trait-based inferences and generalizable judgments. This aligns well with stereotypes, which originate from such group-typical traits (Judd and Park 1993). Incrementalists, on the other hand, refrain from doing so due to their context-based, less generalist view of the world, allowing for more nuanced judgments and therefore do not consider groups as homogeneous entities. Applying this process of reasoning to mental-illness stigma should yield a similar prediction, as its purely negative attitudes are also developed from generalizing judgments of groups or individuals (Corrigan 2004a). Its special function as a separator between ill people and the healthy self (Corrigan et al. 2006) might even act as an amplifier as entity theorists might be more prone to set clear boundaries between them and the mentally ill, while incrementalists should adopt a more moderate and context dependent view (Levy et al. 1998). Therefore, we formally hypothesize:

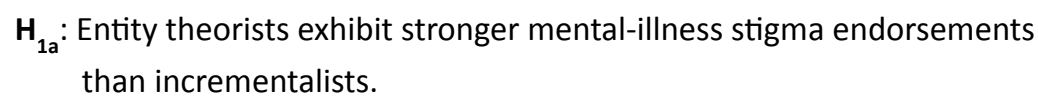

Typical anti-stigma campaigns (e.g., timetochange.org) use counter-stigmatic information in their messages (e.g., "Myth: People with mental illnesses can't work. Fact: You're probably working with somebody who has a mental illness") to educate people about the truth behind mental illnesses (Romer and Bock 2008). Entity theorists were shown to ignore counter-stereotypical information, which challenges their worldview of the consistency and predictability of a target (Plaks et al. 2001). Incrementalists, instead, accept inconsistent actions by a target, because in their worldview, inconsistency and malleability are inherent features of any target (Jain et al. 2009). Therefore, we predict in turn that entity theorists are not convinced by counterstigmatic messages, as they are inconsistent with their worldview, while incrementalists are likely to process them. The difference in stigma endorsement between entity theorists and incrementalists thus should persist, even after exposures to a typical antistigma campaign which uses counter-stigmatic information. Formally, we hypothesize: 


$$
\begin{aligned}
& \mathbf{H}_{\mathbf{1 b}} \text { : Entity theorists continue to exhibit stronger mental-illness } \\
& \text { stigma endorsements than incrementalists after both } \\
& \text { groups are confronted with counter-stigmatic information. }
\end{aligned}
$$

After the main effect of implicit theories, we now turn towards their interplay with the two predominant mental-illness messages. Any marketing message is more convincing if it matches the target's worldview (see e.g. Daryanto et al. 2010). A message that resembles the recipient's own attitudes seems more familiar, which increases the cognitive ease of processing it (Kahneman 2011). This, in turn, causes the message to appear more convincing, because cognitive ease evokes positive feelings about the message, leading to fewer doubts about its truthfulness. In contrast, a message that violates a person's worldview seems unfamiliar and causes more skeptical reactions (Kahneman 2011).

These findings also apply to the stereotype domain (Plaks, Grant, and Dweck 2005). If counter-stereotypical information is presented in such a way that it does not violate their perspectives, entity theorists are more prone to process it. That is, there might be ways to circumvent the reluctance of entity theorists to process anti-stigma information. Just as entity theorists do, incrementalists have faith in their worldview and do not like information that violates it, such that they likely engage in biased processing of such information (Plaks et al. 2005). Incrementalists' theories can be violated if the information suggested a person was unable to change certain character traits or behaviors, which might suggest stereotypes of mental weakness (Bastian and Haslam 2006). In this sense, the medical or the BPS message could either violate or affirm a person's implicit orientation. We consider whether it is possible to match counterstigmatic information with a recipient's (entity or incremental) view of the world.

As we noted, criticisms of the BPS perspective focus on its eclecticism and lack in generalizability, whereas positive assessments note its nuanced diagnoses and focus on the individual patient (Ghaemi 2009). These properties contrast with an entity view of the world in which: (i) traits provide clearly diagnosable information (Chiu et al. 1997), (ii) observations can be generalized from individuals and groups (Levy et al. 1998), and (iii) there is a sharp contrast between good and bad (Plaks et al. 2001). We thus predict that a message that reflects the BPS message will not alter stigma endorsements by entity theorists, because the information will not align with their worldview (Plaks 
et al. 2005). The medical message instead, provides unambiguousness, clarity, and a categorical structure, which may lead to overgeneralizations (Ghaemi 2009). Therefore, it should work particularly well for entity theorists, who prefer clear, categorical information that defines things as good or bad (Dweck et al. 1995). The medical message does not violate an entity theorist's view but rather supports it. Therefore, we expect that entity theorists should process stigma-reducing or counter-stigmatic information better if that information reflects the medical message.

$$
\begin{aligned}
& \mathbf{H}_{2 \mathbf{a}} \text { : Entity theorists exhibit lower levels of mental-illness stigma } \\
& \text { endorsement after exposure to a medical message on mental } \\
& \text { illness than after exposure to a BPS message. }
\end{aligned}
$$

In contrast, the contextual and individual focus of the BPS message is much more in line with an incremental worldview, which makes fewer generalizations and assigns more importance to the context (Chiu et al. 1997). The focus on individual cases and room for interpretation provided by the BPS message accords closely with the nuanced judgments preferred by incrementalists (Dweck et al. 1995), such that the BPS perspective should support an incrementalist's view of the world. For the medical model though, we predict the exact opposite for incrementalists: Even though they endorse stereotypes less overall, incrementalists might increase their stereotyping behaviors if their theory-orientation is violated (Bastian and Haslam 2006). The medical message does so, by depicting illnesses in isolation from the context, which may foster a sense of powerlessness and inability to change a patient's state (Read et al. 2006). Therefore, the medical view, which is less proactive and individual-focused, should conflict with an incrementalist's view of the world and therefore increase the stigma endorsement. Formally, we predict:

$$
\begin{aligned}
& \mathbf{H}_{\mathbf{2 b}} \text { : Incrementalists exhibit higher levels of mental-illness stigma } \\
& \text { endorsement after exposure to a medical message on mental } \\
& \text { illness than after exposure to a BPS message. }
\end{aligned}
$$




\section{EMPIRICAL STUDIES}

Analysis Strategy. In the following empirical section of this paper, we formally test our hypotheses. In the first two studies, we show the effect of implicit worldviews on stigma endorsement, and demonstrate that the effect persists through typical antistigma campaigns with counter-stereotypical information. Next, we assess our second set of hypotheses, and show the interaction between mental-illness messages and implicit orientations in two studies and show that our results hold for both, implicit and explicit levels of stigma. Finally, in the last two studies, we explore the effects of controllability and illness severity on our findings. Our conceptual framework and the studies are summarized in Figure 1.

\section{Figure 1: Conceptual FrameWork}

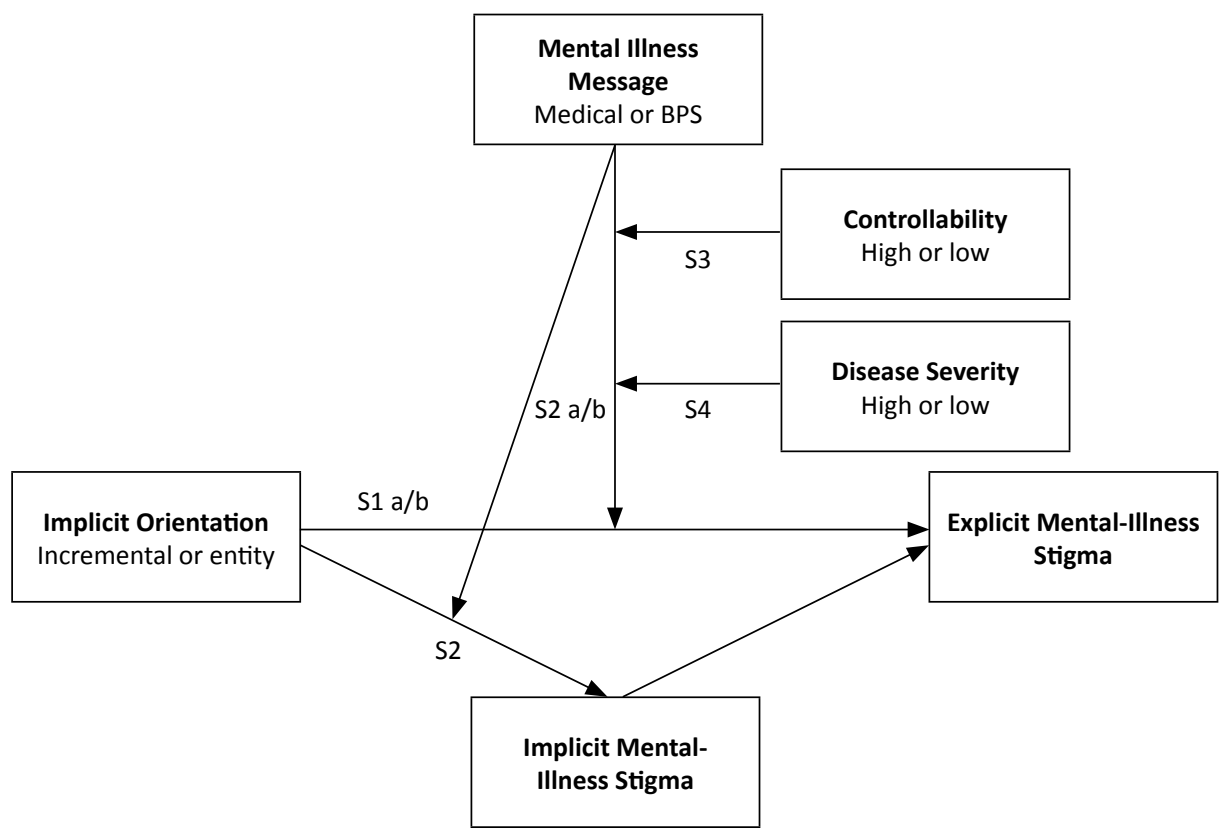




\section{STUDY 1}

In the first studies, we investigate our first set of hypotheses, namely $\mathrm{H} 1 \mathrm{a}$ and $\mathrm{H} 1 \mathrm{~b}$. In particular, we examine whether incrementalists, who have a more malleable worldview, exhibit less stigma than entity theorists who consider character traits fixed. First, we explore the general phenomenon by using broad settings. Then, we investigate a specific situation that exposes respondents to an anti-stigma campaign with anti-stigma information.

\section{STUDY $1 \mathrm{~A}$}

Design and procedure. To investigate mental-illness stigma broadly, we used an online questionnaire and panel participants, which helped maximize the number of complete responses ( $n=453$ ) and ensured variance in age, nationality, income, and educational backgrounds. A control question at the end of the study evaluated the seriousness of their efforts by asking respondents if they had honestly evaluated all the measures, along with a note that a negative response would not affect their compensation. After screening out 47 unserious responses, 406 questionnaires remained for the analysis. We applied this procedure in all the studies we report herein.

The respondents' self-assessments of their implicit orientation appeared prior to all other measures. Because we were interested in their general orientation, we used a three-item domain-general measure of implicit theories suggested by Dweck, Chiu, and Hong (1995). It assessed respondents' agreement, on a six-point scale, with statements such as, "The kind of person someone is, is something basic about them and it can't be changed very much." Next, respondents read one of six randomly assigned newspaper articles dealing with mental disorders, which featured different valences (positive/ negative), lengths (short/long), and styles (narrative/factual). The use of multiple articles gave us a means to assess the robustness of the effect across different situations.

Dependent measures. After some filler questions, we measured stigma toward mentally ill persons using the Community Attitude toward the Mentally III (CAMI) scale (Chambers et al. 2010). It consists of 20 items assessed by five-point Likert scales that measure four underlying factors of stigma: community mental-health ideology, authoritarianism, benevolence, and social restrictiveness (Link and Phelan 
2006). These dimensions are essential for determining stigma toward mentally ill people (Corrigan, 1999).

Reliability and coding. Responses to the implicit theory measure were highly reliable (Cronbach's $\alpha=.87$ ). As Dweck, Chiu, and Hong (1995) do, we calculated the average of the three items to measure participants' chronic implicit theory orientation. Mean scores lower than 3.5 indicated incrementalists $(n=202)$; those with a mean greater than 3.5 were coded as entity theorists $(n=204)$. The CAMI scale proved reliable for the scale as a whole $\left(\alpha_{\text {Total }}=.82\right)$ and for the different factors $\left(\alpha_{\text {Authoritarianism }}=.71\right.$; $\alpha_{\text {Benevolence }}=.80 ; \alpha_{\text {Ideology }}=.90 ; \alpha_{\text {SocialResponsibility }}=.85$ ). These factors were coded such that higher scores reflected a more positive, or in other words, less stigmatized attitude toward mental illnesses.

Results. A series of one-way analyses of covariance (ANCOVA) allowed us to examine the effect of implicit worldview on perceived stigma, while controlling for the version of the newspaper article and the respondent's age, gender, education, and nationality. The effect of implicit orientation proved significant on the scale as a whole $\left(\mathrm{M}_{\text {Entity }}=3.07, \mathrm{M}_{\text {Incremental }}=3.43 ; \mathrm{F}(1,386=22.25, p<.01)\right.$, as well as on the sub dimensions of authoritarianism, benevolence, ideology, and social responsibility $(F(1,386)=7.47,9.55,11.04$, and 26.77 , respectively; all $p s<.01)$, as we depict in Figure 2. These findings affirm our Hypothesis 1 a, i.e., entity theorists show a higher level of stigmatization towards the mentally ill than incrementalists. These results demonstrate the importance of implicit theory orientation in the domain of mental-illness stigma.

\section{STUDY 1B}

Design and procedure. With this study, we aimed to replicate the results from Study $1 a$ in a specific setting that exposed respondents to an anti-stigma campaign with counter-stereotypical information. Of the 285 U.S. panel respondents who started our questionnaire, 217 provided complete questionnaires; the screening for the seriousness of the answers (see Study 1a) led us to delete 12 responses, for a final sample of 205 respondents. Similarly to study 1 a, we measured implicit orientations with the three-item scale by Dweck, Chiu, and Hong (1995). After this assessment, respondents completed an unrelated filler task before being exposed to a real life anti-stigma campaign with counter-stereotypical information (see Appendix 1). 


\section{FIGURE 2:}

\section{StUdY 1A: EFFECTS OF IMPLICIT ORIENTATION ON STIGMA DIMENSIONS}

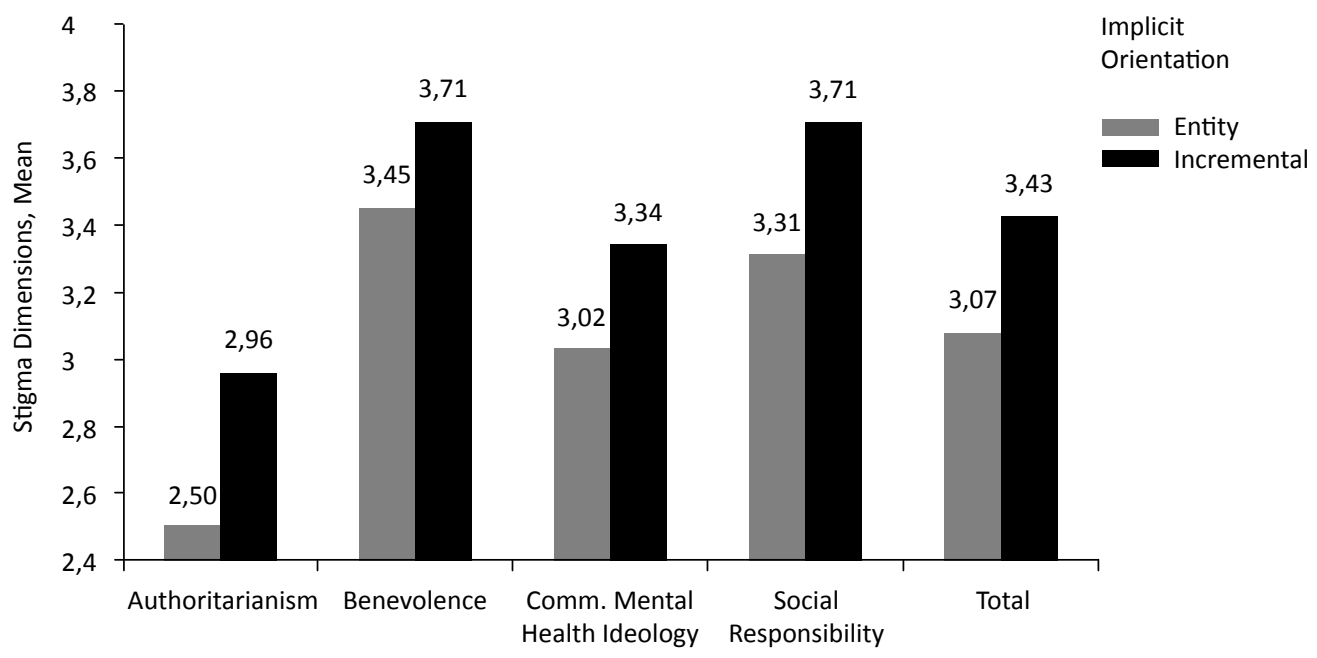

Dependent measures. After the advertisement, respondents completed the mentalillness stigma scale developed by Day, Edgren, and Eshleman (2007). This scale consists of 28 items which are measured on seven-point scales to assess stigma endorsements against mental illnesses and mentally ill people. We also applied the social distance scale (Link et al. 1999) to assess respondents' willingness to interact with mentally ill people. This very pure measure of stigma indicates behavioral intentions to avoid or discriminate against mentally ill people, in accordance with the third stage of the stigmatization process we described previously (Corrigan, 1999). This scale consists of five items, measured on seven-point Likert scales. Finally, we asked demographic questions and assessed familiarity with mental illnesses with a seven-item measure developed by Schomerus, Matschinger, and Angermeyer (2007).

Coding and reliability. The implicit theory measure was assessed with the same method from Study 1a: Mean scores lower than 3.5 indicated incrementalists ( $\mathrm{n}=$ $94)$, and means greater than 3.5 represented entity theorists $(n=111)$. Both stigma measures showed good reliability $\left(\alpha_{\text {stigma }}=.88, \alpha_{\text {socialDistance }}=.84\right)$. Again, all measures 
were coded such that higher scores indicated a more favorable or less stigmatized attitude toward mental illnesses.

Results. Two ANCOVAs helped us examine the effect of implicit orientations on mental-illness stigma and social distance, after the respondents' exposure to the counter-stigmatic information. We controlled for respondents' familiarity with mental illnesses, age, gender, and education. The effect of implicit orientation was significant for the mental illness stigma scale $\left(M_{\text {Entity }}=4.89, M_{\text {Incremental }}=5.18 ; F(1,201=3.61, p<\right.$ $.05)$ and the social distance scale $\left(M_{\text {Entity }}=3.94, M_{\text {Incremental }}=4.47 ; F(1,201)=8.01, p<\right.$ .01). These results (see Figure 3 ) lend further support to our prediction that the effect of implicit orientation on stigma does not vanish due solely to typical and commonly used anti-stigma campaigns wit counter-stereotypical information $\left(\mathrm{H}_{1 \mathrm{~b}}\right)$.

\section{FIGURE 3:}

\section{Study 1B: EfFECt Of IMPLICIT ORIENTATION ON Stigma AfTER EXPOSURE}

\section{TO ANTI-STIGMA CAMPAIGN}

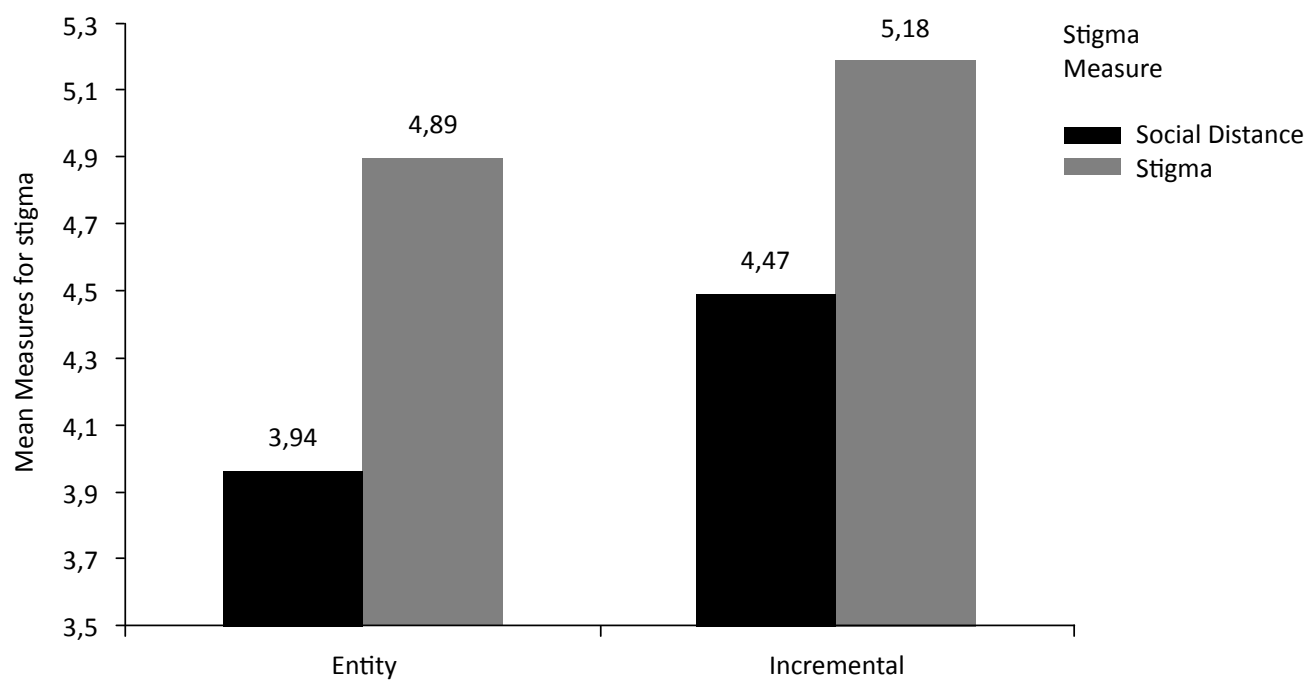




\section{DISCUSSION}

Both studies demonstrate a main effect of implicit orientation on the stigma surrounding mental illnesses and the mentally ill. They support our hypotheses that, in general, entity theorists display a higher stigma endorsement than incrementalists. They also indicate robustness across various settings, measures, and countries. Moreover, we show that a typical anti-stigma campaign with counter-stereotypical information is ineffective in reducing this difference. Therefore, in the following studies, we explore how expert views might fit with implicit orientations to address the stigma problem.

\section{STUDY 2}

In Studies $2 \mathrm{a}$ and $2 \mathrm{~b}$, we assess the proposed fit between implicit orientations and expert views and the resulting effects on stigmatization. We test our prediction that entity theorists adopt a more favorable attitude toward mental illnesses after being exposed to the medical message, while incrementalists prefer the BPS message. Furthermore, we demonstrate that the effects are the same for implicit and explicit stigma attitudes, and show that implicit attitudes mediate the effect of explicit stigma. We replicate these findings in Study $2 \mathrm{~b}$ with a broader audience, and we demonstrate the causality of our effects by manipulating participants' implicit theory orientation.

\section{STUDY 2A}

Design and procedure. We set up a 2 (BPS vs. medical) 2 (entity theorists vs. incrementalists) between-subjects experiment with 146 students from a midsized European university, who received course credit for their participation. Again, we evaluated the seriousness of the participants' answers as described in study $1 \mathrm{a}$, which left 138 respondents in the analysis. They were mostly of European origin (81\%), though $12 \%$ of the respondents came from the Americas, and the remaining $8 \%$ were of Asian descent. The mean age was 22 years, ranging from 20 to 29 years, and most respondents reported a high school diploma (58\%) as the highest level of 
education they had completed thus far. Implicit orientations were assessed at the very beginning of the study with the three-item domain-general measure and coded according to Dweck, Chiu, and Hong (Dweck et al. 1995). After a short, unrelated filler task, participants reviewed one of the two messages, adapted from Ghaemi (2009). The medical message read: "Mental illnesses are disorders in which a person's thoughts, emotions, or behavior are so abnormal as to cause suffering. They are various clearly separable diseases and can be diagnosed according to predefined categories. They are caused by biological dysfunctions, and the different diseases do not change over time or across cultures." The BPS message stated, "Mental illnesses are disorders in which a person's thoughts, emotions, or behavior are so abnormal as to cause suffering. They are often connected to each other and cannot always be uniquely diagnosed according to predefined categories. They are socially constructed, their causes are complex and the different disorders may change over time or across cultures." After participants indicated that they had carefully read the message, we showed them an advertisement with counter-stigmatic information (the same as the one used in Study 1b).

Measures. After another unrelated filler task, we assessed stigma on two different levels. Whereas Study 1 used only explicit stigma scales, stigma can be manifest implicitly too. A common way to assess implicit stigma is the implicit association test (IAT; Teachman, Wilson, and Komarovskaya (2006)). The IAT measures reaction speeds in a classification task. For our study, respondents considered a certain number of physical or mental illnesses, described by words with positive or negative connotations. The physical (e.g., coronary heart disease, multiple sclerosis) and mental (e.g., schizophrenia, borderline disorder) illnesses were pretested as equivalent in terms of perceived severity and treatability. After a series of practice rounds, participants classified two blocks. One block paired the categories "mental illness" and "bad" on one side of the screen and "physical illness" and "good" simultaneously on the opposite side. In another block, the stimuli featured "mental illnesses" and "good", and "physical illnesses" and "bad." The two blocks appeared in random order, to prevent a systematic bias through learning effects. The differences in participants' response times between blocks provided measures of mental-illness stigma relative to physical diseases. If the difference between block 1 and 2 was negative, participants took longer to connect positive associations with mental illnesses than with physical illnesses, but they had an easier time linking negative words with mental illnesses than with physical diseases. That is, 
more negative scores represented higher levels of stigma. In addition, we included the short explicit stigma measure from Study $1 b$, to determine the link between implicit and explicit stigma (Teachman et al. 2006), and controlled for the respondents familiarity with mental illnesses.

Coding and reliability. The reaction times for the mental illness implicit association test were coded according to the transformation suggested by Greenwald, Nosek, and Banaji (2003). The explicit stigma scale showed acceptable reliability ( $\alpha$ Stigma $=.67$ ). Higher scores again indicated a more favorable, less stigmatized attitude toward mental illnesses.

\section{FIGURE 4:}

Study 2A: IMPLICIT STIGMA -- COMBINED EFFECT OF MESSAgE With

SELF-ASSESSED IMPLICIT ORIENTATION ON STIGMA

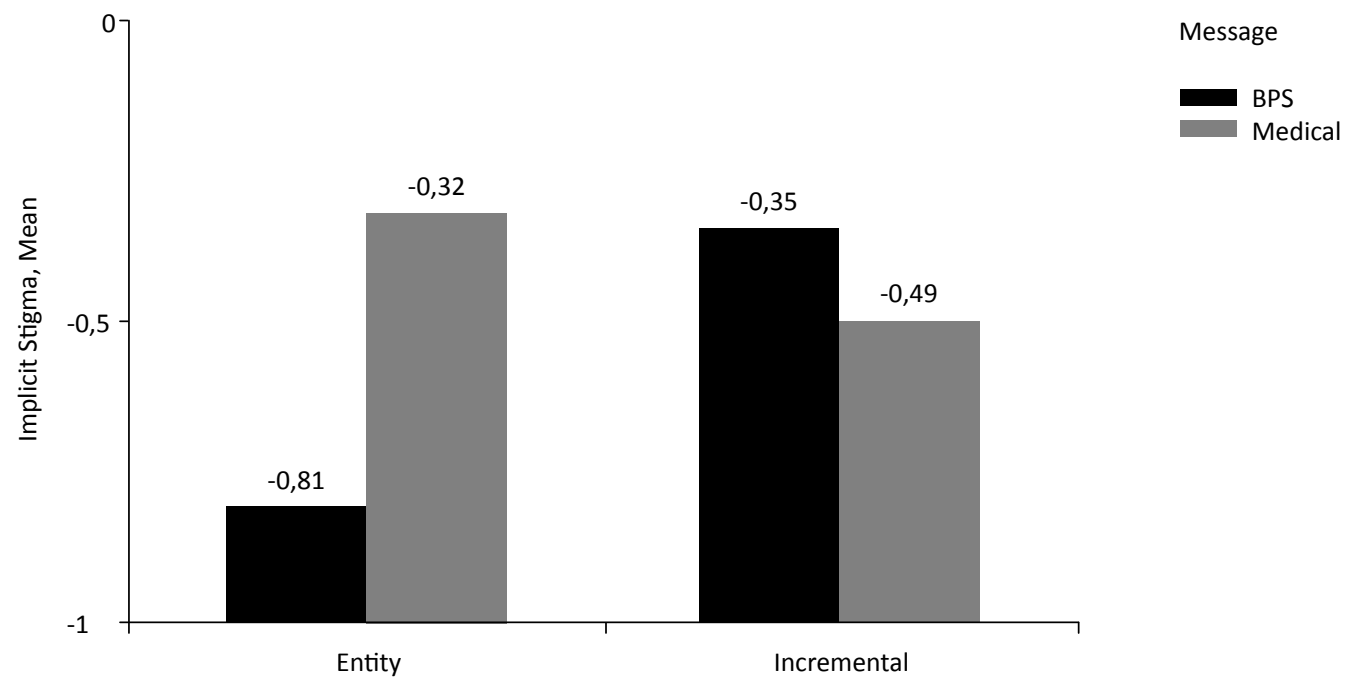

Implicit stigma. A significant two-way ANCOVA $(F(4,133)=4.45, p<.01)$ controlling for familiarity, indicated a marginally significant main effect of the expert view applied $(F(1,133)=2.95, p<.10)$ and an insignificant main effect for the implicit orientations $(F(1,133)=2.03, p>.10)$. However, the interaction between implicit worldview and mental-illness message was highly significant, as we hypothesized $(F(1,133)=11.10$, 
$p<.01)$. The follow-up contrasts that served to test our predictions confirmed $\mathrm{H}_{2 \mathrm{a}}$ : The medical message decreased the stigma endorsement of entity theorists $\left(M_{\text {EntMed }}=-.32\right.$, $\left.\mathrm{SD}=.64 ; \mathrm{M}_{\text {EntBPS }}=-.81, \mathrm{SD}=.61 ; \mathrm{F}(1,133)=4.81, p<.01\right)$. However, incrementalists did not significantly increase their stigma endorsement when they considered the medical message $\left(\mathrm{M}_{\text {IncBPS }}=-.35, \mathrm{SD}=.53 ; \mathrm{M}_{\text {IncMed }}=-.49, \mathrm{SD}=.42, \mathrm{~F}(1,133)=.78, p>.10\right)$, so we cannot confirm $\mathrm{H}_{2 b}$ (though the results indicate the expected direction). Finally, the difference in stigma endorsement between entity theorists and incrementalists vanished when we exposed entity theorists to the medical message, as illustrated in Figure 4.

\section{Figure 5}

\section{Study 2A: Explicit Stigma -- COMbined Effect of MeSSAge With SELF-ASSESSED IMPLICIT ORIENTATION ON STIGMA}

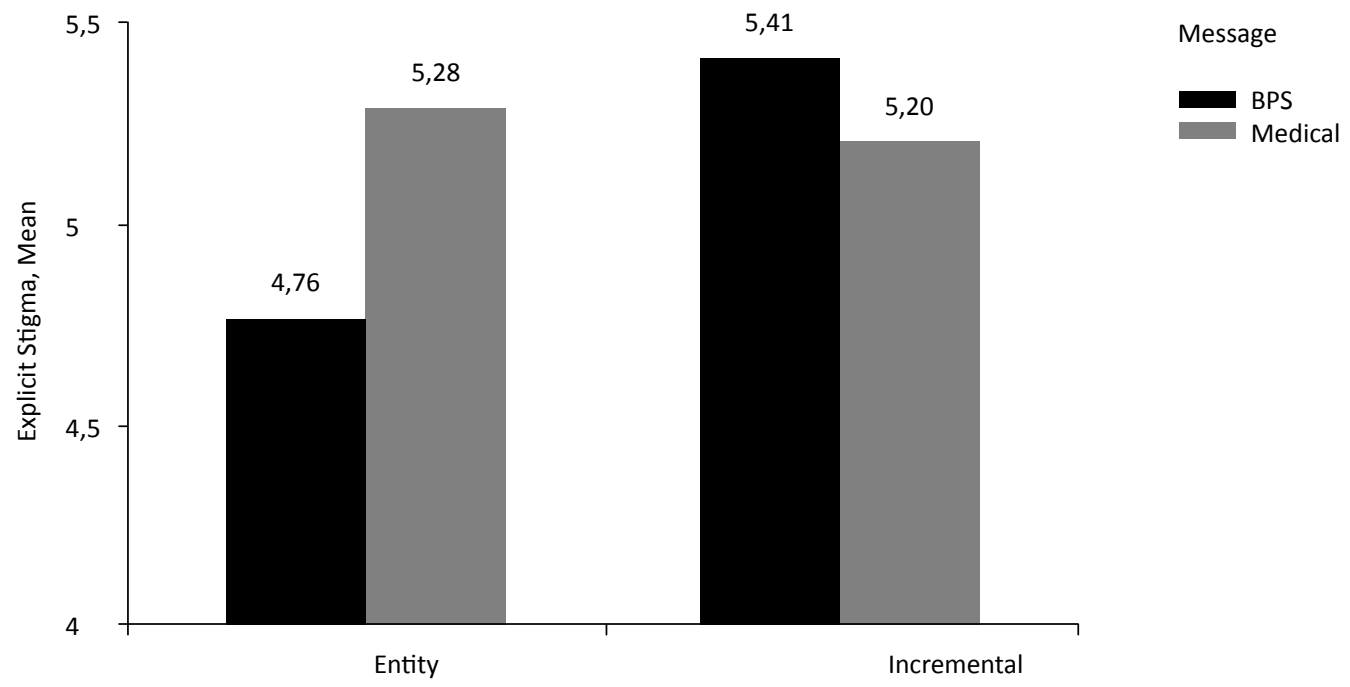

Explicit stigma. A significant two-way ANCOVA $(F(4,133)=2.88, p<.05)$ showed no significant main effects of the mental-illness message $(F(1,133)=.76, p>.1)$ or implicit orientation $(F(1,133)=2.74, p>.1)$. However, we again found a significant interaction between implicit orientations and the mental-illness messages $(F(1,133)=4.79, p<.05)$. The follow-up contrasts revealed a pattern in the explicit stigma results similar to the one we reported for the implicit stigma scale. We thus confirmed our prediction that 
the medical definition significantly improved the attitude of entity theorists, compared with the BPS message $\left(\mathrm{M}_{\text {EntMed }}=5.28, \mathrm{SD}=1.04 ; \mathrm{M}_{\text {EntBPS }}=4.76, \mathrm{SD}=.97 ; \mathrm{F}(1,133)=4.81\right.$, $p<.01)$, as we emphasize in Figure 5. However, again there was no significant difference for incrementalists with regard to the two different messages $\left(M_{\text {IncMed }}=5.20, S D=0,97\right.$; $\left.\mathrm{M}_{\text {InCBPS }}=5.41, \mathrm{SD}=.94 ; \mathrm{F}(1,133)=0.78, p>.1\right)$

Mediation. A test for moderated mediation can establish implicit stigma as an antecedent of explicit stigmatization (Muller et al. 2005). Therefore, following the procedure recommended by Preacher et al. (2007), we regressed explicit stigma on the mental-illness messages, implicit orientation, and their interaction, controlling for familiarity. This analysis replicated the ANCOVA results for explicit stigma and showed a significant interaction of implicit orientation $\times$ mental-illness message $(\beta=.64, \mathrm{SE}=.33 ; p=.052)$. When we regressed implicit stigma on the same specification, the interaction between implicit orientation and mental-illness messages remained significant $(\beta=.65, \mathrm{SE}=.18, p<.01)$. Adding implicit stigma as an independent variable to the first model revealed that implicit stigma predicted explicit stigma $(\beta=1.05, \mathrm{SE}=.12, p<.001)$, but the interaction of implicit orientation and mental-illness messages became insignificant $(\beta=-.05, \mathrm{SE}=.27, p>.10)$. Conditional indirect effects (Preacher et al. 2007) confirmed the mediating role of implicit stigma for entity theorists $(t=3.61, p<.01)$, whereas the effect remained insignificant for incrementalists $(t=$ $1.17, p<.10)$. This finding was not surprising; the two different mental-illness messages affected neither the implicit nor the explicit stigma endorsement of the latter.

Discussion. Our results supported $\mathrm{H}_{2 \mathrm{a}}$, in that entity theorists exhibited lower levels of stigma endorsement when approached with a medical message. However, we cannot confirm $\mathrm{H}_{2 \mathrm{~b}}$, because incrementalists did not change their stigma endorsement across the two mental-illness messages. We found no significant differences in stigma endorsement in the comparison of the entity-medical setting with either the incremental-BPS or incremental-medical scenario, across both explicit and implicit measures. In the BPS condition, our results mirrored the first two studies, such that entity theorists displayed more stigma than incrementalists.

\section{STUDY 2B}

To replicate our results for $\mathrm{H}_{2 \mathrm{a}}$ and $\mathrm{H}_{2 \mathrm{~b}}$, and to demonstrate that implicit theory orientations are the causal mechanism underlying our findings, we conducted an 
analogous study in which we manipulated implicit orientations instead of relying on self-assessments.

Design and procedure. We set up another 2 (medical vs. BPS) $\times 2$ (entity theorists vs. incrementalists) between-subjects experiment. One hundred fifty-three respondents from a U.S.-based online panel completed the questionnaire; after our routine check for seriousness, 17 respondents were removed. In this study, we also included text comprehension questions related to the priming materials, to ensure that participants properly understood the materials. Another nine participants answered incorrectly, so 127 participants remained eligible for the analysis. The sample consisted of $98 \%$ U.S. citizens, who had an average age of 35 years, ranging from 18 to 75 years. In addition, $52 \%$ of the respondents had a college education, whereas $45 \%$ had earned a high school diploma. We manipulated their implicit orientations at the very beginning of the study with a shortened version of the entity and incremental orientation prime developed by Chiu, Hong, and Dweck (1997), which has been used in several studies (see e.g. Yorkston et al. 2010). It consists of two versions of a newspaper article. The incremental prime stresses that people's characters can change over time and underlines these statements with examples and scientific evidence. The entity version contains the opposite information, portraying people's basic character traits as fixed over time, with other examples and academic studies. According to prior studies (Levy et al. 1998; Yorkston et al. 2010), implicit theory orientations are a trait-state variable, such that people may hold both worldviews, even if one is usually more accessible, and both orientations can be primed. After the prime and some filler questions, participants saw either the medical or the BPS message of mental illnesses, followed by the same anti-stigma campaign flyer from the timetochange.org initiative.

Dependent measures. As we did in Study 1b, we measured stigma with the social distance scale (Link et al. (1999). After the advertisement, respondents completed the social distance scale and we controlled again for personal experience with mental illnesses.

Manipulation check. We used the implicit orientation assessment scale at the very end of the experiment as a manipulation check, which proved successful $\left(\mathrm{M}_{\text {Incremental }}=3.08\right.$, $\left.\mathrm{SD}=1.04 ; \mathrm{M}_{\text {Entity }}=3.69, \mathrm{SD}=1.10 ; \mathrm{t}(126)=-3.15, p<.05\right)$. Our dependent measure proved reliable $\left(\alpha_{\text {socialDistance }}=.82\right.$ ) and was coded in such a way that higher values indicated more positive attitudes toward mental illnesses. 
Results. A significant two-way ANCOVA $(F(4,122)=5.25, p<.01)$ displayed no significant main effects for the message conditions $(F(1,122)=.51, p>.1)$ or implicit orientations conditions $(F(1,122)=1.43, p>.1)$, as shown in Figure 6 . The interaction between the message conditions and the implicit orientation again proved significant $(F(1,122)=4.11, p<.05)$. When inspecting the follow-up contrast effects, we found a pattern similar to that revealed in Study 2a. For example, entity theorists exhibited a significant improvement in attitudes when they received the medical rather than the BPS message $\left(M_{\text {EntBPS }}=3.54, S D=1.37 ; M_{\text {EntMed }}=4.38, S D=1.41 ; F(1,122)=3.78\right.$, $p<.05)$. Incrementalists did not significantly change their attitudes in either message condition $\left(\mathrm{M}_{\text {IncBPS }}=4.45, \mathrm{SD}=1.36 ; \mathrm{M}_{\text {IncMed }}=4.17, \mathrm{SD}=1.33 ; \mathrm{F}(1,122)=.85, p>.10\right)$.

Discussion. These results with manipulated implicit orientations, mirror our findings from Study 2a, in which participants assessed their own implicit orientations. Therefore, the medical message appears capable of reducing the stigma displayed by entity

\section{FIGURE 6}

\section{STUdY 2B): COMBINED EFFECT OF MESSAGE WITH PRIMED IMPLICIT} ORIENTATION ON STIGMA

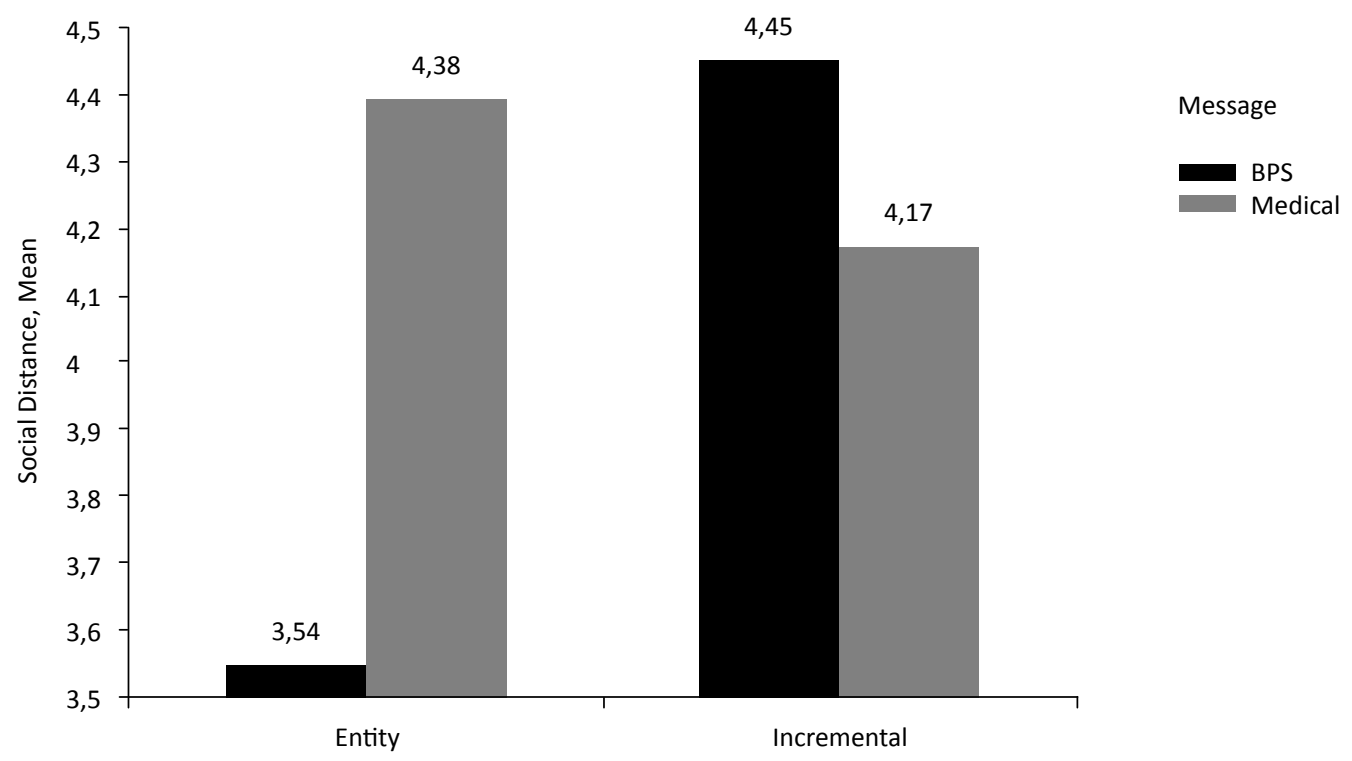


theorists significantly in comparison to a BPS message, on both implicit and explicit levels, but it cannot alter the stigma endorsement of incrementalists. Furthermore we are reassured about the causality of the observed effects due to our manipulations. The general difference between incrementalists and entity theorists also vanished in both studies when we exposed the entity theorists to a medical message of mental illness. Therefore, it seems reasonable to recommend increased use of the medical message, which does not increase the stigma endorsement for incrementalists but reduces it for entity theorists. Here, we showed that theorists continued exhibiting a higher stigma endorsement when they considered the BPS message. However, the BPS message also gained popularity among the expert community and is widely used in practice (Ghaemi 2009). In Study 3, we investigate how make the BPS message more suitable for entity theorists.

\section{STUDY 3}

We investigate two possible mechanisms to block the effect of a BPS message on entity theorists' stigma endorsement, i.e., increasing the perceived controllability of the message, and (ii) priming an incremental orientation.

First, we investigate the effect of controllability. Perceptions of whether an illness is controllable by therapeutic treatment is an important element in successful health communications (Raghubir and Menon 2005). Controllability is especially important when the illness itself is ambiguous and its consequences are hard to estimate (Menon et al. 2008). The ambiguousness and eclecticism of the BPS perspective invoke its strongest criticisms, and, as we showed in Studies 2a and $2 b$, entity theorists are not convinced by such a message. Instead, they prefer clear information that enables them to develop a positive attitude toward a stimulus. Without such information, they engage in stereotyping to overcome the discomfort of an unknown situation (Plaks et al. 2005). Therefore, we investigate whether an increase in controllability might mitigate the stigma-increasing effect of the BPS message among entity theorists. 
Second, we investigate how entity theorists react after being primed with an incremental orientation. Both self-assessed and primed incrementalist world views reduced stigma endorsement after a BPS message in Study $2 a$ and $b$. We investigate whether the priming effects hold even after people come to recognize their own chronic implicit orientation through a self-assessment.

Design and procedure. To investigate the proposed effects of controllability and an incrementalist prime after activating a chronic entity orientation for responses to a BPS message of mental illnesses, we set up a 3 (entity theorists vs. entity theorists with incremental prime vs. incrementalists) $\times 2$ (regular vs. controllability advertisement) design. Three hundred fifty respondents from an online panel participated in the study, and were, prescreened for their chronic implicit orientation such that we ensured a 2:1 entity-to-incremental proportion. After the check for seriousness, 329 respondents remained. These respondents had a mean age of 32 years, with a range of 18 to 71 years. Most (97\%) were U.S. citizens, and $3 \%$ were of other nationalities. Approximately $48 \%$ attended an undergraduate university. As in the other studies, we assessed participants' chronic implicit orientation at the very beginning of the study. Contingent on their answer, incrementalists immediately moved on to the next part of the study; entity theorists were divided randomly into groups that either read the incrementalist prime or moved on to the next part of the study. As priming material, we used the newspaper article from Study $2 \mathrm{~b}$. Next, all respondents read the BSP message and were exposed, randomly, to the regular advertisement from the previous studies or a new version that highlighted controllability over mental illness. Specifically, the controllability advertisement had an additional line to the regular advertisement: " $70 \%$ of people with a diagnosed mental illness experience relief from their symptoms after following an individual treatment plan" (see Appendix 2). This statement came from the website of the National Institute of Mental Health. We also pretested and confirmed its effects on perceived controllability. We found no differences between the controllability and regular advertisements in terms of credibility or message strength, but the former significantly increased viewers' perceived controllability (Menon et al. 2002).

Dependent measure. We used the same dependent measure as in Studies $1 \mathrm{~b}$ and $2 \mathrm{~b}$, again controlling for mental-health experience. We measured the perceived controllability of mental illnesses with a measure developed by Menon, Block, and Ramanathan (2002). 
Results. A significant two-way ANOVA $(F(6,321)=10.96, p<.01)$ displayed significant main effects for the three implicit orientation conditions (entity, entity prime, and incremental; $F(2,322)=4.32, p<.05)$, a significant main effect for the advertisement version (regular or controllability; $F(1,321)=5.24, p<.05)$, and a marginally significant interaction effect $(F(2,321)=2.53, p<.10)$. Considering the follow-up contrasts to test our hypotheses, we found that entity theorists without the prime significantly improved their attitude toward mental illnesses due to exposure to the advertisement with increased controllability $\left(\mathrm{M}_{\text {EntNoControl }}=3.56, \mathrm{SD}=1.33 ; \mathrm{M}_{\text {EntControl }}=4.27, \mathrm{SD}=1.36\right.$; $F(1,321)=9.71, p<.01)$, in support of our expectation that entity theorists improve their attitudes in the BPS condition if they perceive greater controllability. However, when entity theorists received the incrementalist prime, their attitude did not change significantly in response to the controllability advertisement $\left(\mathrm{M}_{\text {EntPrimeNocontrol }}=3.92\right.$, $\left.\mathrm{SD}=1.23 ; \mathrm{M}_{\text {EntPrimeControl }}=4.12, \mathrm{SD}=1.16 ; \mathrm{F}(1,321)=.01, p>.10\right)$, similar to the incrementalists $\left(\mathrm{M}_{\text {IncNoControl }}=4.47, \mathrm{SD}=1.01 ; \mathrm{M}_{\text {IncControl }}=4.49, \mathrm{SD}=1.39 ; \mathrm{F}(1,321)=.55\right.$, $p>$.10). Finally, adding an incrementalist prime for entity theorists only marginally improved their attitudes $\left(\mathrm{M}_{\text {EntNoControl }}=3.56 ; \mathrm{SD}=1.33, \mathrm{M}_{\text {EntPrimeNoControl }}=3.92, \mathrm{SD}=1.23\right.$; $\mathrm{F}(1,321)=2.65, p=.11)$, which remained marginally worse than the situation in which entity theorists just saw the controllability advertisement $\left(\mathrm{M}_{\text {EntPrimeNocontrol }}=3.92, \mathrm{SD}=1.23\right.$ $\left.M_{\text {EntControl }}=4.27, S D=1.36 ; F(1,321)=2.65, p=.11\right)$. We depict these results in Figure 7.

Discussion. The results of Study 3 support our prediction that enhancing the controllability of an advertisement's message can reduce stigma endorsement for entity theorists when mental illnesses are represented with a BPS message. Furthermore, we show that incrementalists are not affected by this measure-a lack of effect that also holds for entity theorists primed with an incrementalist view. However, priming entity theorists with an incremental view or even combining both measures is marginally less effective than simply increasing controllability. Therefore, we can recommend the use of controllability-increasing messages in combination with a BPS message of mental illness, which reduces entity theorists' stigma endorsement while leaving incrementalists unaffected. Adding controllability thereby eliminates the chronic difference in stigma endorsement between the two world views under a BPS condition. This difference, which already emerged in studies $2 a$ and $2 b$, could again be replicated here, as entity theorists showed a higher stigma endorsement than incrementalists when controllability was low. 


\section{FIGURE 7}

\section{StUdy 3: EFFECTS OF CONTROLLABILITY AND INCREMENTALIST PRIMES ON ENTITY THEORISTS' STIGMA ENDORSEMENT WITH A BPS MESSAGE}

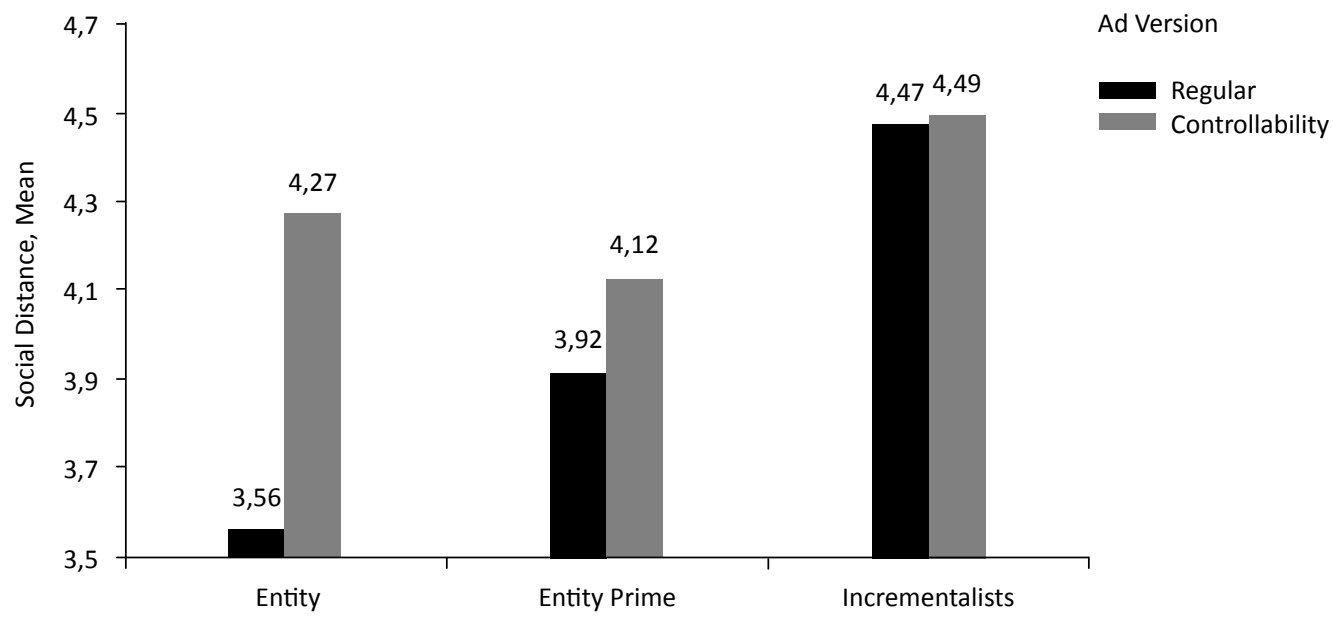

Thus we have confirmed our main findings from study $2 a$ in several further studies, including a lab context and large-scale surveys. The next step is to identify boundary conditions on our mental-illness message-implicit orientation matches. In particular, mental-illness stigma can be multifaceted and manifested differently for separate illnesses (Gaebel et al. 2006). Thus far we have pursued general findings and investigated mental illnesses as a whole. In Study 4, we adopt a more specific view to investigate whether illness severity influences the findings.

\section{STUDY 4}

Mental-illness stigma exists for most types of mental disorders (Teachman et al. 2006), but recent research suggests that disease severity alters the perceived stigma (Gaebel et al. 2006). Different disorders vary in the degree to which they affect a person's life and surroundings, and thus in the degree or type of stigma they invoke. Illnesses 
with lower severity may prompt prejudices that affected people are not really ill and should "pull themselves together." More severe disorders are more widely accepted as illnesses, but cause prejudices related to fear of the unpredictability of affected persons (Gaebel et al. 2006). Therefore, we investigate how illness severity interacts with the implicit orientation-mental illness message connection we have established. In a low severity condition, the illness likely has more ambiguous symptoms, allowing for a debate about whether it is actually an illness (Coffey et al. 2011). This debate likely affects entity theorists more than incrementalists, because they lean toward making extreme judgments, especially in situations that offer little or ambiguous information (Plaks et al. 2001). Regarding the stigma in which ill people are not taken seriously or the low severity illness is dismissed as personal weakness, we posit that entity theorists engage in stereotyping when they consider the BPS message but not when they read a medical message, which gives them clear information. Incrementalists, instead, engage in more nuanced judgment processes and should therefore exhibit equally low stigma endorsement levels irrespective of whether they consider the medical or BPS message (as in our previous studies). That is, the low illness severity condition should be comparable to the general view in our previous studies, such that the same results should emerge.

In contrast, our findings might not apply when the illness is extremely severe, because little debate remains about the detrimental effects of such illnesses on people's lives (Coffey et al. 2011). On the one hand, greater severity might increase acceptance of the condition as a true illness and reduce attributions of blame toward ill people. On the other hand, a general consensus about the abnormality of certain behaviors displayed by a person with a more severe illness could provoke constant, persistent stigma (Socall and Holtgraves 1992), which would be hard to change. Therefore, we expect no significant differences across implicit theories, regardless of the message used, when the mental illness is very severe.

Design and procedure. To investigate the proposed moderation effects of illness severity on the implicit-expert interaction, we set up a 2 (medical vs. BPS) $\times 2$ (entity vs. incrementalists) 2 (illness severity: low vs. high) between-subjects experiment. Three hundred thirty-two respondents from a U.S.-based online panel completed the questionnaire, and after our check for seriousness, 24 respondents were removed. Furthermore 26 respondents were excluded as they failed to answer the implicit 
orientation prime comprehension checks. Thus, 282 participants remained eligible for the analysis. The final sample had an average age of 33 years, ranging from 18 to 69 years, and $99 \%$ of the respondents were U.S citizens. Finally, $23 \%$ of the respondents finished high school, another $21 \%$ had completed an apprenticeship or additional training, and $56 \%$ held a college degree.

The study was structured as follows. First, participants were randomly exposed to the entity and incremental orientation primes from Study $2 b$ (Chiu, Hong, and Dweck (1997)). Second, they received either the medical or the BPS message of mental illnesses. Third, participants considered two new versions of the study advertisements, referring to Internet addiction and schizophrenia (Appendix 3). We pretested a list of eight mental disorders with regard to their perceived severity using the three-item scale developed by Witte (1996). Internet addiction, which falls within the family of impulse control disorders (WHO 2001), emerged as the least severe disorder, with a perceived severity statistically equal to the neutral scale midpoint $\left(\mathrm{M}_{\text {Severity }}=4.38, \mathrm{SD}=1.65\right.$; $t(31)=1.31, p>.1)$. Schizophrenia, instead, was evaluated as the most severe disorder $\left(M_{\text {Severity }}=6.33, S D=1.79\right)$. A paired samples t-test of the two disorders confirmed the significant difference in their perceived severity $\left(M_{\text {Internet }}-M_{\text {Schizophrenia }}=-1.95, S D=1.53\right.$; $\mathrm{t}(31)=7.21, p<.01)$.

Measures. We again used the social distance scale to measure explicit mental-illness stigma and controlled for mental-health experience.

Results. A significant three-way ANCOVA $(F(8,273)=2.371, p<.05)$ demonstrated a marginally significant three-way interaction of implicit orientation $\times$ mental-illness message $\times$ illness severity $(F(1,273)=3.37, p<.1)$. All other main and interaction effects were insignificant. Next, we ran the follow-up contrasts to investigate our hypothesis of a moderating role of illness severity. The results showed that the low severity condition replicated our results from Study 2: Incrementalists exhibited more positive attitudes toward mental illnesses than entity theorists after seeing the BPS message $\left(\mathrm{M}_{\text {InCBPS }}=4.30, \mathrm{SD}=1.27 ; \mathrm{M}_{\text {EntBPS }}=3.61, \mathrm{SD}=1.12, \mathrm{~F}(1,273)=4.17, p<.05\right)$. The medical message significantly improved the attitudes of entity theorists, compared with the BPS message $\left(\mathrm{M}_{\text {EntMed }}=4.25, \mathrm{SD}=1.29 ; \mathrm{M}_{\text {EntBPS }}=3.61 \mathrm{SD}=1.12 ; \mathrm{F}(1,273)=4.42, p<.05\right)$. Incrementalists did not significantly alter their attitudes across messages $\left(M_{\text {IncMed }}=4.07\right.$, $\left.\mathrm{SD}=1.31 ; \mathrm{M}_{\text {InCBPS }}=4.30, \mathrm{SD}=1.27 ; \mathrm{F}(1,273)=.59, p>.1\right)$; entity theorists who read a medical message displayed similar stigma levels to those exhibited by incrementalists 
$\left(\mathrm{M}_{\text {EntMed }}=4.25, \mathrm{SD}=1.29\right.$; comparison with BPS $\mathrm{F}(1,273)=.00, p>.10$; comparison with medical $F(1,281)=.61, p>.10)$. In contrast, when illness severity was high, the followup contrasts revealed no significant differences $\left(M_{\text {IncBPS }}=4.11, S D=1.29 ; M_{\text {IncMed }}=4.07\right.$, $\mathrm{SD}=1.44 ; \mathrm{M}_{\text {EntBPS }}=4.26, \mathrm{SD}=1.58 ; \mathrm{M}_{\text {EntMed }}=4,00, \mathrm{SD}=1.18 ;$ all $\left.p s>.1\right)$. We depict these results in Figures 8 and 9.

Discussion. The results confirm our predictions, because our findings hold when the mental illness is less severe but vanish when it is more severe. This outcome is logical, in that a severe mental condition such as schizophrenia induces less ambiguity about its status as an illness, whereas the low severity condition leaves more room for discussion. Therefore, this last study helps complete the picture painted by our previous findings. Indeed, the results suggest that, as long as campaigns are domain-general or focused on low severity illnesses, the messages must combat stigma with a medical message or a BPS message that emphasizes increased controllability. On the other hand, when the campaign is focused on a very severe mental illness, differences between the two implicit theory orientations disappear, and either type of message can be used to reduce stigma against the mentally ill.

\section{FIGURE 8}

StUdy 4: IMPLiCit ORIENTATION-MESSAgE INTERACTION: LOW ILLNESS SEVERITY

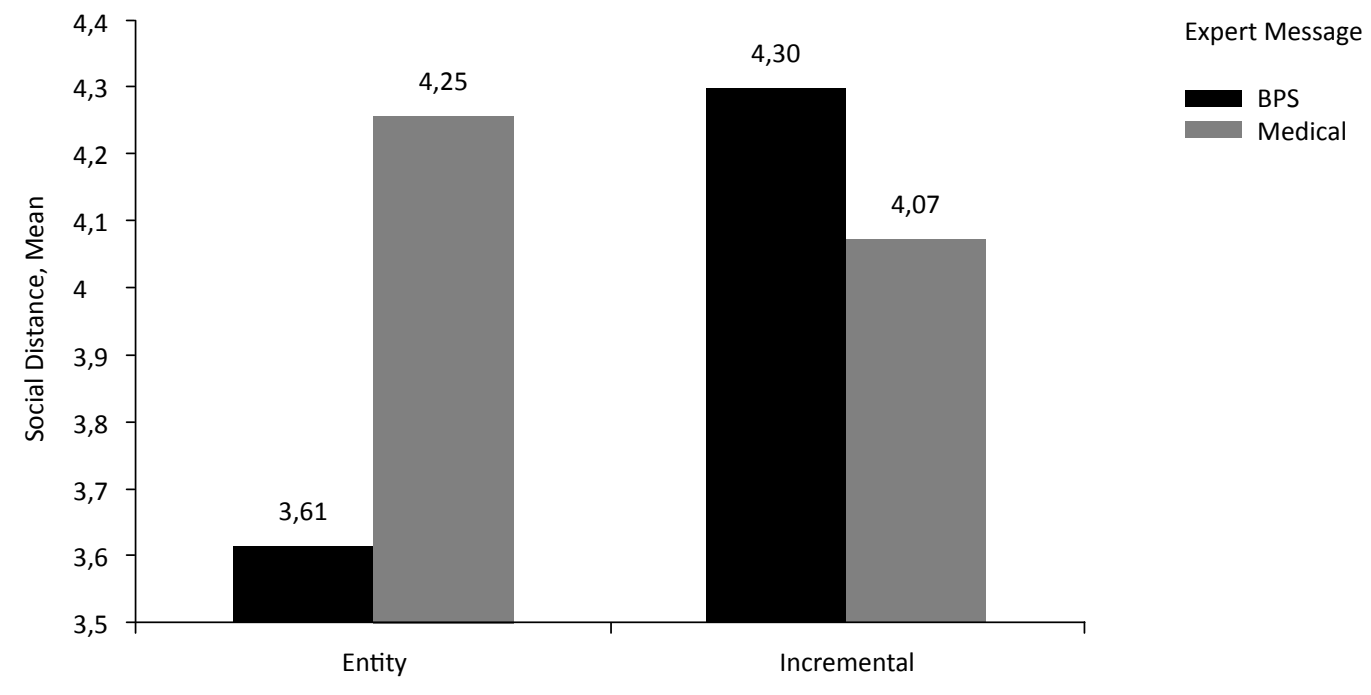




\section{FIGURE 9}

StUdy 4: IMPLICIT ORIENTATION-MESSAge INTERACTION: HIGH ILLNESS SEVERITY

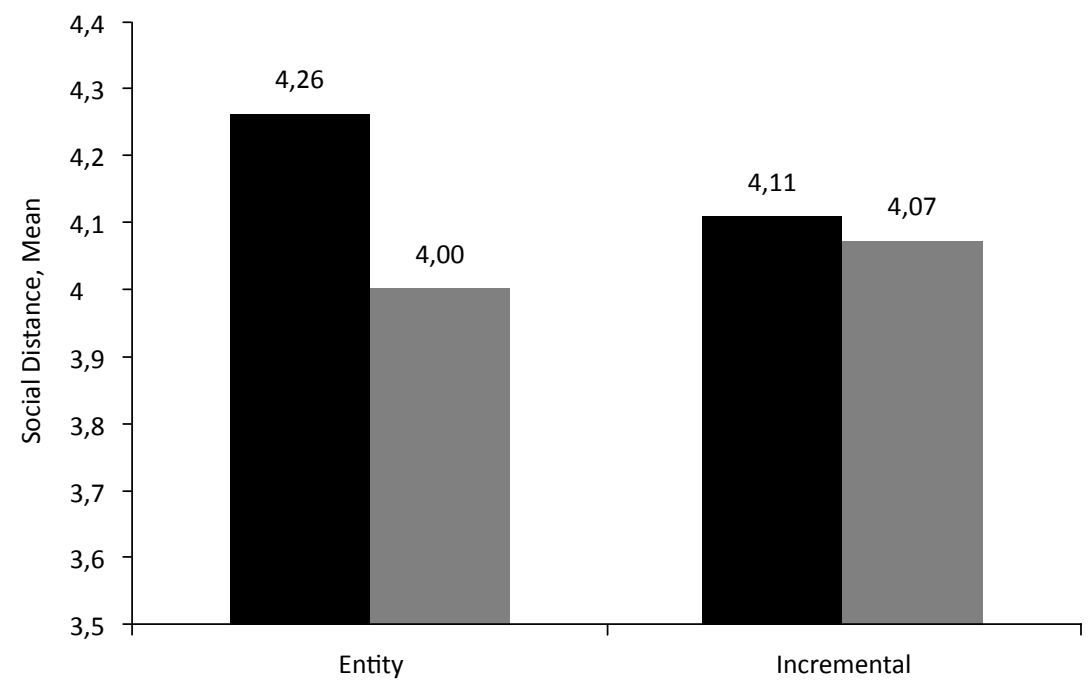

Expert Message

BPS

\section{GENERAL DISCUSSION}

Combating mental-illness stigma is a necessary to make people seek for help sooner, and to improve the success of the treatment (Corrigan 2004a). We seek to contribute to the research on mental-illness stigma by offering a fresh theoretical perspective on stigma antecedents to improve the effectiveness of social marketing actions. We are able to show that an individual's implicit theory orientation about the malleability or fixedness of human character traits is an important determinant of the level of stigma endorsement. Furthermore, we integrate the two implicit orientations with the two dominant expert schools of thought on how to communicate on mental disorders in order increase the effectiveness of anti-stigma campaigns. 


\section{IMPLICATIONS FOR THEORY}

Our study contributes to research on social marketing and cognitive psychology in several ways. First, we extend the relevance of implicit theory orientations to the field of mental illnesses. Entity theorists, who endorse stereotypes more than incrementalists (Levy et al. 1998), also are more likely to endorse mental-illness stigma. In addition, we demonstrate the persistence of this difference when exposing respondents to a typical anti-stigma campaign. This shows that simply providing counter-stigmatic information is not enough to overcome this difference.

Second, we integrate implicit orientations with two different mental-illness message designs. Our results show that it is possible to display counter-stigmatic information in such a way that it fits the perspective of entity theorists, without violating the worldview of incrementalists. Accordingly, we illustrate how to eliminate the chronic difference in stigma endorsements between people who embrace one or the other implicit theory, without altering their chronic orientation (Plaks et al. 2001). It is thus critical not only to communicate the right message but also to choose the right perspective of getting it across. Although we actively avoid taking any position in the message debate, our results indicate that the medical perspective performs better for entity theorists. To address this issue, we demonstrate that an increase in controllability (Menon et al. 2008) has a similar effect on entity theorists when they are exposed to information that generally would not reduce their stigma endorsement. Furthermore our results show that a further attitudinal improvement of incrementalist's view on mental illnesses seems to be difficult. It could be that their attitudes already have reached sort of a positive ceiling effect, and therefore they do not change their attitudes based on additional information.

\section{IMPLICATIONS FOR POLICY MAKERS AND MANAGERS}

In addition to our theoretical contributions, this study also offers a range of insights for managers and policy makers in the field. First of all, we are able to shed light on the issue of why social marketing campaigns can yield mixed results. If anti-stigma campaigns choose neither to endorse a medical or a BPS message, or if they target entity theorists with BPS messages, the campaigns will not reach the desired effect. 
Our results also show that incrementalists should not be the primary targets of such campaigns per se. They already have a lower level of stigma endorsement in comparison to entity theorists, and they seem to be indifferent as to the type of message used. This finding might be another reason for unsuccessful campaigns, as seemingly, incrementalists already reached sort of a ceiling effect in their degree of stigma endorsement.

Furthermore, our studies recommend a clear way of communicating anti-stigma messages through a medical perspective in order to reduce stigma. However, it might not always be a feasible recommendation to rely on the medical perspective in all cases, as often, practitioners themselves prefer one mental-illness message over the other (Keller, 2005). Therefore, our results also develop guidance on how to approach people in a way that it fits with a person's implicit orientation, for both types of messages of mental illnesses. If practitioners endorse the BPS perspective, it is of fundamental importance to support it with a higher perceived controllability of mental illnesses. This increase in security makes up for the otherwise eclectic and blurry message of the BPS perspective, which is contradictory to the clear-cut view of entity theorists.

Finally, it is important for managers to consider the focus of the campaign. Our results only hold for mental illnesses in general or for illnesses with a lower perceived severity. However, not all campaigns are domain general as our example used in the different studies. In recent years, a number of different illness-specific campaigns were launched to combat the stigma towards a specific disease, such as depression or schizophrenia (Rochlen et al. 2005). Therefore illness severity needs to be taken into account and thus should be assessed a priori to the launch of a campaign, as for more severe illness conditions, the message perspective does not matter.

\section{LIMITATIONS AND AVENUES FOR RESEARCH}

The limitations in this study largely stem from the data collection. We tried to reach broad audiences, replicated our results in various settings and used different measurements, however it would be interesting to replicate them in a longitudinal frame, which was shown to be important in stereotype contexts (Macrae et al. 1994). Furthermore, our results reflect explicit and implicit stigma attitudes, not actual stigmatizing behavior, which might differ from attitudinal measures (Sheeran 2002). We assert that it is possible 
to reduce mental-illness stigma endorsements of entity theorists by matching information with their worldview. Further research needs to test whether our claims generalize to other contexts in which stereotyping and prejudice are problems, such as racial and gender-related issues.

Moreover, the impact of implicit orientation could be studied in other social marketing contexts, such as cancer or AIDS prevention, which also strive on the interplay or fit between message design and personal orientations (Keller and Lehmann 2008). In a similar vein, it might be interesting to see how implicit orientations interact with other interpersonal differences like regulatory focus, which proved relevant for the success of marketing stimuli in many different contexts (Daryanto et al. 2010).

Additionally, researchers could investigate whether our results can be extended beyond the use of advertisements and media campaigns to actual behavioral settings. Many patients with mental illnesses do not complete their treatments or even refuse to start them after an unsuccessful initial talk (WHO 2001). Perhaps people who endorse one or the other implicit worldview are more likely to follow a treatment plan that is positioned as medical or BPS-oriented in its approach. Assessments of patients' implicit orientations could be implemented easily during intake procedures. Thus, we hope further research investigates whether our findings might suggest methods to increase compliance rates or improve treatment outcomes. Finally, more research into the effects of illness severity clearly is needed. Beyond a certain threshold level, our results appear not to hold any longer. It would be interesting to test our findings with a broader range of mental illness severity, to find the point at which they can be generalized. 
Chapter 4

CONCLUSION 
This dissertation addresses the important issues of depressions and recessions in the healthcare sector from a social marketing perspective. Both of our studies enhance theoretical concepts from marketing and economics and make use of innovative, healthcare-specific outcome measurements. Our results yield theoretical insights on the market and consumer level from a micro and a macroeconomic perspective, which translate into a rich body of implications for both policy makers and managers. In doing so, we contribute to the growing stream of healthcare-specific marketing research, which centers around delivering social and managerial insights from both a macro and a micro perspective (Stremersch 2008). Our findings demonstrate the importance of thorough marketing communications and strategies for both the individual and the aggregate level of populations in the healthcare sector. For instance, we can show that on a national level, higher degrees of preventive activities, such as public campaigns can mitigate adverse long-term consequences of economic downturns. On the other hand we demonstrate that marketers and policy makers need to carefully design anti-stigma campaigns to achieve the desired outcomes.

Furthermore, our results depict various possible responses in the healthcare sector during economic downturns and demonstrate the long-term adverse consequences of procyclical fluctuations on population health as well as the overall cost development. Likewise, we provide exploratory advice on how to mitigate adverse long-term effects from a managerial as well as a public policy perspective. Next to this, we tackle the issue of mental-illness stigma and demonstrate that anti-stigma campaigns can improve their effectiveness by matching the communicated message with the receiver's implicit theory orientation. In the following part, we summarize our theoretical and practical contributions in more detail and provide ideas for future research.

\section{CONTRIBUTIONS TO THEORY}

Our studies show the importance to conduct marketing research in the field of healthcare and add to the growing stream of work focusing on the macro and microeconomic perspectives of the healthcare market (Stremersch 2008). We explore interesting and central phenomena which we aim to explain with innovative measurements, new linkages and relationships between concepts which were previously unexplored. Our research allows adding new and different perspectives to both the overall economic 
environment of the healthcare sector, and the area of mental illnesses in specific. We augment the knowledge about the relationship of healthcare and the overall economy by adding the business cycle timeframe, list consequences of procyclical fluctuations, and show exploratory evidence how such procyclicality can be reduced. Moreover, we add to the long stream on healthcare communications (Keller and Lehmann 2008), by adding the field of mental illnesses and demonstrate that marketing communications can take a pivotal role in the reduction of stigma. Next to the usage of an innovative outcome measure for campaign success, we contribute to the theoretical foundations on stigma research in linking and enhancing the role of people's implicit theories as an important antecedent of stigma formation.

More specifically, we show that healthcare can be sensitive to business cycle fluctuations in the overall economy, and the fluctuations differ contingent upon country and expenditure source (private or public). By linking business cycle fluctuations to long-term consequences, we are able to demonstrate that there are some hysteresis effects of cyclical fluctuations in healthcare expenditures to some long-term outcome measures. On the one hand, procyclical private expenditures decrease the long-term health growth of nations due to temporary reductions of prevention treatments or other seemingly "less urgent" procedures which have their benefits on a less immediate time horizon (Gurria 2011). In addition, procyclical public expenditures increase longterm spending and therefore represent a threat to the overall goal of cost-containment in the sector. This might be related to the fact that a missing (often privately paid) preventive therapy or action generally provides a reduced long-term cost, as therapy costs usually soar disproportionally to the urgency of a treatment (OECD 2011).

In addition, we contribute to the domain of stigma-related research by connecting the concept of incremental theories, which has been shown pivotal in a person's stereotype endorsement (Levy et al. 1998), to the field of mental-illness stigma. Mental illness stigma differs from classical stereotype fields such as race or gender due to its purely negative valence and its non-permanence (Corrigan 2004a). In doing so, we augment the knowledge on stigma formation and endorsement and therefore are able to show why current campaigns often yield mixed results (Brindle 2010). Furthermore, we are able to increase the knowledge of implicit theories by demonstrating that it is possible to frame counter-stigmatic information in such a way that the chronic difference in stigma endorsement between entity theorists and incrementalists 
disappears. Finally, we are able to show how our findings can be moderated by controllability and how illness severity acts as a boundary condition to our proposed effects.

\section{COntributions to Managers AND POLICY MAKers}

Both of our studies focus on social implications which can be used by managers and policy makers in the field. We show that public expenditures should not be cut during an economic downturn due to the detrimental effect on long-term expenditures. Therefore policy makers and health-system managers need to devote increased attention to the accumulation of reserves during times of economic prosperity. In addition, it is absolutely necessary to also communicate the harm of cutting private expenditures, which contribute to a lower healthiness of the overall population in the long-run. In line with recent policy recommendations, an increased focus on preventive activities such as public health communications or free preventive treatments is absolutely mandatory, as higher preventive activities are able to mitigate those detrimental long-term effects. For managers, an even greater focus on countercyclical or stable sales activities might be beneficial from a business- as well as from a societal aspect. Our exploratory analysis shows that procyclical sales activities, which represent the majority of marketing activities in this field, contribute to the procyclicality of the entire industry. Therefore, in order to maintain stable sales and to help society as a whole, sales expenditures need to be kept acyclically or even countercyclically, a pattern which also emerged in other industries like FMCGs and durables (Deleersnyder et al. 2009; Lamey et al. 2007).

Secondly, we develop a yardstick how to frame-anti stigma campaigns more effectively and thereby contribute to the discussions on how such campaigns can be made more efficient and yield the desired results (Levy Paluck and Green 2009). In essence, our findings deliver three important insights. First of all, by using implicit theory orientations as an antecedent of stigma formation, we are able to provide insights for the mixed results of existing campaigns. On the one hand, we are able to show that classic anti-stigma campaigns do not suffice to reduce the chronic difference in stigma endorsement between people who see the world as fixed (entity theorists) or dynamic (incrementalists) (Chiu et al. 1997). Secondly, we can demonstrate that 
incrementalists who have a lower stigma endorsement on average, are relatively unaffected by most marketing stimuli and maybe have already reached a ceiling effect. Next to that, our results show that campaigns aiming to decrease stigma should be communicated in a medical way opposed to a biopsychological message, as it fits to the worldview of entity theorists, and accordingly reduces their stigma. If a biopsychological perspective is used, the message should feature enhanced controllability of the message, which makes the message more convincing for entity theorists. Finally, we demonstrate that disease specific campaigns cannot simply take over these recommendations, as the message tactics are less effective in reducing stigma systematically for severe illness conditions.

Our findings display a high degree of practical relevance, as counter-stigmatic messages are probably the most popular communication vehicle in practice. In recent years, most major campaigns in many countries have applied such a strategy. For instance, the New Zealand- based "Like Minds Like Mine" campaign tries to educate its audience about the friendliness and peacefulness of mentally ill people to decrease the stigma of violence and unpredictability (Vaughan and Hansen 2004). The U.S.based "Real Men Real Depression" campaign stresses that it is okay to admit personal weaknesses by illustrating that even "real men" might need help sometimes, lowering the stigma of approaching people with a mental illness (Rochlen et al. 2005). Finally, the Dutch "1 op de 4" (1 out of 4) campaign applied the exact same statistical evidence as the timetochangee.org campaign which served as a base for our study-design, and was stopped in 2012 after 3 years of mixed results (Dekker 2012).

\section{FUTURE RESEARCH}

As mentioned before, our studies put forward a range of theoretical and practical implications, but obviously, our findings raise new questions that may be interesting to investigate in the future. In general, the chosen perspectives for the issues of recessions and depressions were on a macro- and a micro level, respectively. Both approaches are viable for the topics at hand due to their macro and microeconomic nature; however it might yield additional insights to change those perspectives for our topics of investigation (Deleersnyder et al. 2004). For the business cycle perspective, an analysis on an institutional or consumer level might yield more detailed insights on 
the exact mechanisms during a crisis, while for our individually based mental-illness study, additional field studies on a larger scale could deliver additional insights in the robustness and length of our proposed effects (Sheeran 2002).

To get a more detailed insight on the relationship between business cycles and the healthcare sector, different sub-parts of the healthcare sectors could be investigated in more detail. This might provide more thorough implications where exactly to devote the attention when trying to reduce procyclicality. Furthermore, a larger scaled analysis investigating the underlying reasons for procyclicality in the healthcare sector might be needed, as our exploratory analysis is by no means complete. This was mainly due to a lack of more extensive data, preventing more detailed investigations on the chosen macro level of analysis. Thus, it might be insightful to approach the recession aspect from a more micro- or consumer level perspective to gain more insights about individual motivations or urges to alter healthcare consumption patterns during economic downturns. Finally, analyses from other markets have shown that different marketing measures differ in the effectiveness to combat procyclicality of a market (Lamey et al. 2012). Therefore, it might be insightful to study the different marketing measures such as detailing and advertising in isolation, an aspect which might also work better on an individual or a company level.

Our contributions to the field of mental-illness stigma could be transferred to some other fields of physical illnesses, which are subject to stigmatization, such as AIDS or other diseases which co-occur with a certain blame directed at infected people (Brown et al. 2003). It might be interesting to investigate, which particular ways of framing are able to reduce the stigma endorsement of entity theorists in other fields. Another aspect is to translate our findings of matching an individual's implicit worldview with a communication framing to other contexts, where implicit theories were shown to exert influence on judgments and evaluations, such as brand extensions (Yorkston et al. 2010). Furthermore, the interaction of implicit theories with other important selfrelated concepts such as regulatory focus is insufficiently explored. Exploring such relationships might help finding more detailed insights and maybe lead to an explanation for the ceiling effect, which we observe for incrementalists. Finally we could go one step further and observe how our findings can improve real life fields such as treatment compliance or success. It has been shown that believing in treatments can contribute a lot to a patient's compliance and the later treatment outcome (Turner et al. 1994). 
The effect of tailoring or framing a treatment program in a manner to match a patient's implicit orientation, might help to reach these desired effects and therefore not only reduce stigma around mental illnesses but might as well contribute to curing them.

\section{FINAL CONCLUSION}

Our studies highlight the need for tailored research on the healthcare market due to its uniqueness and social importance. We aim to address the timely issues of economic downturns and mental illnesses, thereby contributing to the growing stream of literature that investigates micro- and macroeconomic issues from a marketing perspective in the healthcare sector. Our studies develop detailed insights into the market mechanisms of the healthcare market, as well as for the field of consumer psychology exploring people's way of processing counter-stigmatic messages. These insights can be helpful for marketers and policy makers when addressing mental illness problems and economic downturns, and guide them to make more effective decisions. 
REFERENCES 
Barro, Robert J. (1979), “On the Determination of the Public Debt," Journal of Political Economy, 87 (5), 940-71.

Barros, Pedro Pita (1998), "The black box of health care expenditure growth determinants," Health Economics, 7, 533-44.

Bastian, Brock and Nick Haslam (2006), "Psychological essentialism and stereotype endorsement," Journal of Experimental Social Psychology, 42 (2), 228-35.

Baxter, Marianne (1994), "Real Exchange Rates and Real Interest Differentials. Have we Missed the Business Cycle Relationship?," Journal of Monetary Economics, 33 (1), 5-37.

Baxter, Marianne and Robert G. King (1999), "Measuring Business Cycles: Approximate Band-Pass Filters for Economic Time Series," Review of Economics and Statistics, 81 (4), 575-93.

Belei, Nina, Kelly Geyskens, Caroline Goukens, Suresh Ramanathan, and Jos Lemmink (2012), "The Best of Both Worlds? Effects of Attribute-Induced Goal Conflict on Consumption of Healthful Indulgences," Journal of Marketing Research, 49 (6), 900-09.

Berkowitz, Eric (2010), Essentials of health care marketing: Jones \& Bartlett Learning.

Blanchard, Olivier J. and Lawrence H. Summers Eds. (1986), Hysteresis and the European Unemployment Problem: MIT Press.

Blomqvist, A.G. and R.A.L. Carter (1997), "Is health care really a luxury," Journal of Health Economics, 16, 207-29.

Brenner, M. Harvey and Anne Mooney (1983), "Unemployment and Health in the Context of Economic Change," Social Science and Medicine, 17 (16), 1125-38. 
Brindle, David (2010), "Mental health anti-stigma campaign fails to shift health professionals' attitudes," (accessed 27.05, 2013), [available at http://www.guardian. co.uk/healthcare-network/2013/apr/03/mental-health-anti-stigma-campaign].

Bronnenberg, Bart J., Carl F. Mela, and William Boulding (2006), "The Periodicity of Pricing," Journal of Marketing Research, 43 (3), 477-93.

Brown, Lisanne, Kate Macintyre, and Lea Trujillo (2003), "Interventions to reduce HIV/ AIDS stigma: What have we learned?," AIDS Education and Prevention, 15 (1), 49-69.

Brown, Malcom C. (1987), "Caring for profit: Economic dimensions of Canada's health industry," (Fraser Institute, Vancouver).

Burns, L. R. (2005), The Business of Healthcare Innovation. Cambridge, U.K.: Cambridge University Press.

Byrne, Peter (2000), "Stigma of mental illness and ways of diminishing it," Advances in Psychiatric Treatment, 6 (1), 65-72.

Camacho, Nunon Miguel Almeida (2011), Health and Marketing: Essays on Physician and Patient Decision-Making: Erasmus University Rotterdam.

Chambers, Mary, Veslemøy Guise, Maritta Välimäki, MA Botelho, Anne Scott, Vida Staniuliené, and Renzo Zanotti (2010), "Nurses' attitudes to mental illness: a comparison of a sample of nurses from five European countries," International journal of nursing studies, 47 (3), 350.

Chew-Graham, Carolyn A., Anne Rogers, and Nuha Yassin (2003), "'I wouldn't want it on my CV or their records': medical students' experiences of help-seeking for mental health problems," Medical education, 37 (10), 873-80.

Chiu, Chi Yue, Ying Yi Hong, and Carol S Dweck (1997), "Lay dispositionism and implicit theories of personality," Journal of Personality and Social Psychology, 73, 19-30. 
Clement, Sarah, Manuela Jarrett, Claire Henderson, and Graham Thornicroft (2010), "Messages to use in population-level campaigns to reduce mental health-related stigma: consensus development study," Epidemiol Psichiatr Soc, 19 (1), 72-9.

Clemente, Jesus, Carmen Marcuello, Antonio Montanes, and Fernando Pueyo (2004), "On the international stability of health care expenditure functions: are government and private functions similar?," Journal of Health Economics, 23, 589-613.

Coffey, Rosanna M. , Robert Houchens, Bong-Chul Chu, Cheryl A. Kassed, Pamela Owens, Carol Stocks, Rita Vandivort-Warren, and Marguerite L. Barrett (2011), “A severityof-illness classification for mental and substance-use-disorders for use with hospital administrative data." Rockville, MD: Healthcare Cost and Utilization Project (HCUP).

Cook, Steven (1999), “Cyclicality and durability: Evidence from U.S. consumer's expenditure," Journal of Applied Economics, 2 (2), 299-310.

Corrigan, Patrick (2004a), "How stigma interferes with mental health," American Psychologist, 59 (7).

---- (2004b), “How stigma interferes with mental health care," American Psychologist, 59 (7), 614 .

---- (1999), "The impact of stigma on severe mental illness," Cognitive and behavioral practice, 5 (2), 201-22.

Corrigan, Patrick , Amy C. Watson, and Leah Barr (2006), "The self-stigma of mental illness: implications for self-esteem and self-efficacy," Journal of Social and Clinical Psychology, 25 (8), 875-84.

Daryanto, Ahmad, Ko de Ruyter, Martin Wetzels, and Paul G. Patterson (2010), "Service firms and customer loyalty programs: a regulatory fit perspective of reward preferences in a health club setting," Journal of the Academy of Marketing Science, 38 (5), 604-16. 
Day, Emer N, Kara Edgren, and Amy Eshleman (2007), “Measuring Stigma Toward Mental Illness: Development and Application of the Mental IIIness Stigma Scale1," Journal of Applied Social Psychology, 37 (10), 2191-219.

De Meijer, Claudine, Owen O'Donnell, Marc Koopmanschap, and Eddy van Doorslaer (2013), "Health expenditure growth: Looking beyond the average through decomposition of the full distribution," Journal of health economics, 32 (1), 88-105.

Dekker, Rob (2012), “Campagne 1opde4 beeindigd," (accessed 25.01.2012, [available at www.psywerkt.nl/home/nieuwsbericht/article/campagne-1opde4-beeindigd.htm].

Deleersnyder, Barbara, Marnik G. Dekimpe, Miklos Sarvary, and Philip M. Parker (2004), "Weathering Tight Economic Times: The Sales Evolution of Consumer Durables over the Business Cycle," Quantitative Marketing and Economics 2, 347-83.

Deleersnyder, Barbara, Marnik G. Dekimpe, Jan-Benedict E. M. Steenkamp, and Peter S. H. Leeflang (2009), "The Role of National Culture in Advertising's Sensitivity to Business Cycles: An Investigation across all Continents," in Journal of Marketing Research Vol. 46.

Deloitte (2011), "2011 U.S. and Global Survey of Health Care Consumers," (accessed 06.03., [available at http://www.deloitte.com/us/2011consumerism].

Demyttenaere, Koen, Ronny Bruffaerts, Jose Posada-Villa, Isabelle Gasquet, Viviane Kovess, Jean Pierre Lepine, Matthias C. Angermeyer, Sebastian Bernert, Giovanni de Girolamo, and Pierluigi Morosini (2004), "Prevalence, severity, and unmet need for treatment of mental disorders in the World Health Organization World Mental Health Surveys," JAMA: the journal of the American Medical Association, 291 (21), 2581.

Di Matteo, Livio and Rosanna Di Matteo (1998), “Evidence on the determinants of Canadian provincial government health expenditures: 1965-1991," Journal of Health Economics, 17 (2), 211-28. 
Dowideit, Anette and Marc Neller (2011), “Das Geschäft mit der kranken Seele," [available at http://www.welt.de/print/wams/wirtschaft/article13700764/DasGeschaeft-mit-der-kranken-Seele.html].

Doyle, Peter (2000), "Value-based marketing," Journal of Strategic Marketing, 8 (4), 299-311.

Dreger, Christian and Hans-Eggert Reimers (2005), "Health care expenditures in OECD countries: A panel unit root and cointegration analysis," IZA: Institute for the Study of Labour, 1469.

Dweck, Carol S, Chi-yue Chiu, and Ying-yi Hong (1995), "Implicit theories and their role in judgments and reactions: A word from two perspectives," Psychological Inquiry, 6 (4), 267-85.

Engle, Robert F. (1974), “Band Spectrum Regression,” International Economic Review, 15 (1), 1-11.

Estelami, Hooman, Donald R. Lehmann, and Alfred C. Holden (2001), "Macro-economic determinants of consumer price knowledge: A meta-analysis of four decades of research," International Journal of Research in Marketing, 18 (4), 341-55.

Flanagan, Scott C. and Aie-Rie Lee (2003), "The New Politics, Culture Wars, and The Authoritarian-Libertarian Value Change in Advanced Industrial Democracies," Comparative Political Studies, 36 (3), 235-70.

Gaebel, Wolfgang, Harald Zäske, and Anja E. Baumann (2006), "The relationship between mental illness severity and stigma," Acta Psychiatrica Scandinavica, 113 (s429), 41-45.

Gerdtham, Ulf-G. and Mickael Loethgren (2000), “On stationarityand cointegration of international health expendidure and GDP," Journal of Health Economics, 19, 461-75. 
Getzen, Thomas E. (2000), "Health care is an individual necessity and a national luxury: Applying multilevel decision models to the analysis of health care "Journal of Health Economics, 19, 259-70.

Ghaemi, S Nassir (2009), "The rise and fall of the biopsychosocial model," The British Journal of Psychiatry, 195 (1), 3-4.

Gijsenberg, M.J., H.J. van Heerde, Marnik G. Dekimpe, and Jan-Benedict E. M. Steenkamp (2009), "Advertising and price effectiveness over the business cycle," Katholieke Unversiteit Leuven.

Glied, Sherry A. (2008), “Health Care Financing, Efficiency, and Equity,” NBER No. 13881.

Goozner, Merril (2012), "Prevention Axed To Pay for Doc-Fix," (accessed 06.11., 2012), [available at http://gooznews.com/?p=3656].

Greenwald, Anthony G, Brian A Nosek, and Mahzarin R Banaji (2003), “Understanding and using the Implicit Association Test: I. An improved scoring algorithm," Journal of Personality and Social Psychology, 85 (2), 197-216.

Gurria, Angel (2011), “Healthcare and the value of prevention,” (accessed 06.12., 2012), [available at http://www.oecdobserver.org/news/fullstory.php/aid/3318/Healthcare_ and_the_value_of_prevention.html].

Guze, Samuel B (1992), Why psychiatry is a branch of medicine: Oxford University Press New York.

Hannan, E. J. and B. G. Quinn (1979), "The Determination of the Order of an Autoregression," Journal of the Royal Statistical Society. Series B (Methodological), 41 (2), 190-95.

Hansen, Paul and Alan King (1996), "The determinants of health care expenditure: A cointegration approach," Journal of Health Economics, 15, 127-37. 
Hartwig, Jochen (2008), "What drives health care expenditure? - Baumol's model of 'unbalanced growth' revisited," Journal of Health Economics, 27, 603-23.

Haslam, Nick and Donald Ernst (2002), "Essentialist beliefs about mental disorders," Journal of Social and Clinical Psychology, 21 (6), 628-44.

Haslam, Nick, Louis Rothschild, and Donald Ernst (2002), "Are essentialist beliefs associated with prejudice?," British Journal of Social Psychology, 41 (1), 87-100.

Herwartz, Helmut and Bernd Theilen (2003), "The determinants of health care expenditure: testing pooling restrictions in small samples," Health Economics, 12 (2), 113-24.

Hitiris, Theo and John Posnett (1992), "The determinants and effects of health expenditure in developed countries," Journal of Health Economics, 11, 173-81.

Hodrick, Robert J. and Edward C. Prescott (1997), “Postwar U.S. Business Cycles: An Empirical Investigation," Journal of Money, Credit \& Banking, 29 (1), 1-16.

Hong, Ying-yi, Sheri R Levy, and Chi-yue Chiu (2001), "The contribution of the lay theories approach to the study of groups," Personality and Social Psychology Review, 5 (2), 98-106.

Huber, Manfred (1999), "Health expenditure trends in OECD countries, 1970-1997," Health Care Financing Review, 21 (2), 99-117.

Huber, Manfred and Eva Orosz (2003), "Health Expenditure Trends in OECD Countries, 1990-2001," Health Care Financing Review, 25 (1), 1-22.

Inglehart, Ronald and W. E. Baker (2000), "Modernization, cultural change and the persistence of traditional values," American Sociological Review 65, 19-51. 
Jacobsen, Grant D. and Kathryn H. Jacobsen (2011), "Health awareness campaigns and diagnosis rates: Evidence from National Breast Cancer Awareness Month," Journal of Health Economics, 30 (1), 55-61.

Jain, Shailendra Pratap, Pragya Mathur, and Durairaj Maheswaran (2009), "The influence of consumers' lay theories on approach/avoidance motivation," Journal of Marketing Research, 46 (1), 56-65.

Judd, Charles M and Bernadette Park (1993), "Definition and assessment of accuracy in social stereotypes," Psychological review, 100 (1), 109.

Kahneman, Daniel (2011), Thinking, fast and slow: Macmillan.

Kamperman, Astrid M, Jens Henrichs, Stefan Bogaerts, Emmanuel MEH Lesaffre, André I Wierdsma, Razia RR Ghauharali, Wilma Swildens, Yolanda Nijssen, Mark van der Gaag, and Jan R Theunissen (2014), "Criminal Victimisation in People with Severe Mental Illness: A Multi-Site Prevalence and Incidence Survey in the Netherlands," PloS one, 9 (3), e91029.

Katona, George (1974), "Psychology and Consumer Economics," Journal of Consumer Research, 1 (1), 1-8.

Keller, Johannes (2005), "In genes we trust: the biological component of psychological essentialism and its relationship to mechanisms of motivated social cognition," Journal of Personality and Social Psychology, 88 (4), 686.

Keller, Punam A and Donald R Lehmann (2008), “Designing effective health communications: a meta-analysis," Journal of Public Policy \& Marketing, 27 (2), 117-30.

Keller, Punam Anand, Isaac M Lipkus, and Barbara K Rimer (2002), "Depressive realism and health risk accuracy: The negative consequences of positive mood," Journal of Consumer Research, 29 (1), 57-69. 
Kiesler, Donald J (1999), Beyond the disease model of mental disorders: Praeger Publishers.

Kotler, Philip (2011), "Reinventing marketing to manage the environmental imperative," Journal of Marketing, 75 (4), 132-35.

Kotler, Philip, Ned Roberto, and Nancy R Lee (2002), Social marketing: Improving the quality of life: Sage.

Lamey, Lien, Barbara Deleersnyder, Marnik G. Dekimpe, and Jan-Benedict E. M. Steenkamp (2007), "How Business Cycles Contribute to Private-Label Success: Evidence from the United States and Europe," Journal of Marketing, 71 (1), 1-15.

Lamey, Lien, Barbara Deleersnyder, Jan-Benedict E. M. Steenkamp, and Marnik G. Dekimpe (2012), "The effect of business-cycle fluctuations on private-label share: what has marketing conduct got to do with it? ," Journal of Marketing, 76 (1), in press.

Lane, Philip R. (2003a), "Business Cycles and Macroeconomic Policy in Emerging Market Economies," International Finance, 6 (1), 89-108.

---- (2003b), "The cyclical behaviour of fiscal policy: evidence from the OECD," Journal of Public Economics, 87 (12), 2661-75.

Lemmens, Aurelie, Christophe Croux, and Marnik G. Dekimpe (2007), “Consumer confidence in europe: United in diversity " International Journal of Research in Marketing, 24 (2), 113-27.

Leu, R. (1986), "The public-private mix and international health care costs," in Public and private health services, A.J. Culyer and B. Jönsson, eds.: Basil Blackwell, Oxford (1986).

Levy Paluck, Elizabeth and Donald P Green (2009), "Prejudice reduction: What works? A review and assessment of research and practice," Annual review of psychology, 60, 339-67. 
Levy, Sheri R, Steven J Stroessner, and Carol S Dweck (1998), "Stereotype formation and endorsement: The role of implicit theories," Journal of Personality and Social Psychology, 74, 1421-36.

Link, Bruce G and Jo C Phelan (2006), "Stigma and its public health implications," Lancet, 367 (9509), 528-28.

Link, Bruce G, Jo C Phelan, Michaeline Bresnahan, Ann Stueve, and Bernice A Pescosolido (1999), "Public conceptions of mental illness: labels, causes, dangerousness, and social distance," American Journal of Public Health, 89 (9), 1328-33.

Loebel, A. D., J. A. Lieberman, J. M. Alvir, D. I. Mayerhoff, S. H. Geisler, and S. R. Szymanski (1992), "Duration of psychosis and outcome in first-episode schizophrenia," The American journal of psychiatry, 149 (9), 1183-8.

Macrae, C Neil, Galen V Bodenhausen, Alan B Milne, and Jolanda Jetten (1994), “Out of mind but back in sight: Stereotypes on the rebound," Journal of personality and social psychology, 67 (5), 808.

Manchanda, Puneet and Elizabeth Honka (2005), "The effects and role of direct-tophysician marketing in the pharmaceutical industry: an integrative review. ," Yale Journal pf Health Policy, Law and Ethics, 5 (2), 785-822.

Mascarenhas, Briance and David A. Aaker (1989), "Strategy Over the Business Cycle," Strategic Management Journal, 10 (3), 199-210.

McCoskey, Suzanne K. and Thomas M. Selden (1998), “Health Care Expenditures and GDP: Panel Data Unit Root Test Results," Journal of Health Economics, 17 369-76.

Menon, Geeta, Lauren G Block, and Suresh Ramanathan (2002), "We're at as much risk as we are led to believe: Effects of message cues on judgments of health risk," Journal of Consumer Research, 28 (4), 533-49. 
Menon, Geeta, Priya Raghubir, and Nidhi Agrawal (2008), “Health risk perceptions and consumer psychology," Haugtveldt, Herr, \& Kardes (Eds.), Handbook of consumer psychology, 981-1010.

Millet, Kobe, Lien Lamey, and Bram Van den Bergh (2012), “Avoiding negative vs. achieving positive outcomes in hard and prosperous economic times," Organizational Behavior and Human Decision Processes, 117 (2), 275-84.

Mills, Terence C. (2001), "Business cycle asymmetry and duration dependence: An international perspective," Journal of Applied Statistics, 28 (6), 713-24.

Mladovsky, Philipa, Divya Srivastava, Jonathan Cylus, Marina Karanikolos, Tamás Evetovits, Sarah Thomson, and Martin McKee (2012), "Health policy in the financial crisis," Eurohealth, 18 (1), 3-6.

Morris, Sonya (2008), "Is Health Care Immune to a Recession?," (accessed 06.11., 2012), [available at http://www.morningstar.com/advisor/t/42990900/is-health-care-immuneto-a-recession.htm].

Muether, Philipp, Robert Hoerster, Manuel Hermann, Bernd Kirchhof, and Sascha Fauser (2012), "Long-term effects of ranibizumab treatment delay in neovascular age-related macular degeneration," Graefe's Archive for Clinical and Experimental Ophthalmology, 1-6.

Muller, Dominique, Charles M Judd, and Vincent Y Yzerbyt (2005), "When moderation is mediated and mediation is moderated," Journal of personality and social psychology, 89 (6), 852.

Musgrove, Philip (1987), "The Economic Crisis and its Impact on Health and Health Care in Latin America and the Caribbean," International Journal of Health services, 7 (3), 411-41.

Narasimhan, Chakravarthi, Scott A. Neslin, and Subrata K. Sen (1996), "Promotional Elasticities and Category Characteristics," Journal of Marketing, 60 (April), 17-30. 
Narayan, Paresh Kumar and Seema Narayan (2008), "The Role of Permanent and Transitory Shocks in Explaining International Health Expenditures," Health Economics, 17 10, 1171-86.

Neumayer, Eric (2004), “Recessions lower (some) mortality rates: Evidence from Germany," Social Science and Medicine, 58 (1037-1047).

Newhouse, J.P. (1977), “Cross national differences in health spending: what do they mean?," Journal of Health Economics, 6, 159-62.

Nijs, Vincent R., Marnik G. Dekimpe, Jan-Benedict E.M. Steenkamp, and Dominique M. Hanssens (2001), "The Category-Demand Effects of Price Promotions," Marketing Science, 20 (Winter), 1-22.

Nijs, Vincent R., Shuba Srinivasan, and Koen Pauwels (2007), "Retail-Price Drivers and Retailer Profits," Marketing Science, 26 (4), 473-87.

OECD (2011), "Health at a Glance 2011: OECD Indicators," OECD Publishing.

---- (2010), “OECD Health Data 2010,” Marie-Clémence Canaud (Ed.).

---- (2012), Sick on the Job?: OECD Publishing.

Orszag, Peter R. and Philip Ellis (2007), "The Challenge of Rising Health Care Costs - A View from the Congressional Budget Office," New England Journal of Medicine, 357 (18), 1793-95.

Pearson, Mark (2011), “Budget Treatment,” (accessed 06.11., 2012), [available at http:// www.oecdobserver.org/news/fullstory.php/aid/3393/Budget_treatment.html].

Pechmann, Cornelia and Chuan-Fong Shih (1999), "Smoking scenes in movies and antismoking advertisements before movies: effects on youth," The Journal of Marketing, 1-13. 
Petersen, Maya L, Mark J van der Laan, Sonia Napravnik, Joseph J Eron, Richard D Moore, and Steven G Deeks (2008), "Long-term consequences of the delay between virologic failure of highly active antiretroviral therapy and regimen modification," AIDS, 22 (16), 2097-106.

Plaks, Jason E, Heidi Grant, and Carol S Dweck (2005), "Violations of implicit theories and the sense of prediction and control: Implications for motivated person perception," Journal of Personality and Social Psychology, 88 (2), 245-62.

Plaks, Jason E, Steven J Stroessner, Carol S Dweck, and Jeffrey W Sherman (2001), "Person theories and attention allocation: Preferences for stereotypic versus counterstereotypic information," Journal of Personality and Social Psychology, 80 (6), 876-93.

Preacher, Kristopher J, Derek D Rucker, and Andrew F Hayes (2007), “Addressing moderated mediation hypotheses: Theory, methods, and prescriptions," Multivariate behavioral research, 42 (1), 185-227.

Price, Georgia (2009), “Is Healthcare Really Recession-Proof?,” (accessed 06.11., 2012), [available at http://allhealthcare.monster.com/benefits/articles/3148-is-healthcarereally-recession-proof?page=2].

Raghubir, Priya and Geeta Menon (2005), “Depressed or Just Blue? The Persuasive Effects of a Self-Diagnosis Inventory1," Journal of Applied Social Psychology, 35 (12), 2535-57.

Read, John, Nick Haslam, Liz Sayce, and Emma Davies (2006), “Prejudice and schizophrenia: a review of the 'mental illness is an illness like any other'approach," Acta Psychiatrica Scandinavica, 114 (5), 303-18.

Rochlen, Aaron B and Wayne D Hoyer (2005), "Marketing mental health to men: Theoretical and practical considerations," Journal of Clinical Psychology, 61 (6), 675-84. 
Rochlen, Aaron B, Margaret R Whilde, and Wayne D Hoyer (2005), “The Real Men. Real Depression Campaign: Overview, Theoretical Implications, and Research Considerations," Psychology of Men \& Masculinity, 6 (3), 186.

Romer, Daniel and Mary Bock (2008), "Reducing the stigma of mental illness among adolescents and young adults: the effects of treatment information," Journal of health communication, 13 (8), 742-58.

Rosenthal, Robert (1991), Meta-Analytic Procedures for Social Research: Newbury Park: Sage.

Rubin, Rita (2012), "Health suffers in recession; preventive care often cut first.," (accessed 06.11., 2012), [available at http://www.usatoday.com/news/health/2009-0624-prevention-recession_N.htm].

Rüsch, Nicolas, Andrew R Todd, Galen V Bodenhausen, Peter J Weiden, and Patrick W Corrigan (2009), "Implicit versus explicit attitudes toward psychiatric medication: Implications for insight and treatment adherence," Schizophrenia research, 112 (1), 119-22.

Sareen, Jitender, Amit Jagdeo, Brian Cox, Ian Clara, Margreet ten Have, Shay-Lee Belik, Ron de Graaf, and Murray Stein (2007), "Perceived barriers to mental health service utilization in the United States, Ontario, and the Netherlands," Psychiatric Services, 58 (3), 357-64.

Schomerus, Georg, Herbert Matschinger, and Matthias C Angermeyer (2007), "Familiarity with mental illness and approval of structural discrimination against psychiatric patients in Germany," The Journal of nervous and mental disease, 195 (1), 89-92.

Sheeran, Paschal (2002), "Intention-behavior relations: A conceptual and empirical review," European review of social psychology, 12 (1), 1-36. 
Sheng, Shibin, Kevin Zheng Zhou, and Julie Juan Li (2011), "The effects of business and political ties on firm performance: Evidence from China," Journal of Marketing, 75 (1), 1-15.

Simon, Hermann (1997), "Hysteresis in Marketing--A New Phenomenon?," Sloan Management Review, 38 (3), 39-49.

Socall, Daniel W and Thomas Holtgraves (1992), "Attitudes toward the mentally ill," The Sociological Quarterly, 33 (3), 435-45.

Spilimbergo, Antonio, Steve Symansky, Olivier Blanchard, and Carlo Cottarelli (2008), "Fiscal Policy For The Crisis," International Monetary Fund, IMF Staff Position Note (December).

Steenkamp, Jan-Benedict E. M. and Eric Fang (2011), "The Impact of Economic Contractions on the Effectiveness of R\&D and Advertising: Evidence from U.S. Companies Spanning Three Decades," Marketing Science, 30 (4), 628-45.

Steinbrook, Robert (2009), "Health Care and the American Recovery and Reinvestment Act," New England Journal of Medicine, 360 (11), 1057-60.

Stier, Andrea and Stephen P Hinshaw (2007), “Explicit and implicit stigma against individuals with mental illness," Australian Psychologist, 42 (2), 106-17.

Stock, James H. and Mark Watson, W. (1999), Business Cycle fluctuations in U.S. Macroeconomic Time Series. Amsterdam: Elsevier Science.

Stremersch, Stefan (2008), "Health and marketing: The emergence of a new field of research," International Journal of Research in Marketing, 25 (4), 229-33.

Stremersch, Stefan and Aurelie Lemmens (2009), "Sales Growth of New Pharmaceuticals Across the Globe: The Role of Regulatory Regimes," Marketing Science (Articles in Advance), 1-19. 
Stremersch, Stefan and Walter van Dyck (2009), "Marketing of the Life Sciences:

A New Framework and Research Agenda for a Nascent Field," Journal of Marketing, 73 (4), 4-30.

Strøm-Erichsen, Anne-Grete (2011), "Health challenges after the crisis," (accessed 06.13., 2012), [available at http://www.oecdobserver.org/news/fullstory.php/ aid/3321/].

Stuckler, David, Sanjay Basu, Mark Suhrcke, Adam Coutts, and M McKee (2009a), "The public health effect of economic crises and altermative poliocy responses in Europe: An empirical analysis," Lancet, 374 (July), 315-23.

Stuckler, David, Sanjay Basu, Mark Suhrcke, and Martin McKee (2009b), "The health implications from a financial crisis: A review of the evidence " Ulster Medical Journal, 78 (3), 142-45.

Suhrcke, M, M McKee, David Stuckler, R Arce, S Tsolova, and J Mortensen (2006), "The Contribution of health to the economy in the European Union," Public Health, 120, 9941001.

Teachman, Bethany A, Joel G Wilson, and Irina Komarovskaya (2006), "Implicit and explicit stigma of mental illness in diagnosed and healthy samples," Journal of Social and Clinical Psychology, 25 (1), 75-95.

Turner, Judith A, Richard A Deyo, John D Loeser, Michael Von Korff, and Wilbert E Fordyce (1994), "The importance of placebo effects in pain treatment and research," Jama, 271 (20), 1609-14.

van Dorresteijn, Mark (2012), "Aantal cliënten en toetreders in ggz blijft toenemen," (accessed 27.05., 2013), [available at http://www.zorgvisie.nl/Financien/ Nieuws/2012/1/Aantal-clienten-en-toetreders-in-ggz-blijft-toenemen-ZVS013156W/]. 
Vaughan, Gerard and Chris Hansen (2004), “'Like Minds, Like Mine': a New Zealand project to counter the stigma and discrimination associated with mental illness," Australasian Psychiatry, 12 (2), 113-17.

WHO (2001), World health report 2001: mental health: new understanding, new hope: World Health Organization.

Witte, Kim (1996), “Predicting risk behaviors: Development and validation of a diagnostic scale," Journal of health communication, 1 (4), 317-42.

Wolfe, Barbara L. (1986), “Health status and medical expenditures: Is there a link?," Social Science and; Medicine, 22 (10), 993-99.

Yorkston, Eric A, Joseph C Nunes, and Shashi Matta (2010), "The malleable brand: The role of implicit theories in evaluating brand extensions," Journal of Marketing, 74 (1), 80-93.

Zhao, Guangzhi and Cornelia Pechmann (2007), "The impact of regulatory focus on adolescents' response to antismoking advertising campaigns," Journal of Marketing Research, 671-87.

Zurawicki, Leon and Nestor Braidot (2005), "Consumers during crisis: responses from the middle class in Argentina," Journal of Business Research, 58 (8), 1100-09. 
APPENDIX 
Appendix 1. Regular Advertisement for Studies 1b, 2, and 3

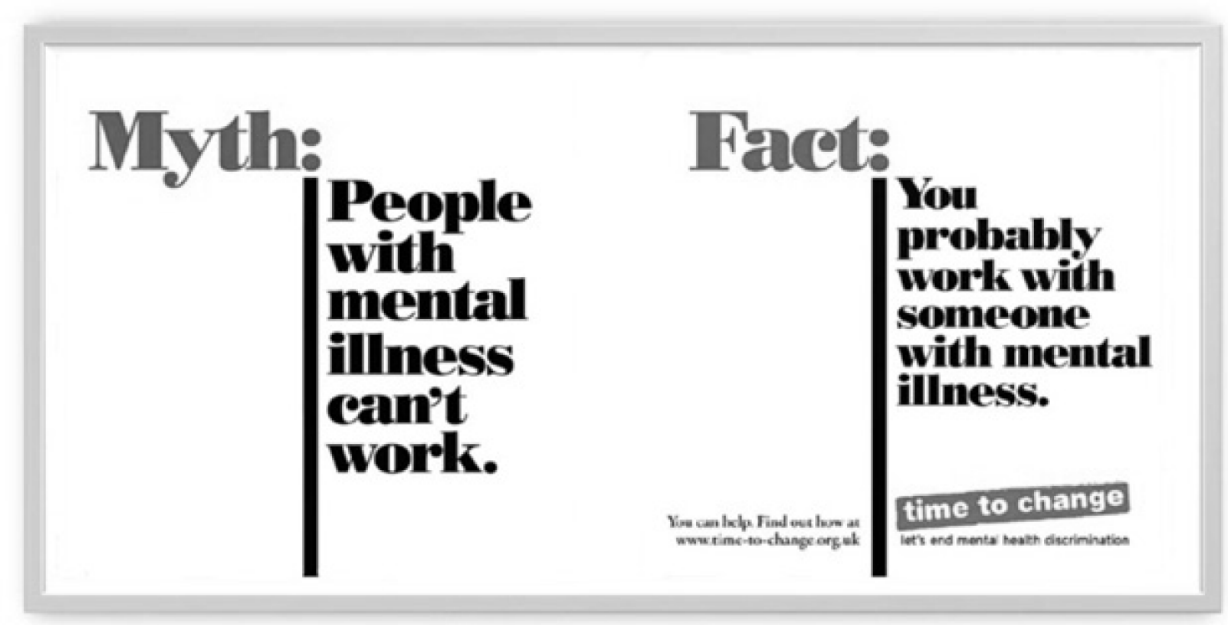

Appendix 2. Controllability Advertisement for Study 3
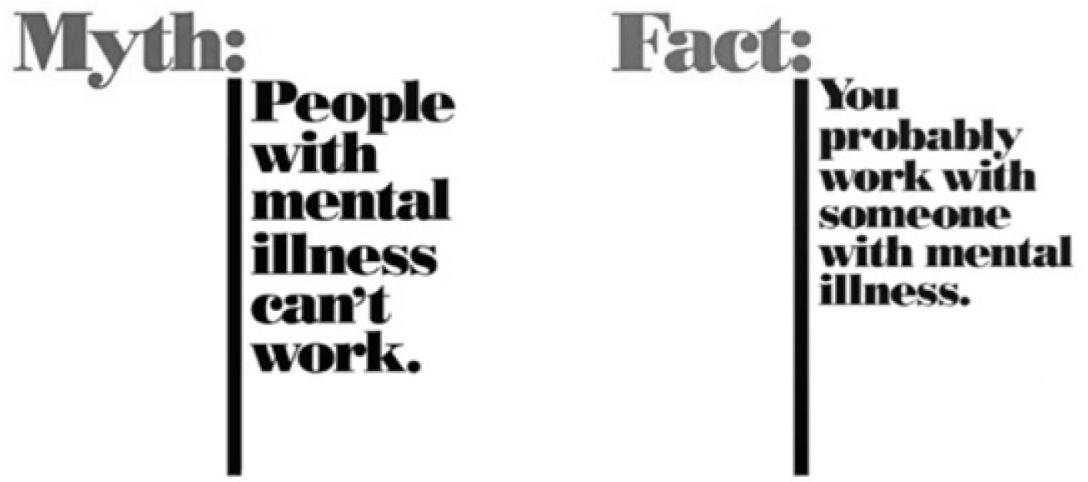

Mental illnesses are treatable

$70 \%$ of people diagnosed with a mental illness experience relief from their symptoms by participating in an individual treatment plan. 
Appendix 3. Advertisements with Different Degrees of Illness Severity for Study 4

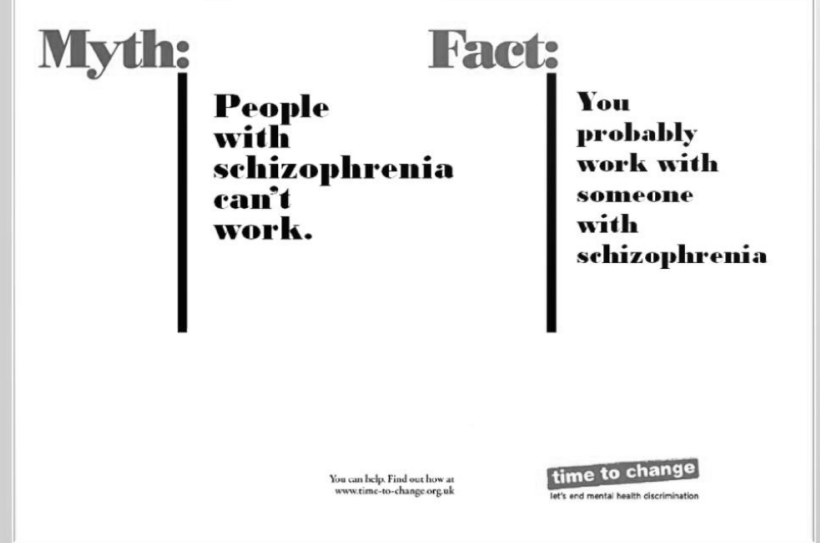

\section{Myth: \\ People with internet addiction can't work.

Fact:
\[ \begin{array}{l}\text { You } \\ \text { probalbly } \\ \text { work with } \\ \text { someone } \\ \text { with } \\ \text { internet } \\ \text { addlietion }\end{array} \]




\section{SCALES:}

Implicit theory orientation (Dweck et al. 1995) S1a \& b; S2a; S3.

1. The kind of person someone is, is something basic about them, and it can't be changed very much.

2. People can do things differently but the important parts of who they are can't really be changed.

3. Everyone is a certain kind of person, and there's not much that they can do to really change that.

Social Distance Items (Link, 1994) S1b; S2b; S3;,S4.

1. How would you feel about renting a room in your home to someone with a mental illness?

2. How would you feel as a worker on the same job as someone with a mental illness?

3. How would you feel having someone with a mental illness as a neighbor?

4. How about a person with a mental illness as the caretaker of your children for a couple of hours?

5. How about having your children marry someone with a mental illness?

6. How would you feel about introducing a person with a mental illness to a young woman you are friendly with?

7. How would you feel about recommending someone with a mental illness for a job working for a friend of yours?

Mental illness stigma scale Day, (2007) S1b

1. There are effective medications for mental illnesses that allow people to return to normal and productive lives.

2. I don't think that it is possible to have a normal relationship with someone with a mental illness.

3. I would find it difficult to trust someone with a mental illness.

4. People with mental illnesses tend to neglect their appearance.

5. It would be difficult to have a close meaningful relationship with someone with a mental illness.

6. I feel anxious and uncomfortable when I'm around someone with a mental illness. 
7. It is easy for me to recognize the symptoms of mental illnesses.

8. There are no effective treatments for mental illnesses.

9. I probably wouldn't know that someone has a mental illness unless I was told.

10. A close relationship with someone with a mental illness would be like living on an emotional roller coaster.

11. There is little that can be done to control the symptoms of mental illness.

12. I think that a personal relationship with someone with a mental illness would be too demanding.

13. Once someone develops a mental illness, he or she will never be able to fully recover from it.

14. People with mental illnesses ignore their hygiene, such as bathing and using deodorant.

15. Mental illnesses prevent people from having normal relationships with others.

16. I tend to feel anxious and nervous when I am around someone with a mental illness.

17. When talking with someone with a mental illness, I worry that I might say something that will upset him or her.

18. I can tell that someone has a mental illness by the way he or she acts.

19. People with mental illnesses do not groom themselves properly.

20. People with mental illnesses will remain ill for the rest of their lives.

21. I don't think that I can really relax and be myself when I'm around someone with a mental illness.

22. When I am around someone with a mental illness I worry that he or she might harm me physically.

23. Psychiatrists and psychologists have the knowledge and skills needed to effectively treat mental illnesses.

24. I would feel unsure about what to say or do if I were around someone with a mental illness.

25. I feel nervous and uneasy when I'm near someone with a mental illness

26. I can tell that someone has a mental illness by the way he or she talks.

27. People with mental illnesses need to take better care of their grooming (bathe, clean teeth, use deodorant).

28. Mental health professionals, such as psychiatrists and psychologists, can provide effective treatments for mental illnesses. 
